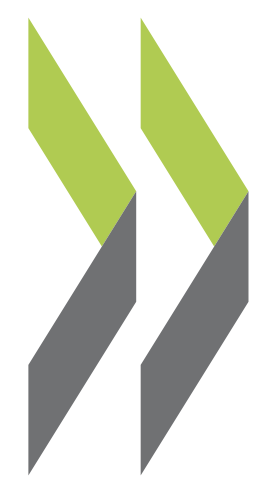

OECD Health Working Papers No. 56

\title{
Description of Alternative Approaches to Measure and Place a Value on Hospital Products in Seven OECD Countries
}

\section{Luca Lorenzoni,} Mark Pearson 
Organisation de Coopération et de Développement Économiques

Organisation for Economic Co-operation and Development

14-Apr-2011

DIRECTORATE FOR EMPLOYMENT, LABOUR AND SOCIAL AFFAIRS

English text only

HEALTH COMMITTEE

Health Working Papers

OECD HEALTH WORKING PAPERS NO. 56

DESCRIPTION OF ALTERNATIVE APPROACHES TO MEASURE AND PLACE A VALUE ON HOSPITAL PRODUCTS IN SEVEN OECD COUNTRIES

Luca Lorenzoni and Mark Pearson

JEL Classification: H51, I12, and I19

JT03300281

Document complet disponible sur OLIS dans son format d'origine

Complete document available on OLIS in its original format 


\title{
DIRECTORATE FOR EMPLOYMENT, LABOUR AND SOCIAL AFFAIRS
}

\author{
www.oecd.org/els
}

\section{OECD HEALTH WORKING PAPERS}

\section{http://www.oecd.org/els/health/workingpapers}

This series is designed to make available to a wider readership health studies prepared for use within the OECD. Authorship is usually collective, but principal writers are named. The papers are generally available only in their original language - English or French - with a summary in the other.

Comment on the series is welcome, and should be sent to the Directorate for Employment, Labour and Social Affairs, 2, rue André-Pascal, 75775 PARIS CEDEX 16, France.

The opinions expressed and arguments employed here are the responsibility of the author(s) and do not necessarily reflect those of the OECD.

\section{Applications for permission to reproduce or translate all or part of this material should be made to:}

\author{
Head of Publications Service \\ OECD \\ 2, rue André-Pascal \\ 75775 Paris, CEDEX 16 \\ France
}

Copyright OECD 2011 


\section{TABLE OF CONTENTS}



\section{Tables}

Table 1 Main characteristics of the diagnosis code system. Selected OECD member states ....................10

Table 2 Main characteristics of the procedure code system. Selected OECD member states ..................12

Table 3 Main characteristics of the classification system. Selected OECD member states.......................15

Table 4 Main characteristics of the cost-finding methods. Selected OECD member states .....................17 


\section{ACKNOWLEDGEMENTS}

This report was prepared under the contribution agreement between the Italian Ministry of Health and the OECD for the implementation of the action entitled Description of alternative approaches for case mix measurement at hospital level. This action is an integral part of the current Programme of Work of the OECD on the Development of Health-Specific Purchasing Power Parities. The OECD would like to acknowledge the importance of the contribution by the Italian Ministry of Health to support this work.

The Authors gratefully acknowledge the contribution but remain responsible for any errors in compiling or interpreting the results 


\section{EXECUTIVE SUMMARY}

1. There are many reasons to be interested in the 'cost' of different services provided by hospitals. In particular, many international comparisons focus on how much is spent on health care or different types of health services. But expenditures may be higher in one country than another both because more health care is being delivered, or because the cost of providing health care is higher. The policy conclusions that should be drawn in response to the higher spending should depend on which explanation is valid. Only by looking beyond expenditures is it possible to separate out these two causes.

2. However, whereas for most of the economy it is possible to identify a cost by looking at the price charged for a good or service, this is rarely possible in the case of health, as public provision and regulation mean that prices are rarely fixed by market mechanisms. This paper discusses the possibility of an alternative means of identifying cost: to look at the administrative payments that many countries use to finance hospital procedures.

3. Most OECD countries use a mix of payment arrangements to finance hospital acute care. These lead to various different incentives for the quantity, quality and productive efficiency of hospital services. Of particular interest are per case/diagnosis related group (DRG) payments, which directly relate to actual levels of activity. They are fees established prospectively for a single "product" delivered by the hospital. In a survey of health systems characteristics carried out in 2009, 17 (out of 29 respondents) OECD countries reported the use of a payment per case/DRG ${ }^{1}$. But are these DRG-based prices a reliable way of comparing costs across countries? The answer depends crucially on whether the same definitions are used to generate DRG payments across countries.

4. This paper provides a description of the classification systems used to measure hospital services in selected OECD countries: Australia, Canada, England, France, Germany, Norway, and the United States. Three classifications are relevant: those on diagnoses; on procedures; and on products. In addition, methods used to measure the cost of hospital services are reviewed.

5. We conclude first that comparisons are possible notwithstanding the different approaches used in developing DRG prices. Secondly, we conclude that secondary data sets available through health administrations and national insurance funds for purposes of reimbursement, health financing, and hospital budgeting can indeed be used to estimate the cost of a representative basket of hospital products to compare price levels across countries.

Paris et al, 2009. 


\section{RÉSUMÉ}

6. Il est intéressant d'étudier le « coût » des différents services fournis par les hôpitaux, et ce, à plus d'un titre. En particulier, de nombreuses comparaisons internationales portent sur les fonds consacrés aux soins ou à différents types de services de santé, mais les dépenses peuvent être plus élevées dans un pays que dans un autre, soit parce que les soins sont prodigués en plus grande quantité, soit parce que le coût de leur prestation est supérieur. Pour l'action publique, les conclusions à tirer de la hausse des dépenses dépendront de l'explication retenue. Ce n'est qu'en regardant au-delà des dépenses que l'on pourra dissocier ces deux causes.

7. Toutefois, si pour la plus grande part de l'économie, il est possible de déterminer un coût en étudiant le prix d'un bien ou d'un service, ce n'est guère le cas dans le domaine de la santé, où l'offre publique et la réglementation font que les prix sont rarement dictés par les mécanismes du marché. Dans le présent rapport, on envisage une autre manière de déterminer le coût, en examinant les paiements administratifs que de nombreux pays utilisent pour financer les procédures hospitalières.

8. La plupart des pays de l'OCDE ont recours à plusieurs dispositifs de paiement pour financer les soins aigus à l'hôpital, dispositifs qui favorisent de diverses façons la quantité, la qualité et l'efficience productive des services hospitaliers. À cet égard, on citera tout particulièrement les paiements effectués sur la base de séjours/groupes homogènes de malades (GHM), qui sont directement liés aux niveaux d'activité réels. Il s'agit de prix établis au préalable pour un «produit » spécifique fourni par l'hôpital. Il ressort d'une enquête menée en 2009 sur les caractéristiques des systèmes de santé que 17 pays de l'OCDE interrogés (sur 29) utilisent un dispositif de paiements sur la base de groupes homogènes de malades/séjours ${ }^{2}$, mais ces prix fondés sur les GHM sont-ils fiables pour comparer les coûts à l'échelle internationale? Tout dépend de savoir si les mêmes définitions s'appliquent pour fixer ces prix dans l'ensemble des pays.

9. Ce rapport décrit les systèmes de classification utilisés pour évaluer les services hospitaliers dans plusieurs pays de 1'OCDE : Allemagne, Angleterre, Australie, Canada, États-Unis, France, y Norvège. Trois classifications sont pertinentes: elles portent sur les diagnostics, les procédures et les produits. Par ailleurs, les méthodes utilisées pour estimer le coût des services hospitaliers sont examinées.

10. Les analyses effectuées permettent de conclure en premier lieu que des comparaisons sont possibles, malgré les différentes méthodes utilisées pour établir les prix sur la base des GHM. Ensuite, les ensembles de données secondaires disponibles par l'intermédiaire des administrations chargées de la santé et des caisses d'assurance nationales concernant les remboursements, le financement de la santé et l'établissement des budgets des hôpitaux peuvent effectivement être utilisées pour estimer le coût d'un panier représentatif des produits hospitaliers, en vue de comparer les niveaux de prix entre les pays. 


\section{Introduction}

11. In international comparisons, the relative prices for a particular product or group of product are called Purchasing Power Parities (PPPs). PPPs are regularly measured for all components of GDP ${ }^{3}$. Despite a long tradition of work in the area, the task remains challenging. Three main problems have to be addressed in the measurement of PPPs. The first issue is to identify products that are comparable across countries: while simple in some cases (a particular type of a washing machine) this can be complicated in many other cases because products are not identical, because there are differences in quality or because products simply do not exist in all countries. The second issue is to ensure representativeness of products: whatever price is compared, it has to be the price of a product that is widely and typically purchased in each country. The third issue arises when there is a product, but no meaningful market price for comparison. Issues one and two arise in the comparison of all prices, issue three arises in the comparison of products that are produced and delivered outside markets. In many countries, health services count among these products.

12. When goods or services are supplied by a non-market producer such as the government, the prices charged to consumers are often significantly below the price that a market producer would charge. In some cases, the price may even be zero. It would make no sense to compare such prices charged to patients or consumers across countries as they reflect administrative decisions and not the value of products. It has therefore been customary in PPP compilations to compare costs of producing non-market goods and services.

13. There are two possibilities for comparing costs, one based on inputs and one based on outputs. The input-based method, traditionally applied in PPP comparisons of non-market products, consists of comparing the prices of inputs in the production process of non-market services. In the case of health services, an input-based method would, for example, compare the wage rate of a surgeon in different countries. In other words, the price comparison is approximated through a comparison of wages or values per unit of inputs. Apart from the fact that it is notoriously difficult to compare wages across countries (even for the same type of occupation, qualifications may be different, it is hard to control for experience and seniority payments etc.) the main drawback of this methodology is that it ignores any productivity differences between countries. In other words, if health services are provided more efficiently in one country compared to another, this would go unnoticed in a PPP comparison that is based on the price of inputs.

14. The second option for comparing costs is based on outputs. Here, PPPs are measured by comparing the costs per unit of output, in the case of medical services this is typically the cost per treatment. In the health domain, costs per unit of output are not generally readily observable but there is an alternative source of information that provides valuations of outputs: in many OECD countries, health services are managed through reimbursement schemes where health providers and health administrations or insurance companies either negotiate reimbursements per treatment or where the government administers reimbursements per treatment. Reimbursement values per treatment or per episode of illness can be used to emulate the role that prices play for other goods and services.

15. Negotiated or administered rates could be labelled as 'quasi-prices' to signal that they are not necessarily the result of market transactions, that they are not prices that apply to transactions between producers and consumers of health services, and that they are not observed. The comparison of quasi-

For a full description of the methods used, the reader is referred to Eurostat-OECD (2006). 
prices per unit of treatment is an output-based approach, and in principle is capable of reflecting productivity differences between countries ${ }^{4}$. It is thus conceptually preferable to input-based approaches.

\section{Quasi-prices in health}

16. It is rare that hospital services can be directly measured and valued through free-standing costing studies and clinical trials with concurrent economic evaluation. A more promising avenue is to use secondary data sets available through health administrations and national insurance funds for purposes of reimbursement, health financing, and hospital budgeting.

17. Two main issues may limit the use of secondary datasets for across country price comparisons: differences in products classification; differences in how prices are set.

18. As to the former, measures of hospital production may differ across countries in terms of diagnosis coding systems (e.g. WHO International Classification of Diseases, ICD) and procedure coding systems (like the Canadian Classification of Intervention, CCI) used to report clinical information on hospitalizations, and classification systems (e.g. Australian Refined DRG, AR-DRG) used to measure hospital product (Hakkinen and Joumard 2007).

19. As to the latter, quasi-prices comprise both negotiated prices and administered prices. The former are established through independent negotiations between purchasers/third party payers and providers, and are not necessarily directly tied to the cost of care. For instance, negotiated prices could include profit margins (or losses if some services are cross-subsidised by others).

20. Administered quasi-prices, on the other hand, are likely to be reflective of average costs per product. In the case of administered quasi-prices that typically reflect average costs of service provision, it is important that the scope of costs reflected in the administered price is similar across countries. As a general principle, the full set of costs should be reflected in the quasi-price. These comprise compensation of employees, depreciation of capital, intermediate inputs, and taxes on production. Both costs relating to health services directly as well as overhead costs should be reflected.

\section{Characteristics of national systems}

21. To assess the feasibility of using information derived from secondary data sets to feed an outputbased PPP methodology for hospital services, we reviewed the main characteristics of secondary datasets for selected OECD countries ${ }^{5}$ in terms of:

- the diagnoses and procedures coding standards used

- the DRG classification systems in place

- the cost-finding methods used to estimate average cost by product, on which "quasi-prices" are based An extensive discussion of the measurement of output-based health and education services is provided in Schreyer (2010).

5 Australia, Canada, England, France, Germany, Norway, and the United States participated in the OECD PPP pilot studies carried out to assess the feasibility of the proposed approach in 2008 and 2009 (Koechlin et al 2010).
} 
22. The Annex reports the description of the tools used in each country in study, followed by a brief description of the WHO ICD classifications. The following sections summarise the results in each of the key dimensions.

\subsection{Diagnoses reporting}

23. Table 1 describes the main characteristics of the classification systems used by the countries in study to report diagnoses.

- All countries (except the United States) use the World Health Organisation International Classification of Diseases, tenth revision (ICD-10) or a modification based on this. This means that there is generally good international comparability in diagnosis codes. All countries code their diagnoses using a length of 5 characters, and codes are alphanumeric ${ }^{6}$ (both letters and numbers are used).

- The classifications are updated annually or every two years by countries. A shorter update period may result in more clinically up-to-date and meaningful classifications.

- The responsibility for the update varies, involving university-based independent organisations (Australia), independent non-profit organisations (Canada and Norway), and government agencies (England, France, Germany, and the United States).

- With the exceptions of Australia and Canada, the classifications are in the public domain, that is the handbook containing the definition of the classification taxonomy is accessible over the internet at no charge.

- In all countries in study, guidelines to maintain and improve the quality of coded clinical data are available. The use of guidelines improves the accuracy and reliability of coded data.

24. Hence it can be concluded that the information on diagnoses is generated from similar processes across countries, and a presumption that information is likely to be comparable seems reasonable. The annex to this paper describes the details of the coding and information gathering at a National level in more detail.

For the US, alphanumeric codes are used only for the supplementary classifications of factors influencing health status and other contacts with health services ( $\mathrm{V}$ codes) and of external causes of injury and poisoning (M codes). 
Table 1 Main characteristics of the diagnosis code system. Selected OECD member states

\begin{tabular}{|c|c|c|c|c|c|c|c|}
\hline & \multicolumn{7}{|c|}{ Country } \\
\hline Characteristic & Australia & Canada & England & France & Germany & Norway & United States \\
\hline $\begin{array}{l}\text { Name of the } \\
\text { system }\end{array}$ & ICD-10-AM & ICD-10-CM & ICD-10 & ICD-10 7 & ICD-10-GM & ICD-10 & ICD-9-CM \\
\hline $\begin{array}{l}\text { Classification } \\
\text { on which it is } \\
\text { based }\end{array}$ & WHO ICD-10 & WHO ICD-10 & & & WHO ICD-10 & & WHO ICD-9 \\
\hline $\begin{array}{l}\text { Type of code } \\
\text { (maximum } \\
\text { length) }\end{array}$ & $\begin{array}{l}\text { Alphanumeric } \\
\text { (5 characters) }\end{array}$ & $\begin{array}{l}\text { Alphanumeric } \\
\text { (5 characters) }\end{array}$ & $\begin{array}{l}\text { Alphanumeric } \\
\text { (5 characters) }\end{array}$ & $\begin{array}{l}\text { Alphanumeric (5 } \\
\text { characters) }\end{array}$ & $\begin{array}{l}\text { Alphanumeric (5 } \\
\text { characters) }\end{array}$ & $\begin{array}{l}\text { Alphanumeric } \\
\text { (5 characters) }\end{array}$ & $\begin{array}{l}\text { Numeric (5 } \\
\text { characters) }^{8}\end{array}$ \\
\hline $\begin{array}{l}\text { Timeliness for } \\
\text { modification }\end{array}$ & Biannual & Biannual & Annual & Annual & Annual & Annual & Annual \\
\hline $\begin{array}{l}\text { Organisation } \\
\text { responsible for } \\
\text { modifications }\end{array}$ & $\begin{array}{l}\text { National Centre } \\
\text { for } \\
\text { Classification } \\
\text { in Health }\end{array}$ & $\begin{array}{l}\text { Canadian } \\
\text { Institute for } \\
\text { Health } \\
\text { Information }\end{array}$ & $\begin{array}{l}\text { NHS } \\
\text { Classifications } \\
\text { Service }\end{array}$ & $\begin{array}{l}\text { Agence Technique } \\
\text { de l'Information } \\
\text { sur } \\
\text { l'Hospitalisation }\end{array}$ & $\begin{array}{l}\text { German Institute } \\
\text { of Medical } \\
\text { Documentation } \\
\text { and Information }\end{array}$ & $\begin{array}{l}\text { Nordic Centre } \\
\text { for } \\
\text { Classification in } \\
\text { Health Care }\end{array}$ & $\begin{array}{l}\text { National } \\
\text { Center for } \\
\text { Health } \\
\text { Statistics }\end{array}$ \\
\hline Public domain? & No & No & Yes & Yes & Yes & Yes & Yes \\
\hline $\begin{array}{l}\text { Coding } \\
\text { standards } \\
\text { available? }\end{array}$ & Yes & Yes & Yes & Yes & Yes & Yes & Yes \\
\hline
\end{tabular}

\footnotetext{
Several coded are added to ICD-10 for use in French hospitals.

8 Alphanumeric only for the $\mathrm{V}$ and $\mathrm{M}$ classifications.
} 


\subsection{Procedure classification systems}

25. The main characteristics of the procedure classification systems are reported in Table 2. Here, there is no common basis similar to the WHO ICD for diagnoses, thus the international comparability of procedure codes is quite low.

- Local classifications differ significantly by type of codes, classification axes, and number of codes. The maximum length of valid procedure codes varies between 4 numeric characters (ICD9-CM in the US) and 10 alphanumeric character (the Canadian CCI). If more characters are available, a greater specificity in coding is possible, which is likely to increase comparability of information.

- The primary axis for classification is either the type of intervention - that is whether the intervention is therapeutic, diagnostic or another type of healthcare - or the body system/anatomical site involved. If the primary axis is the type of procedure, then the secondary axis is based on body system/anatomical site, while if the primary axis is the anatomical site, then the secondary axis is the type of intervention or a body region. England and the US do not use a secondary axis of classification.

- The number of possible codes varies seven-fold, between 3800 in the US and 24000 in Germany.

26. Other aspects of the information on procedures are similar to that of diagnoses, and is less of a cause for concern over comparability:

- The classifications are updated annually or every two years by countries.

- The responsibility for the update is with university-based independent organisations (Australia), independent non-profit organisations (Canada and Norway), and government agencies (England, France, Germany, and the United States).

- The procedure classifications used in Australia, Canada and England are not in the public domain.

27. Hence a priori, there is reason to be concerned about how comparable information on procedures is across countries. In particular, it is necessary to map codes across countries in order to ensure that information is comparable. 
Table 2 Main characteristics of the procedure code system. Selected OECD member states

\begin{tabular}{|c|c|c|c|c|c|c|c|}
\hline Characteristic & Australia & Canada & England & France & Germany & Norway & United States \\
\hline $\begin{array}{l}\text { Name of the } \\
\text { system }\end{array}$ & ACHI & $\mathrm{CCI}$ & OPCS & CCAM & OPS & NCSP & ICD-9-CM \\
\hline $\begin{array}{l}\text { Type of code } \\
\text { (maximum } \\
\text { length) }\end{array}$ & $\begin{array}{l}\text { Numeric (7 } \\
\text { characters) }\end{array}$ & $\begin{array}{l}\text { Alphanumeric } \\
\text { (10 characters) }\end{array}$ & $\begin{array}{l}\text { Alphanumeric (4 } \\
\text { characters) }\end{array}$ & $\begin{array}{l}\text { Alphanumeric (7 } \\
\text { characters) }\end{array}$ & $\begin{array}{l}\text { Alphanumeric } \\
\text { ( } 6 \text { characters) }\end{array}$ & $\begin{array}{l}\text { Alphanumeric } \\
\text { (5 characters) }\end{array}$ & $\begin{array}{l}\text { Numeric (4 } \\
\text { characters) }\end{array}$ \\
\hline Primary axis & Anatomical site & $\begin{array}{l}\text { Type of } \\
\text { intervention }\end{array}$ & Body system & $\begin{array}{l}\text { Anatomo- } \\
\text { physiological } \\
\text { system }\end{array}$ & $\begin{array}{l}\text { Type of } \\
\text { procedure }\end{array}$ & $\begin{array}{l}\text { Functional- } \\
\text { anatomical } \\
\text { (body system) }\end{array}$ & $\begin{array}{l}\text { Body system - } \\
\text { Anatomical } \\
\text { site }\end{array}$ \\
\hline Secondary axis & $\begin{array}{l}\text { Type of } \\
\text { procedure }\end{array}$ & $\begin{array}{l}\text { Body system- } \\
\text { anatomical site }\end{array}$ & - & $\begin{array}{l}\text { Diagnostic versus } \\
\text { therapeutic }\end{array}$ & Anatomical site & $\begin{array}{l}\text { Functional- } \\
\text { anatomical } \\
\text { (region) }\end{array}$ & - \\
\hline $\begin{array}{l}\text { Number of } \\
\text { codes }\end{array}$ & 6,102 & $\begin{array}{l}\text { Approximately } \\
18,000\end{array}$ & $\begin{array}{l}\text { Approximately } \\
6,000\end{array}$ & $\begin{array}{l}\text { Approximately } \\
8,000\end{array}$ & $\begin{array}{l}\text { Approximately } \\
24,000\end{array}$ & 7,436 & 3,824 \\
\hline $\begin{array}{l}\text { Timeliness for } \\
\text { modification }\end{array}$ & Biennial & Biennial & Annual & Biennial & Annual & Annual & Annual \\
\hline $\begin{array}{l}\text { Organisation } \\
\text { responsible for } \\
\text { modifications }\end{array}$ & $\begin{array}{l}\text { National Centre } \\
\text { for Classification } \\
\text { in Health }\end{array}$ & $\begin{array}{l}\text { Canadian } \\
\text { Institute for } \\
\text { Health } \\
\text { Information }\end{array}$ & $\begin{array}{l}\text { NHS } \\
\text { Classifications } \\
\text { Service }\end{array}$ & $\begin{array}{l}\text { Agence } \\
\text { Technique de } \\
\text { l'Information sur } \\
\text { l'Hospitalisation }\end{array}$ & $\begin{array}{l}\text { German } \\
\text { Institute of } \\
\text { Medical } \\
\text { Documentation } \\
\text { and Information }\end{array}$ & $\begin{array}{l}\text { Nordic Centre } \\
\text { for } \\
\text { Classification } \\
\text { in Health Care }\end{array}$ & $\begin{array}{l}\text { Centers for } \\
\text { Medicare and } \\
\text { Medicaid } \\
\text { Services }\end{array}$ \\
\hline Public domain? & No & No & No & Yes & Yes & Yes & Yes \\
\hline
\end{tabular}

ACHI: Australian Classification of Health Interventions; CCI: Canadian Classification of Intervention; OPCS: Office of Population, Censuses and Surveys

Classification of Interventions and Procedures CCAM: Classification Commune des Actes Médicaux; OPS: Classification of Surgical and Medical Procedures; NCPS: NOMESCO Classification of surgical procedures. 


\subsection{Product classification systems}

28. Table 3 reports the main characteristics of the product classification systems in use in the selected countries. It is worth noting that all countries have a classification system which is based largely on the United States Medicare DRGs system as the starting point. However, despite this common origin, taxonomies differ as to scope, number of groups, and measurement of severity of cases.

- As to the scope, Canada and the US limit the use of the classification to the acute inpatient setting ${ }^{9}$, while the other countries include day care services and hospital-based outpatient services to describe services on the basis of what is done rather than where.

- The number of classes mainly depends on the scope of the system and the way severity of cases is measured. At one extreme of the range is France, where the classification system is large in scope (it includes hospital-based outpatient care), and 4 severity levels are defined for each base group. The result is a product classification system that contains 2,368 classes. With so many categories, this leads to a system which arguably has more in common with a fee-for-service system than some of the DRG systems that are used in other countries. At the other end of the spectrum, Canada limits the scope of the system, and uses co-morbidities only to adjust payment. As a result, 562 classes are identified.

- All countries use principal diagnosis areas referred to as Major Diagnostic Categories (MDC). The diagnoses in each MDC correspond to a single organ system or etiology, and in general are associated with a particular clinical specialty. 4 (out of 7) countries use an initial classification step based on procedure (a departure from the use of principal diagnosis as the initial variable in DRG assignment) to identify very resource intensive procedures that can be performed for different diagnoses (e.g. transplants).

29. Classification systems vary substantially in the way "severity" is measured. All systems use a list of diagnoses codes that when reported as secondary diagnosis (co-morbidities ${ }^{10}$ ) may increase the level of severity of a specific case, that is its risk of death, complications, and of additional diagnostic testing and therapeutic interventions. Countries differ significantly in the lists used, in the number of severity levels 2 for selected groups in Norway, 9 in Germany -, and in the use of severity - either as a product classification variable or as a factor to adjust payment.

30. The update of product classification is not as systematic as the update of the coding classifications: 3 countries update the classification every year, 2 every second year, and in 2 countries the update is not regular. The responsibility for the update is with university-based independent organisations (Australia), independent non-profit organisations (Canada and Norway), and government agencies (England, France, and the United States). In Germany, a non-for-profit body (Inek) that is jointly owned by the Health Insurance Bodies and the Association of German Hospitals is responsible for the annual update of the G-DRG system. Hospital product classification standards are not in the public domain in Australia and Canada.

9

It is worth noting that other classification systems are used to measure hospital-based outpatient care, that is Ambulatory Payment Classification (APC) for the US, and Day Procedure Groups (DPG) and Comprehensive Ambulatory Classification System (CACS) for Canada.

The prototypical comorbidity is a chronic condition, such as diabetes mellitus, obstructive pulmonary disease, or chronic ischemic disease. 
31. The upshot of these differences is that the international comparability of product classification systems is quite limited. As with the procedure classifications, it requires careful mapping between the codes used in different national systems in order to get comparable information. 
DELSA/HEA/WD/HWP(2011)2

Table 3 Main characteristics of the classification system. Selected OECD member states

\begin{tabular}{|c|c|c|c|c|c|c|c|}
\hline \multirow{2}{*}{ Characteristic } & \multicolumn{7}{|c|}{ Country } \\
\hline & Australia & Canada & England & France & Germany & Norway & United States \\
\hline $\begin{array}{c}\text { Name of the } \\
\text { system (version) }\end{array}$ & $\begin{array}{l}\text { Australian Refined } \\
\text { DRGs (6.0) }\end{array}$ & $\begin{array}{c}\text { Case Mix } \\
\text { Groups Plus } \\
(2008)\end{array}$ & $\begin{array}{c}\text { Healthcare } \\
\text { Resource Groups } \\
(4)\end{array}$ & $\begin{array}{c}\text { Groupes } \\
\text { Homogènes de } \\
\text { Malades (11.b) }\end{array}$ & $\begin{array}{l}\text { German DRG } \\
\quad(2011)\end{array}$ & $\begin{array}{l}\text { Nord-DRG } \\
\quad(2008)\end{array}$ & $\begin{array}{c}\text { Medicare Severity } \\
\text { DRG (28) }\end{array}$ \\
\hline Scope & $\begin{array}{l}\text { Inpatient + day care } \\
\text { acute admissions }\end{array}$ & Acute inpatient & $\begin{array}{l}\text { Inpatient + } \\
\text { outpatient }\end{array}$ & $\begin{array}{c}\text { Inpatient }+ \text { day care } \\
\text { acute admissions }+ \\
\text { hospital based } \\
\text { outpatient care }\end{array}$ & $\begin{array}{l}\text { Inpatient }+ \text { day } \\
\text { care acute } \\
\text { admissions }\end{array}$ & $\begin{array}{c}\text { Inpatient }+ \text { day } \\
\text { care acute } \\
\text { admissions }+ \\
\text { short therapy }\end{array}$ & $\begin{array}{l}\text { Inpatient acute } \\
\text { admissions }\end{array}$ \\
\hline $\begin{array}{c}\text { Number of } \\
\text { MDCs }\end{array}$ & 23 & 20 & 23 chapters & 27 & 23 & 25 & 25 \\
\hline Pre MDC? & Yes & No & No & No & Yes & Yes & Yes \\
\hline $\begin{array}{c}\text { Number of } \\
\text { groups }\end{array}$ & 698 & 562 & 1,404 & 2,368 & 1,157 & 793 & 747 \\
\hline $\begin{array}{c}\text { Classification of } \\
\text { severity }\end{array}$ & $\begin{array}{l}\text { CC levels }(0-4) \\
\text { Clinical complexity } \\
\text { levels }(0-4)\end{array}$ & $\begin{array}{c}5 \text { severity levels } \\
\text { (comorbidity } \\
\text { factors) }\end{array}$ & 3 severity levels & 4 severity levels & $\begin{array}{c}\text { Clinical } \\
\text { complexity levels } \\
\text { (A-I) }\end{array}$ & $\begin{array}{l}\text { Split into "with } \\
\text { CC" and } \\
\text { "without CC" } \\
\text { for selected } \\
\text { groups }\end{array}$ & 3 severity levels \\
\hline Specificities & & $\begin{array}{c}5 \text { factors to } \\
\text { adjust relative } \\
\text { weights }\end{array}$ & $\begin{array}{l}\text { Groups for high } \\
\text { cost drugs }\end{array}$ & $\begin{array}{c}\text { MDC for hospital- } \\
\text { based outpatient } \\
\text { care }\end{array}$ & & $\begin{array}{c}\text { Groups for short } \\
\text { therapy }\end{array}$ & \\
\hline $\begin{array}{l}\text { Timeliness for } \\
\text { modification }\end{array}$ & Biennial & Biennial & Not regular & Not regular & Annual & Annual & Annual \\
\hline $\begin{array}{l}\text { Organisation } \\
\text { responsible for } \\
\text { modifications }\end{array}$ & $\begin{array}{l}\text { National Centre for } \\
\text { Classification in } \\
\text { Health }\end{array}$ & $\begin{array}{c}\text { Canadian } \\
\text { Institute for } \\
\text { Health } \\
\text { Information }\end{array}$ & $\begin{array}{c}\text { The Information } \\
\text { Centre - The } \\
\text { Casemix Service, } \\
\text { NHS }\end{array}$ & $\begin{array}{c}\text { Agence Technique } \\
\text { de l'Information } \\
\text { sur } \\
\text { l'Hospitalisation }\end{array}$ & $\begin{array}{l}\text { Institute for the } \\
\text { Hospital } \\
\text { Remuneration } \\
\text { System }\end{array}$ & $\begin{array}{c}\text { Nordic Casemix } \\
\text { Centre }\end{array}$ & $\begin{array}{l}\text { Centers for } \\
\text { Medicare and } \\
\text { Medicaid } \\
\text { Services }\end{array}$ \\
\hline Public domain? & No & No & Yes & Yes & Yes & Yes & Yes \\
\hline
\end{tabular}

MDC: Major Diagnostic Category

CC: complications and/or comorbidities 


\subsection{Cost-finding methods}

32. The main characteristics of the cost-finding methods in use in the countries under study are reported in table 4 . The sample varies across countries, and is linked to the mode of participation. The annual exercise is largely voluntary, and the results are publicly available at DRG level. Only Australia and England collect and publish statistics by type of provider. Most countries collect cost and activity data also for private facilities.

33. Approaches to resource consumption measurement vary widely, and are determined by the objective of the cost analysis and the availability of data. At one end of the spectrum, there is the grosscosting or top-down approach. This approach is essentially a product line (or case-mix) cost-accounting model, with the core objective of costing the treatment of individual patients grouped into similar classes. At the other end of the spectrum, there is direct identification and measurement of patient-specific service delivery process, frequently called bottom-up or micro-costing approach. Both top-down and bottom-up practices exist among the countries in study, confirming that "a universally accepted costing methodology does not currently exist in the healthcare sector" (Busse, 2008). However, there is some evidence that topdown and bottom-up costs tend to generate comparable estimates for the costs of inpatient admission (Chapko et al., 2008; Tan et al., 2009). Thus, the different ways of pricing health services (top-down or bottom-up) does not appear to seriously impede comparability.

34. A particular problem is the treatment of capital costs. Treatment of patients involves recurrent costs, but also consumption of capital - wear and tear on buildings, and diagnostic equipment, etc. Sometimes DRG payments are used to compensate providers for such costs, but some countries use other payment systems to pay for capital costs. Of the sample of countries included here, consumption of fixed capital is not included in the estimates for Norway, while for Germany consumption of fixed capital and other costs which are not included in DRG-revenues are not included in the value reported. Hence for those two countries there is likely to be an underestimation of the values reported when comparing across countries. 
DELSA/HEA/WD/HWP(2011)2

Table 4 Main characteristics of the cost-finding methods. Selected OECD member states

\begin{tabular}{|c|c|c|c|c|c|c|c|}
\hline \multirow{2}{*}{ Characteristic } & \multicolumn{7}{|c|}{ Country } \\
\hline & Australia & Canada & England & France & Germany & Norway & United States \\
\hline Sample & $\begin{array}{c}47 \% \text { of public } \\
\text { hospitals } \\
36 \% \text { of private }\end{array}$ & By jurisdiction & $\begin{array}{c}\text { Total } \\
\text { population }\end{array}$ & $\begin{array}{l}41 \text { public } \\
\text { hospitals }\end{array}$ & $\begin{array}{c}16 \% \text { of hospitals } \\
\text { using DRGs }\end{array}$ & $\begin{array}{l}21 \text { public } \\
\text { hospitals }\end{array}$ & Total population \\
\hline $\begin{array}{l}\text { Timeliness of } \\
\text { data collection }\end{array}$ & Annual & Annual & Annual & Annual & Annual & Annual & Annual \\
\hline $\begin{array}{l}\text { Voluntary or } \\
\text { mandatory? }\end{array}$ & Voluntary & Voluntary & Mandatory & Voluntary & Voluntary & Voluntary & $\begin{array}{c}\text { Mandatory } \\
\text { (linked to per } \\
\text { case payment) }\end{array}$ \\
\hline $\begin{array}{c}\text { Public available } \\
\text { statistics }\end{array}$ & Yes & No & Yes & Yes & Yes & No & $\begin{array}{c}\text { Aggregated data } \\
\text { (on request) }\end{array}$ \\
\hline $\begin{array}{c}\text { Figures } \\
\text { available by } \\
\text { hospital type? }\end{array}$ & Yes & No & Yes & No & No & No & No \\
\hline Approach & $\begin{array}{c}\text { Top-down } \\
\text { Bottom-up }^{11}\end{array}$ & Top-down & Top-and-bottom & Top-down & Top-down & Top-down & Bottom-up \\
\hline $\begin{array}{l}\text { Full-costing } \\
\text { approach? }\end{array}$ & Yes & Yes & Yes & Yes & $\begin{array}{c}\text { No. } \\
\text { Consumption of } \\
\text { fixed capital } \\
\text { excluded }\end{array}$ & $\begin{array}{c}\text { No. } \\
\text { Consumption of } \\
\text { fixed capital } \\
\text { excluded }\end{array}$ & Yes \\
\hline $\begin{array}{c}\text { Data collection } \\
\text { for private } \\
\text { hospitals? }\end{array}$ & Yes & No & Yes & Yes & - & No & Yes \\
\hline
\end{tabular}

11

The facility may choose the approach on the basis of data availability. 


\section{Conclusions}

35. We conclude that comparisons are possible notwithstanding the different product classifications in use and the approaches used in developing DRG prices. Secondary data sets available through health administrations and national insurance funds for purposes of reimbursement, health financing, and hospital budgeting can be used to estimate hospital prices to compare price levels across countries. Using routinely collected administrative information through secondary databases to estimate quasi-prices for a representative set of health products has the advantages of larger sample size, greater external data validity and limited costs of collecting data as compared to primary data collection.

36. However, coding systems are not identical across countries, and so perfect comparability is not attainable, even without taking into account the near-inevitable differences in interpretation of guidelines across countries. The possible bias arising from differences in coding systems among countries could be limited by identifying classes of representative hospital products ${ }^{12}$. Product identification via ICD codes along with their verbal description - allows the selection of diagnoses and procedure codes in each country that best match the representative classes of products identified. The correspondence between product classes and the national DRGs can be established through an evaluation of the taxonomy of the classification systems used by the individual country.

37. Nevertheless, a further note of caution is that there is no guarantee that DRG-based quasi-prices reflect costs. Countries have an incentive to get them right in most circumstances. But normative prices could also be used as policy instrument to signal what the health system should be doing, and to sharpen incentives so that good practice is rewarded and emulated. And tariffs could play a more extensive role, so that they are analogous to prices in most markets. It is difficult to assess whether this generates a bias of any kind for spatial hospital price comparisons.

38. The importance of these differences will vary according to the use made of the data. One of the main uses is to develop purchasing power parities for the health sector. In this case, what matters as much as anything is the overall picture of prices of interventions, so minor differences in the coding and recording of individual procedures is not a cause for concern. However, if the data is used to compare the costs of specific interventions across countries, great attention needs to be paid to these coding differences. Relatively minor differences can have a great effect on costs if they result in exclusion of outliers at either end of the cost spectrum when compared to other countries. Furthermore, differences in the treatment of capital costs are potentially important for both purposes, and adjustments to the raw data may be necessary to achieve analytic reliability.

12 For instance, "heart failure" constitutes one product. Each product is identified using ICD codes, and is further specified so as to compare similar occurrencies of services. In the case if heart failure, the indication is given that "no operating room procedure is performed". 


\section{ANNEX}

\section{Australia}

\section{Diagnoses classification and coding}

39. An Australian modification of the World Health Organization's (WHO) International Statistical Classification of Diseases and Related Health Problems, Tenth Revision (ICD-10) and the development of an accompanying Australian procedure classification was endorsed by the Australian Health Ministers' Advisory Council (AHMAC) for introduction as the Australian standard for morbidity coding in health services from 1 July 1998.

40. The National Centre for Classification in Health $(\mathrm{NCCH})^{13}$ has been given the responsibility for the development, introduction and maintenance of the International Statistical Classification of Diseases and Related Health Problems, Tenth Revision, Australian Modification (ICD-10-AM), Australian Classification of Health Interventions (ACHI) and Australian Coding Standards (ACS), under contract from the Australian Department of Health and Ageing, holder of the WHO license to create an Australian version of ICD-10.

41. ICD-10-AM is based on the WHO disease publication ICD-10 and has been modified in Australia by the NCCH with assistance from clinicians and clinical coders to ensure that the classification is current and appropriate for Australian clinical practice. Close links have been maintained with WHO to ensure that international compatibility is maintained.

42. In the development of ICD-10-AM, a number of classification principles were followed:

- no modification was made to the structure of WHO ICD-10

- the meanings of the three-character and four-character codes were not changed, although clarity has been added in several instances

- modifications were consistent with existing WHO ICD-10 codes and conventions

- the ability to compare data over time was not compromised.

43. ICD-10-AM is therefore totally compatible with its parent system, WHO ICD-10, thus meeting the need for comparability of morbidity and mortality statistics at the international level.

13 The NCCH is located at and supported by two of Australia's leading and largest universities, the University of Sydney and Queensland University of Technology. It has seventeen staff in Sydney based at the University of Sydney and eight employees in Brisbane based at the Queensland University of Technology. 
44. The first Australian modification to WHO ICD-10 includes fifth character additions to provide further specificity. A limited number of additions have also been made to third and fourth character categories.

45. The ICD-10-AM consists of a tabular list of diseases and accompanying index. It uses an alphanumeric coding scheme for diseases. It is a variable-axis classification and its structure is designed principally to facilitate epidemiological analysis. Diseases are organised in the following groups: epidemic diseases; constitutional or general diseases; local disease arranged by site; developmental diseases; injuries (the same as WHO ICD-10).

46. The first two, and the last two, of these groups comprise 'special groups', which bring together conditions that would be inconveniently arranged for epidemiological study were they to be scattered, for instance, in a classification arranged primarily by anatomical site. The remaining group, 'local disease arranged by site', includes the ICD-10-AM chapters for each of the main body systems.

47. For several diseases, it mirrors the ICD-10 codes. The ICD-10-AM Acute myocardial infarction codes - as an example- are the same as ICD-10 codes:

I21.0, Acute transmural myocardial infarction of anterior wall

I21.1, Acute transmural myocardial infarction of inferior wall

I21.2, Acute transmural myocardial infarction of other sites

I21.3, Acute transmural myocardial infarction of unspecified sites

I21.4, Acute subendocardial myocardial infarction

I21.9, Acute myocardial infarction unspecified

48. In other cases, a different level of clinical specification is provided using a fifth character. As an example, the following table compares ICD-10 and ICD-10-AM codes for Type I Diabetes mellitus (DM) with coma and/or ketoacidosis.

\begin{tabular}{|c|l|l|l|}
\hline \multicolumn{2}{|c|}{ ICD-10 } & \multicolumn{2}{c|}{ ICD-10-AM } \\
\hline Code & \multicolumn{1}{|c|}{ Description } & Code & \multicolumn{1}{c|}{ Description } \\
\hline E10.0 & Insulin-dependent DM with coma & E10.11 & $\begin{array}{l}\text { Type I DM with ketoacidosis without } \\
\text { coma }\end{array}$ \\
\hline E10.1 & Insulin-dependent DM with ketoacidosis & $\begin{array}{l}\text { E10.12 } \\
\text { E10.13 }\end{array}$ & $\begin{array}{l}\text { Type I DM with ketoacidosis with coma } \\
\text { Type I DM with lactic acidosis without } \\
\text { coma } \\
\text { Type I DM with lactic acidosis with } \\
\text { coma } \\
\text { Type I DM with ketoacidosis/lactic } \\
\text { acidosis without coma } \\
\text { Type I DM with ketoacidosis/lactic } \\
\text { acidosis with coma }\end{array}$ \\
\hline
\end{tabular}

49. Another example relates to the addition of a fifth character to the Malignant immunoproliferative disease (C88), Multiple myeloma and malignant plasma cell neoplasms (C90), Lymphoid leukaemia (C91), Myeloid leukaemia (C92), Monocytic leukaemia (C93), Other leukaemia of specified cell type (C94), Leukaemia of unspecified cell type (C95) categories to specify whether they are "without mention of remission" (0) or "in remission" (1).

50. The current Seventh Edition of ICD-10-AM will be used in Australia till 30 June 2013. 


\section{Procedure classification and coding}

51. The Australian Classification of Health Interventions (ACHI) forms volumes three and four of ICD-10-AM. When Australia decided to move from ICD-9-CM to ICD-10 and modify the latter to meet Australian needs, a decision needed to be made about what procedure classification would be used with ICD-10-AM. After other options were considered, it was decided to develop a new procedure classification at $\mathrm{NCCH}$. Development began in 1995 and the ACHI was implemented in Australian hospitals in 1998 as a companion to ICD-10-AM. Principal specifications for the ACHI are:

- $\quad$ ACHI is published as the Tabular List of Interventions and the Alphabetic Index of Interventions in tandem with ICD-10-AM and the Australian Coding Standards.

- The procedure classification captures procedures and interventions performed in public and private hospitals, day centres and ambulatory settings. Allied health interventions, dental services and procedures performed outside the operating theatre are included.

- The procedure classification is based on the Commonwealth Medicare Benefits Schedule (MBS) - the Australian medical services fee schedule ${ }^{14}$. A two digit extension number has been attached to each MBS item number to represent individual procedural concepts (e.g. 36564-00). Other ACHI procedures and interventions which are not represented in MBS are allocated a code number from the 90000 series.

- The structure of the procedure classification is based on anatomy rather than surgical specialty. Chapters closely follow the chapter headings of the WHO ICD-10 to maintain parity with the disease classification.

- Nonsurgical procedures are listed separately from the surgical procedures, whenever feasible.

52. There are certain chapters that are an exception to the general format:

- Dental services: this chapter is based on 'The Australian Schedule of Dental Services and Glossary, 8th Edition' published by the Australian Dental Association (ADA). The Dental Services chapter is structured on a service basis, for example, diagnostic services, preventative services, oral surgery, etc. Secondary axes, in most instances, relate to procedure type.

- Obstetric procedures: this chapter has a principal axis relating to the pregnancy cycle, for example, antepartum procedures, procedures associated with labour, delivery, etc. Secondary axes relate to procedure type.

- $\quad$ Radiation oncology procedures: this chapter has a principal axis relating to radiation oncology procedures. Secondary axes relate to the type of radiation, for example, external beam therapy, brachytherapy, computerised planning, etc.

- $\quad$ Non-invasive, cognitive and interventions, not elsewhere classified: this chapter has a principal axis relating to the purpose of the intervention, for example diagnostic, therapeutic or administrative/clinical/client support. The secondary axis relates to the type of intervention or the body system.

$14 \quad$ MBS is a fee schedule for Medicare services including general practice consultations, specialist consultations, operations and other medical services such as diagnostic investigations and optometrical services. 
- Imaging services: the principal axis within this chapter relates to the imaging service performed, for example, ultrasound, tomography, radiography, etc. There is no secondary axis within this chapter.

53. The following is a list of the ACHI procedure chapters and the code ranges covered by each.

\begin{tabular}{|c|l|c|}
\hline Chapter & \multicolumn{1}{|c|}{ Procedure classification } & Block range \\
\hline 1 & Procedures on Nervous System & $1-86$ \\
\hline 2 & Procedures on Endocrine System & $110-129$ \\
\hline 3 & Procedures on Eye and Adnexa & $160-256$ \\
\hline 4 & Procedures on Ear and Mastoid Process & $300-333$ \\
\hline 5 & Procedures on Nose, Mouth and Pharynx & $370-422$ \\
\hline 6 & Dental Services & $450-490$ \\
\hline 7 & Procedures on Respiratory System & $520-569$ \\
\hline 8 & Procedures on Cardiovascular System & $600-767$ \\
\hline 9 & Procedures on Blood and Blood-Forming Organs & $800-817$ \\
\hline 10 & Procedure on Digestive System & $850-1011$ \\
\hline 11 & Procedures on Urinary System & $1040-1129$ \\
\hline 12 & Procedures on Male Genital Organs & $1160-1203$ \\
\hline 13 & Gynaecological Procedures & $1240-1299$ \\
\hline 14 & Obstetric Procedures & $1330-1347$ \\
\hline 15 & Procedures on Musculoskeletal System & $1360-1579$ \\
\hline 16 & Dermatological and Plastic Procedures & $1600-1718$ \\
\hline 17 & Procedures on Breast & $1740-1759$ \\
\hline 18 & Chemotherapeutic and Radiation Oncology Procedures & $1780-1799$ \\
\hline 19 & Non-invasive, Cognitive and Other Interventions, not elsewhere classified & $1940-2016$ \\
\hline 20 & Imaging Services & \\
\hline
\end{tabular}

54. Block numbers and procedure codes can vary across editions, with the same block numbers representing two different procedure groups from one to another edition.

55. The five-character MBS code forms the first part of the ACHI code, with an extension code of two characters completing the ACHI code to split out separate components of procedures bundled in MBS.

56. ACHI presents a hierarchical structure with the following axes: anatomical site; procedure type; and procedure description. ACHI codes are not sequential in the tabular list, while block numbers are sequential and are used to group codes that are related. 
57. As an example, codes relating to the insertion of a defibrillator ${ }^{15}$ are reported below.

Chapter 8, Procedure on cardiovascular system (primary axis)

Heart, other sites (secondary axis)

653, Insertion of automatic defibrillator patches, electrodes or generator (tertiary axis) 38524-00, Insertion of automatic defibrillator generator

656, Adjustment, replacement or removal of automatic defibrillator patches, electrodes or generator (tertiary axis)

38524-01, Removal of automatic defibrillator generator

38524-02, Adjustment of automatic defibrillator generator

38524-03, Replacement of automatic defibrillator generator

58. As a reference, the fifth revision of ACHI contains 6102 valid codes.

\section{Timing and process for the revision of the coding schemata}

59. The NCCH is responsible for producing biennial revisions to ICD-10-AM/ACHI in Australia under contract from the Commonwealth Department of Health and Ageing. The update process involves national consultation with clinicians and clinical coders over an eighteen month period. Public submissions also contribute to issues considered, as do queries from Australian state and territory coding committees.

60. The Department of Health and Ageing updates MBS at least twice each year and these code changes are either incorporated into ACHI or the MBS codes are mapped to existing ACHI codes.

\section{Tools used for data quality enhancement}

61. The Australian Coding Standards for the ICD-10-AM and the ACHI apply to all public and private hospitals in Australia. The ongoing revision of the Australian Coding Standards (ACS) ensures that they reflect changes in clinical practice, clinical classification amendments, Australian Refined Diagnosis Related Groups (AR-DRG) grouper updates and various user requirements of inpatient data collections. These clinical coding standards have been written with the basic objective of satisfying sound coding convention according to ICD-10-AM and ACHI. Consideration of the various uses of inpatient data collections was secondary. Issues such as DRG allocation, research and planning aims were considered only after the requirement for accurate ICD-10-AM and ACHI coding was satisfied.

62. The ACSs are designed to be used in conjunction with ICD-10-AM and ACHI. Standard practice is that all hospitals update biennially to the latest version of ICD-10-AM/ACHI and ACS and that the new version should be in use no later than 1 July of the publication year. ICD-10-AM and ACHI tabular lists include an annotation of next to certain codes which indicates that an ACS exists which will assist in the application of the code.

63. Each standard is allocated a four digit ACS number. These numbers are generated by the NCCH as new standards are created and entered into a central database. The number is unique for each standard. When a standard is deleted, the standard and its unique number is retained in the database to allow for time series analysis of coding convention.

15 This example will be used throughout the report to describe the differences in the code structure across countries. 


\section{Classification system}

64. The Australian National Diagnosis Related Groups (AN-DRG) was the first national DRG classification system and was used from 1992-1997. The Australian Refined Diagnosis Related Groups (AR-DRG) are the second, current national DRG classification. These systems have been developed to classify acute admitted patient episodes in public and private hospitals.

65. The latest version of the AR-DRG Classification (Version 6.0) was released in November $2008^{16}$. It contains 698 groups. The number of groups and their relative frequency by Major Diagnostic Category (MDC) is reported in the table below.

\begin{tabular}{|c|l|c|c|}
\hline$M D C$ & \multicolumn{1}{|c|}{ Description } & $\begin{array}{c}\text { Number of } \\
\text { groups }\end{array}$ & $\begin{array}{c}\text { Relative } \\
\text { frequency } \\
(\%)\end{array}$ \\
\hline Pre & Major procedures - principal diagnosis associated with any MDC & 17 & 2.4 \\
\hline 01 & Diseases of nervous system & 61 & 8.7 \\
\hline 02 & Diseases and disorders of the eye & 19 & 2.7 \\
\hline 03 & Diseases and disorders of the ear, nose, mouth and throat & 27 & 3.9 \\
\hline 04 & Diseases and disorders of the respiratory system & 47 & 6.7 \\
\hline 05 & Diseases and disorders of the circulatory system & 80 & 11.5 \\
\hline 06 & Diseases and disorders of the digestive system & 46 & 6.6 \\
\hline 07 & Diseases and disorders of the hepatobiliary system and pancreas & 28 & 4.0 \\
\hline 08 & $\begin{array}{l}\text { Diseases and disorders of the musculoskeletal system and } \\
\text { connective tissue }\end{array}$ & 83 & 11.9 \\
\hline 09 & Diseases and disorders of the skin, subcutaneous tissue and breast & 34 & 4.9 \\
\hline 10 & Endocrine, nutritional and metabolic diseases and disorders & 28 & 4.0 \\
\hline 11 & Diseases and disorders of the kidney and urinary tract & 37 & 5.3 \\
\hline 12 & Diseases and disorders of the male reproductive system & 16 & 2.3 \\
\hline 13 & Diseases and disorders of the female reproductive system & 18 & 2.6 \\
\hline 14 & Pregnancy, childbirth and puerperium & 14 & 2.0 \\
\hline 15 & Newborns and other neonates & 25 & 3.6 \\
\hline 16 & $\begin{array}{l}\text { Diseases and disorders of the blood and blood forming organs and } \\
\text { immunological disorders }\end{array}$ & 9 & 1.3 \\
\hline 17 & Neoplastic disorders (haematological and solid neoplasms $)$ & 18 & 2.6 \\
\hline 18 & Infectious and parasitic diseases & 18 & 2.6 \\
\hline 19 & Mental diseases and disorders & 11 & 1.6 \\
\hline 20 & $\begin{array}{l}\text { Alcohol/drug use and alcohol/drug induced organic mental } \\
\text { disorders }\end{array}$ & 6 & 0.9 \\
\hline 21 & Injuries, poisonings and toxic effects of drugs & 29 & 4.2 \\
\hline 22 & Burns & 8 & 1.1 \\
\hline 23 & Factors influencing health status and other contacts with health \\
\hline 99 & Eervices & 13 & 1.9 \\
\hline & Total DRGs & 698 & 0.9 \\
\hline & & & 100.0 \\
\hline
\end{tabular}

66. The numbering system of the AR-DRGs reveals the broad group (usually the MDC) to which the DRG belongs, the adjacent DRG (and location in terms of a tripartite distribution between medical, surgical and other partitions), and the existence/nature of splits based on resource consumption.

$16 \quad$ Avaialble at: www.health.gov.au 
67. The format of each AR-DRG consists of four alphanumeric characters organised in terms of 'MAAS', where:

- $\mathrm{M}$ : indicates the broad group to which the DRG belongs

- AA : identifies the adjacent DRG within the MDC, and the partition to which the adjacent DRG belongs

- $\mathrm{S}$ : is a split indicator that ranks DRGs within adjacent DRGs on the basis of their consumption of resources

68. With regard to the first character, different letters of the alphabet have been used to signify the broad group to which the DRG belongs, while the number ' 9 ' has been used to identify Error DRGs. For example, it is apparent from the three DRGs numbers B01Z, ZO1A and 901Z that the first relates to the nervous system, the second to factors influencing health status and other contacts with health services, while the third is an Error DRG.

69. The second and third characters of each AR-DRG number - that is, the 'AA' digits - identify the adjacent DRG grouping. DRG numbers that begin with the same letter and share the same middle digits for example, B70A, B70B, B70C, and B70D - may be taken to relate to the same adjacent DRG.

70. In order that the second and third characters of each AR-DRG number may also be used to identify the partition to which the adjacent DRG belongs, three separate ranges - 01 to 39, 40 to 59 and 60 to 99 have been used to indicate the "surgical", "other" and "medical" partitions respectively. For example, the three AR-DRGs numbers P76D, I09B and O40Z reveal that the first is part of a medical partition, the second of a surgical partition, and the third of an 'other' partition.

71. Finally, the fourth character of each AR-DRG has been used as a split indicator to identify the relative importance of DRGs within an adjacent DRG in terms of resource consumption. Any one of a number of values may be used:

- A : highest consumption of resources within the adjacent DRG

- B : second highest consumption of resources

- $\quad \mathrm{C}$ : third highest consumption of resources

- $\quad \mathrm{D}$ : fourth highest consumption of resources

- Z: no split for adjacent DRG

72. The meaning of this split indicator may be gathered from the names of DRGs. For example, the following are the four groups that classify stroke:

- B70A, Stroke with catastrophic complications and/or comorbidities (CC)

- $\quad$ B70B, Stroke with severe CC

- B70C, Stroke without catastrophic or severe CC

- $\quad$ B70D, Stroke, died or transferred $<5$ days 
73. In general, both the DRGs within an adjacent DRG and the adjacent DRGs within the surgical and other partitions are organised hierarchically on the basis of resource consumption.

\section{Variables used in the assignment process}

74. Data items used by the AR-DRG grouper include diagnoses (up to 30), procedures (up to 30), sex, age, mode of separation, length of stay, leave days, admission date, separation date, date of birth, admission weight, mental health legal status and same day status.

75. The assignment process includes the following tasks:

- Demographic and clinical edits

- $\quad$ MDC assignment

- $\quad$ Pre-MDC processing

- $\quad$ Adjacent DRG (ADRG) assignment

- Complication and comorbidity level (CCL) and patient clinical complexity level (PCCL) assignment

- $\quad$ DRG assignment

76. The AR-DRG Classification system is based on hierarchies of diagnoses and procedures distributed between surgical, medical and other partitions.

\section{Timing and process for the revision of the classification system}

77. The development of the AR-DRG classification is an on-going work. Currently, a new version is released every two years. It is produced by the Commonwealth Department of Health \& Ageing, in consultation with the Clinical Casemix Committee of Australia (CCCA), the Clinical Classification and Coding Groups, the NCCH, the State and Territory jurisdictions, and other organisations.

78. The role of the CCCA is to provide clinical advice to the Department of Health and Ageing. The Committee's terms of reference include liaison with clinicians, professional bodies, State and Territory jurisdictions, private and other health organisations on casemix issues.

79. AR-DRG Definitions Manuals are produced and published by the Department for each version of the AR-DRG. The manuals describe the method of the classification, and aim to clarify the DRG assignment process. The AR-DRG Definitions Manuals are available for purchase from the NCCH.

\section{Cost-finding approach}

80. The National Hospital Cost Data Collection (NHCDC) is an annual collection of hospital cost and activity data which has been established to produce annual updates of the national public and private sector cost weights for the AR-DRG. The 2008-09 sample (Round 13, latest available) comprised 262 public hospitals and 110 private hospitals. The 262 public hospitals represent $52 \%$ of all large public hospitals and $91 \%$ of the total acute separations within the year. The 110 private hospitals represent $49 \%$ of the private population hospitals and $71 \%$ of the total acute separations within the private sector within the year. The NHCDC is a voluntary collection, and the sample may not be representative of the full range of 
Australian hospitals. Therefore an estimation process is used to create representative national costing and activity figures from the sample data.

81. Cost weights are available for public and private hospitals, teaching and non-teaching hospitals, major urban and non-major urban hospitals and the five bigger States namely, New South Wales, Victoria, Queensland, South Australia and Western Australia.

82. The NHCDC indicates two approaches to hospital cost calculation: cost modelled; patient costed. The former are hospitals that 'model' their cost centres using pre-determined statistics and 'weights' in order to apportion their costs across product groups and types. This is also known as 'top down' costing because it starts with an aggregate cost and apportion it across cost centres. The latter are hospitals that are able to calculate the cost of care at the patient level. Generally this is done using actual patient level consumption data. This method of costing is also known as a 'bottom up', because cost aggregates are devised from individual items of patient consumption.

83. The steps of the cost calculation using a cost modelled methodology are described below (Australian Government 2007).

Step 1: Preparation of the hospitals General Ledger

The cost centres on the general ledger are arranged so that revenue or offset items are removed (they are not required for costing purposes). Also, cost centres that have a zero dollar total are deleted.

Step 2: Classify cost centres as overhead, direct or non-clinical costs

Step 3: Allocate NHCDC cost centre and line item to each general ledger line item Each account item on the General Ledger should be mapped to one of NHCDC cost centres reported in the table below. 


\begin{tabular}{|l|l|}
\hline Allied & Allied Health \\
\hline Imag & Imaging Services \\
\hline Path & Pathology Services \\
\hline Pharm & Pharmacy Services \\
\hline Critical & Critical Care \\
\hline OR & Operating Rooms \\
\hline SPS & Specialised Procedure Suites \\
\hline ED & Emergency Department \\
\hline Clinical & Clinical Services \\
\hline Pros & Prostheses \\
\hline OtherServ & Other Services \\
\hline Overhead & Overheads \\
\hline
\end{tabular}

84. Each row in the General Ledger must be assigned to one of the NHCDC line items included in the table below.

\begin{tabular}{|l|l|}
\hline OnCosts & Labour (staff) oncosts, all staff types \\
\hline SWNurs & Nursing, Salaries and Wages \\
\hline SWMed & Medical, Salaries and Wages \\
\hline SWAH & Allied Health, Salaries and Wages \\
\hline SWOther & Other staff type, Salaries and Wages \\
\hline Pros & Prostheses \\
\hline Pharm & Drugs \\
\hline MS & All other medical and surgical supplies (excluding prostheses and drugs) \\
\hline Deprec & Capital Depreciation \\
\hline GS & All other Goods and Services \\
\hline Path & Pathology \\
\hline Imag & Imaging \\
\hline Hotel & Hotel Services \\
\hline
\end{tabular}

Step 4: Determine costs in-scope and distribute costs to NHCDC product types

The next step in processing is to populate the product type values: acute; products other than acute; emergency department; outpatients. The figure below describes the flow in defining product types. 


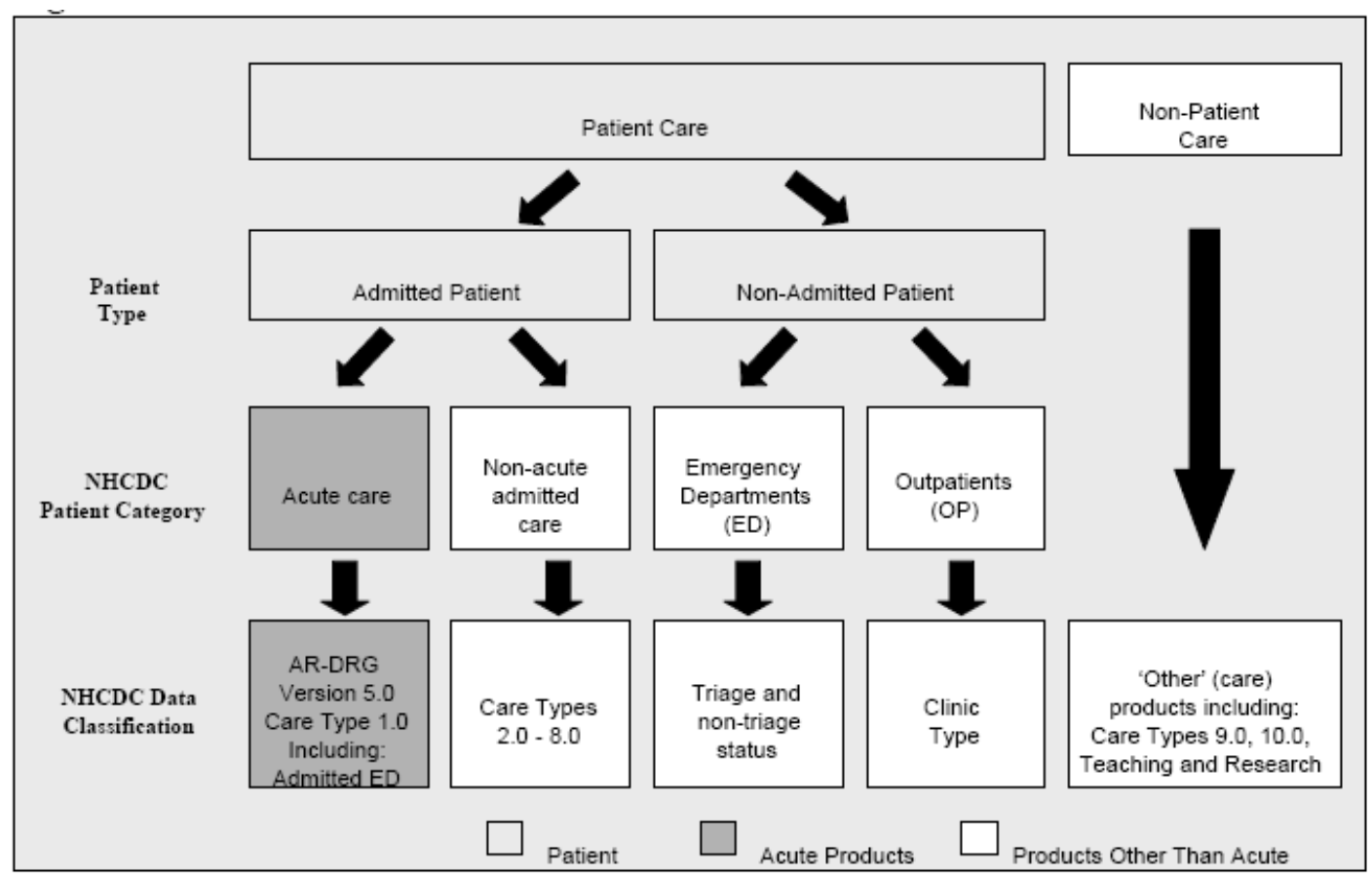

Source: Australian Government, 2007.

85. There are two factors that can be used to allocate costs - the Ifrac (Inpatient fraction) and Pfracs (Product type fraction). In the early days of product costing, hospitals were concerned primarily with acute inpatient costing by DRG and used the Ifrac to specify the proportion of costs for each patient care cost centre that was to be allocated to acute inpatients and the remaining costs were simply discarded. All hospital costs are allocated to product types using Pfracs.

\section{Step 5: Distribute overhead costs across cost centres}

All overhead costs must be distributed across cost centres, so that no overhead costs remain. Overhead cost allocation is a simultaneous reciprocal allocation process. The aim is to pass the costs of all overhead cost centres to the patient care cost centres. This occurs on multiple passes of the overhead allocation calculation through allocation statistics, which are relativities used to distribute overhead costs to the appropriate cost centre. There are two basic types of overhead allocation statistics: financial allocation statistic; statistical allocation. The former uses statistic such as nurse salaries or the cost of telephone calls to allocate the cost of nursing management overhead costs to all relevant cost centres. The latter uses statistic such as the number of meals, meters of floor space, or bed days to allocate an overhead cost to other cost centres.

\section{Step 6: Allocate volumes}

Volumes represent the factors - only defined for direct cost centres - to be used for allocating final costs to products. The volumes for acute inpatient products are counted by numbers of cases, full and part days spent in hospital, and full and part days spent in wards by DRG.

\section{Step 7: Allocate relevant service weights}

A service weight $(\mathrm{SW})$ is a relative value attached to a DRG which reflects the cost of each intermediate resource (i.e. nursing, allied health, medical, pathology, radiology, medical and surgical supplies) used in the respective DRG. SW can be classified according to the target 
population - conditional versus unconditional - and to the type - composite versus component. Conditional SW are calculated on the basis of including only patients who receive (or are charged for) a specified service, as opposed to unconditional SW that are used where it is not possible to determine how many patients in each DRG utilize a given service. Composite SWs are intended to be used to allocate the complete set of costs in the service category. For example, the composite imaging weights are suitable for allocation of the total costs of imaging services (e.g. X-ray + CT + MRI + Ultrasound). Component SWs are those for specific services within each service category. For example, if separate costs for CT scanning are available, the service weights which relate only to CT scanning could be used.

86. The SWs are used to compute an average unit cost by cost bucket by DRG. Cost buckets are the groups against which all costs are mapped. Every item within the general ledger must be classified into cost groups and line items to determine the appropriate cost bucket where expenses will be displayed. Costs associated with each DRG are reported in the following cost buckets:

- Ward Medical: also known as Medical Clinical Services, includes the salaries and wages of all medical officers including seasonal payments. Note that medical costs may also be found in other buckets that have a medical salary and wages component e.g. Imaging, Pathology, Critical Care, operating rooms, Emergency Department, Specialist Procedure Suites, Allied Health and Pharmacy

- Ward Nursing: includes Nursing salaries and wages reported in Clinical Service areas

- Non Clinical Salaries: includes all other costs of service provision for each inpatient separations

- Pathology: includes costs of diagnostic clinical laboratory testing for the diagnosis and treatment of patients

- Imaging: covers the area of diagnostic and therapeutic imaging, produced under the direction of a qualified technician and reported by a medical practitioner

- Allied Health: includes clinical services which are delivered by qualified Allied Health professionals who have direct patient contact in the areas like Audiology, Physiotherapy, Podiatry

- Pharmacy: covers the area of the provision of pharmaceuticals. This includes the purchase, production, distribution, supply and storage of drug products and clinical pharmacy services

- Critical Care: covers the Intensive Care Unit and Coronary Care Units

- Operating rooms: covers the area of a hospital where significant surgical procedures are carried out under surgical conditions under the supervision of qualified medical practitioners

- Emergency Departments (ED): covers the area of the hospital where patients who present in an unscheduled manner can be triaged, assessed and treated

- Supplies and Ward Overheads: includes costs for goods and services, medical and surgical supplies, ward overheads and clinical department overheads. In other words, it includes all costs attributed to a ward that are not included in any other cost buckets 
- $\quad$ The Specialist Procedures Suites: includes costs equipped specifically to provide an environment where diagnostic and therapeutic procedures can be performed under the direction of suitably qualified medical practitioners. Does not include Operating Room costs

- On-costs: includes superannuation, termination payments, workers compensation, long service leave

- Prostheses: includes the costs of all prostheses appearing on hospital accounts and costs incurred by the hospital but have not been included in their accounts

- Hotel Services: includes such items as food service, linen, grocery supplies and recorded as overheads

- Depreciation: includes depreciation for items that are durable, able to support production for an appreciable period of time and purchased outright or donated

87. The following table reports the publicly available statistics for selected products/DRGs (Australian Government 2010). These are representative national costing and activity figures from the sample data of public hospitals. It is worth noting that values reported in the "cost weight" column equal the total average cost by DRG divided by the National Public sector average $(\$ 4,133)$. Similar figures are available by hospital status (i.e. teaching versus non-teaching), location (major urban versus non-major urban), and state and territories (New South Wales, Victoria, Queensland, South Australia and Western Australia) for public facilities and - as a total - for private facilities. Cost weights are also available for private day hospitals: 59 hospitals (41\% of cases) reported an average cost of $\$ 683$ in round 13 . 
DELSA/HEA/WD/HWP(2011)2 DRG Description

\begin{tabular}{|c|c|}
\hline DRG & DRG Description \\
\hline$\overline{\mathrm{A} 01 \mathrm{Z}}$ & Liver Transplant \\
\hline$\overline{\mathrm{A} 03 \mathrm{Z}}$ & Lung Or Heart/Lung Transplant \\
\hline$\overline{\mathrm{A} 05 \mathrm{Z}}$ & Heart Transplant \\
\hline$\overline{\mathrm{A} 06 \mathrm{Z}}$ & Tracheostomy Or Ventilation $>95$ \\
\hline$\overline{\mathrm{A} 07 \mathrm{Z}}$ & Allog Bone Marrow Transplant \\
\hline$\overline{\mathrm{A08A}}$ & Auto Bone Marrow Transplnt+CCC \\
\hline$\overline{\mathrm{A08B}}$ & Auto Bone Marrow Transplnt-CCC \\
\hline$\overline{\mathrm{A09A}}$ & Renal Transplant+Pancreas/+CCC \\
\hline$\overline{A 09 B}$ & Renal Transplant -Pancreas-CCC \\
\hline$\overline{\mathrm{A} 40 \mathrm{Z}}$ & Ecmo - Cardiac Surgery \\
\hline$\overline{\mathrm{A} 41 \mathrm{~A}}$ & Intubation $\mathrm{Age}<16+\mathrm{CC}$ \\
\hline$\overline{\mathrm{A} 41 \mathrm{~B}}$ & Intubation $\mathrm{Age}<16-\mathrm{CC}$ \\
\hline B01Z & Ventricular Shunt Revision \\
\hline
\end{tabular}

\begin{tabular}{|c|c|c|c|c|c|c|c|c|c|c|c|c|c|c|}
\hline \multirow{3}{*}{$\begin{array}{c}\text { Cost } \\
\text { Weight }\end{array}$} & \multirow{3}{*}{$\begin{array}{l}\text { Standard } \\
\text { Error }\end{array}$} & \multirow{3}{*}{$\begin{array}{l}\text { Number } \\
\text { of Seps }\end{array}$} & \multirow{3}{*}{$\begin{array}{l}\text { Number } \\
\text { of Days }\end{array}$} & \multirow{3}{*}{$\begin{array}{l}\text { ALOS } \\
\text { (Days) }\end{array}$} & \multicolumn{3}{|c|}{ Average Cost per DRG (\$) } & \multicolumn{7}{|c|}{ Average Component Cost per DRG (\$) } \\
\hline & & & & & \multirow[t]{2}{*}{ Total } & \multirow[t]{2}{*}{ Direct } & \multirow[t]{2}{*}{ Ohead } & \multicolumn{2}{|c|}{ Ward Medical } & \multicolumn{2}{|c|}{ Ward Nursing } & \multirow{2}{*}{$\begin{array}{c}\text { Non } \\
\text { Clinical } \\
\text { Salaries }\end{array}$} & \multicolumn{2}{|c|}{ Pathology } \\
\hline & & & & & & & & Direct & Ohead & Direct & Ohead & & Direct & Ohead \\
\hline 30.34 & 0.49 & 179 & 4,590 & 25.66 & 125,404 & 107,020 & 18,384 & 27,761 & 2,200 & 12,043 & 1,771 & 5,250 & 4,932 & 1,052 \\
\hline 28.57 & 0.14 & 109 & 3,742 & 34.38 & 118,073 & 104,694 & 13,379 & 10,142 & 1,712 & 9,063 & 969 & 2,564 & 7,384 & $\overline{933}$ \\
\hline 42.32 & 1.16 & 61 & 2,450 & 39.89 & 174,929 & 154,030 & 20,899 & 25,396 & 4,462 & 9,794 & 1,323 & 1,796 & 7,765 & 1,108 \\
\hline 23.66 & 0.08 & 8,904 & 259,334 & 29.13 & 97,781 & 80,339 & 17,442 & 6,145 & 810 & 5,975 & 1,275 & 2,334 & 3,950 & 455 \\
\hline 21.09 & 0.51 & 406 & 13,924 & 34.26 & 87,164 & 72,414 & 14,750 & 4,880 & 1,552 & 19,757 & 3,652 & 4,063 & 5,864 & $\overline{990}$ \\
\hline 10.45 & 0.27 & \begin{tabular}{ll|}
474 \\
\end{tabular} & 11,263 & 23.76 & 43,207 & 35,177 & 8,030 & 3,309 & 974 & 10,852 & 2,451 & 1,693 & 3,062 & 644 \\
\hline 3.72 & 0.18 & $\begin{array}{l}353 \\
\end{array}$ & 3,457 & 9.79 & 15,371 & 12,333 & 3,038 & 919 & 245 & 3,964 & 549 & 983 & 1,130 & $\overline{183}$ \\
\hline 11.81 & 0.20 & \begin{tabular}{|l|l|}
302 \\
\end{tabular} & 4,685 & 15.51 & 48,801 & 41,096 & 7,705 & 4,632 & 941 & 8,299 & 1,278 & 1,661 & 2,490 & 385 \\
\hline 7.31 & 0.09 & $\begin{array}{ll}482 \\
\end{array}$ & 3,864 & 8.02 & 30,195 & 25,983 & 4,213 & 3,122 & 516 & 4,329 & 622 & 1,312 & 1,168 & 142 \\
\hline 38.90 & 0.45 & \begin{tabular}{|l|}
124 \\
\end{tabular} & 4,264 & 34.41 & 160,790 & 135,399 & 25,391 & 15,332 & 2,530 & 6,144 & 1,307 & 1,230 & 10,823 & 2,260 \\
\hline 4.01 & 0.28 & 74 & 476 & 6.43 & 16,559 & 13,062 & 3,497 & 1,728 & 206 & 2,915 & 418 & 850 & 619 & 46 \\
\hline 1.48 & 0.02 & $\begin{array}{ll}96 \\
\end{array}$ & 221 & 2.31 & 6,137 & 4,949 & 1,189 & 693 & 46 & 585 & 87 & 289 & 190 & 23 \\
\hline 2.83 & \begin{tabular}{l|l|}
0.02 \\
\end{tabular} & \begin{tabular}{|l|l|}
387 & \\
\end{tabular} & 2,248 & 5.81 & 11,690 & 9,479 & 2,211 & 1,574 & 250 & 2,187 & 480 & 477 & 237 & 35 \\
\hline
\end{tabular}

\begin{tabular}{|c|c|c|c|c|c|c|c|c|c|c|c|c|c|c|c|c|c|c|c|c|c|}
\hline \multirow[b]{3}{*}{ DRG } & \multicolumn{21}{|c|}{ Average Component Cost per DRG (\$) } \\
\hline & \multicolumn{2}{|c|}{ Imaging } & \multicolumn{2}{|c|}{ Allied } & \multicolumn{2}{|c|}{ Pharmacy } & \multicolumn{2}{|c|}{ Critical Care } & \multicolumn{2}{|c|}{ Oper Rooms } & \multicolumn{2}{|c|}{ Emerg Depts } & \multicolumn{2}{|c|}{ Supplies } & \multicolumn{2}{|c|}{ Spec Proc Suites } & \multirow{2}{*}{$\begin{array}{l}\text { Pros- } \\
\text { theses }\end{array}$} & \multirow{2}{*}{$\begin{array}{c}\text { On- } \\
\text { Costs }\end{array}$} & \multirow[t]{2}{*}{ Hotel } & \multirow[t]{2}{*}{ Deprec } & \multirow{2}{*}{$\begin{array}{l}\text { No. of } \\
\text { Hosps }\end{array}$} \\
\hline & Direct & Ohead & Direct & Ohead & Direct & Ohead & Direct & Ohead & Direct & Ohead & Direct & Ohead & Direct & Ohead & Direct & Ohead & & & & & \\
\hline$\overline{\mathrm{A} 01 \mathrm{Z}}$ & 2,366 & 201 & 2,069 & 337 & 14,062 & 403 & 12,986 & 1,989 & 16,128 & 1,888 & 540 & 130 & 4,327 & 2,155 & 17 & 3 & 1,531 & 4,812 & 2,830 & 1,621 & 10 \\
\hline$\overline{\mathrm{A} 03 \mathrm{Z}}$ & 2,769 & 614 & 2,675 & 434 & 14,227 & 275 & 31,257 & 3,706 & 15,605 & 2,233 & 80 & 20 & 5,098 & 268 & 188 & 19 & 710 & 3,207 & 1,069 & 852 & 4 \\
\hline$\overline{\mathrm{A} 05 \mathrm{Z}}$ & 2,637 & 530 & 2,860 & 573 & 14,328 & 627 & 53,031 & 7,676 & 20,599 & 2,661 & 64 & 15 & 2,862 & 126 & 649 & 240 & 8,351 & 3,550 & 886 & 1,022 & 5 \\
\hline A06Z & 2,257 & 348 & 2,547 & 495 & 3,892 & 211 & 41,064 & 8,185 & 4,235 & 838 & 440 & 95 & 1,253 & 493 & 249 & 47 & 1,161 & 4,815 & 2,205 & 2,007 & 113 \\
\hline$\overline{\mathrm{A} 07 \mathrm{Z}}$ & 1,053 & 172 & 1,582 & 293 & 24,922 & 1,470 & 3,817 & 733 & 434 & 90 & 20 & 4 & 2,237 & 1,019 & 2,302 & 1,108 & 49 & 2,911 & 1,174 & 1,016 & 20 \\
\hline$\overline{\mathrm{A08A}}$ & 888 & 249 & 871 & 182 & 8,261 & 343 & 1,961 & 317 & 247 & 49 & 26 & 6 & 1,281 & 474 & 1,510 & 773 & 50 & 1,373 & 903 & 460 & 36 \\
\hline$\overline{\mathrm{A} 08 \mathrm{~B}}$ & 242 & 37 & 238 & 50 & 3,310 & 178 & 15 & 3 & 109 & 22 & 8 & 2 & 659 & \begin{tabular}{l|}
392 \\
\end{tabular} & 433 & 233 & 17 & 727 & 443 & 280 & 36 \\
\hline$\overline{\mathrm{A} 09 \mathrm{~A}}$ & 1,270 & 165 & 676 & 109 & 11,839 & 530 & 1,576 & 262 & 5,243 & 1,145 & 85 & 24 & 1,306 & 588 & 11 & 1 & 508 & 1,738 & 1,241 & 796 & 20 \\
\hline$\overline{\mathrm{A} 09 \mathrm{~B}}$ & 644 & 88 & 352 & 54 & 7,080 & 286 & 250 & 55 & 4,970 & 1,069 & 35 & 8 & 819 & 269 & 1 & 0 & 448 & 1,350 & 684 & 522 & 20 \\
\hline A40Z & 2,765 & 510 & 2,892 & 586 & 6,172 & 445 & 65,449 & 12,711 & 15,576 & 2,312 & 146 & 30 & 877 & 305 & 565 & 95 & 5,378 & 2,253 & 917 & 1,180 & 21 \\
\hline A41A & 419 & 69 & 491 & 130 & 612 & 38 & 3,123 & 640 & 962 & 176 & 351 & 82 & 297 & 598 & 0 & 0 & 140 & 767 & 548 & 334 & 34 \\
\hline$\overline{\text { A41B }}$ & 178 & 23 & 110 & 26 & 136 & 20 & 1,066 & 233 & 805 & 126 & 392 & 79 & 47 & 186 & 0 & 0 & 91 & 375 & 178 & 154 & 49 \\
\hline$\overline{\text { B01Z }}$ & 472 & 63 & 186 & 34 & 182 & 22 & 179 & 33 & 2,312 & 396 & 316 & 79 & 228 & \begin{tabular}{l|}
199 \\
\end{tabular} & 5 & 1 & 727 & 470 & 314 & 232 & 31 \\
\hline
\end{tabular}




\section{Canada}

\section{Diagnoses classification and coding}

88. The International Statistical Classification of Diseases and Related Health Problems-Tenth Revision, Canada, referred to as ICD-10-CA, is a Canadian modification of the disease classification published by the WHO. The classification includes a tabular listing (listing of codes in alphanumeric order), an alphabetical index, as well as relevant coding guidelines/recording instructions.

89. ICD-10-CA is organized in sections (chapters) according to body system/anatomy with the exception of some additional chapters for certain conditions, causes or factors influencing health status. The ICD-10-CA chapters and code ranges are identical to the WHO ICD-10 classification.

90. Each chapter is further subdivided first into blocks, then into categories and potentially subcategories. The blocks divide chapters into sections of similar content. For example the chapter for diseases of the circulatory system includes blocks for acute rheumatic fever; chronic rheumatic heart disease; hypertensive disease; ischaemic heart disease; diseases of pulmonary circulation; and other forms of heart disease.

91. ICD-10-CA currently has an alphanumeric format A\#\#.BBB where:

$$
\begin{aligned}
& A=\text { alpha character } \\
& \#=\text { numeric character } \\
& B=\text { numeric character or blank }
\end{aligned}
$$

92. Valid ICD-10-CA disease codes include three (e.g. N72, Inflammatory disease of cervix uteri), four (e.g. J20.6, Acute bronchitis due to rhinovirus), five (e.g. see table below for secondary hypertension), and six character codes (e.g. see table below for infections of genitourinary tract in pregnancy).

\begin{tabular}{|ll|l|l|}
\hline I15 Secondary hypertension & $\begin{array}{l}\text { Benign or } \\
\text { unspecified }\end{array}$ & Malignant \\
\hline I15.0 Renovascular hypertension & $\mathrm{I} 15.00$ & $\mathrm{I} 15.01$ \\
\hline $\begin{array}{l}\text { I15.1 Hypertension secondary to other renal } \\
\text { disorders }\end{array}$ & $\mathrm{I} 15.10$ & $\mathrm{I} 15.11$ \\
\hline I15.2 Hypertension secondary to endocrine disorders & $\mathrm{I} 15.20$ & $\mathrm{I}$ \\
\hline I15.8 Other secondary hypertension & $\mathrm{I} 15.80$ & $\mathrm{I15.81}$ \\
\hline I15.9 Secondary hypertension, unspecified & $\mathrm{I} 15.90$ & $\mathrm{I} 15.91$ \\
\hline
\end{tabular}




\begin{tabular}{|c|c|c|c|}
\hline $\begin{array}{l}\text { O23 Infections of } \\
\text { genitourinary tract in } \\
\text { pregnancy }\end{array}$ & $\begin{array}{l}\text { Delivered, with or } \\
\text { without mention of } \\
\text { antepartum condition }\end{array}$ & $\begin{array}{l}\text { Antepartum condition } \\
\text { or complication }\end{array}$ & $\begin{array}{l}\text { Unspecified as to } \\
\text { episode of care, or not } \\
\text { applicable }\end{array}$ \\
\hline $\begin{array}{l}\text { O23.0 Infections of kidney in } \\
\text { pregnancy }\end{array}$ & $023.001 \%$ & $023.003^{4}$ & $\mathrm{O} 23.009^{4}$ \\
\hline $\begin{array}{l}\text { O23.1 Infections of bladder in } \\
\text { pregnancy }\end{array}$ & $023.101^{*}$ & O23.103* & O23.109 \\
\hline $\begin{array}{l}\text { O23.2 Infections of urethra in } \\
\text { pregnancy }\end{array}$ & $\mathrm{O} 23.201$ & $\mathrm{O} 23.203$ & $\mathrm{O} 23.209^{\star}$ \\
\hline $\begin{array}{l}\text { O23.3 Infections of other parts } \\
\text { of urinary tract in pregnancy }\end{array}$ & O23.301 & $\mathrm{O} 23.303 *$ & O23.309 \\
\hline $\begin{array}{l}\text { O23.4 Unspecified infection of } \\
\text { urinary tract in pregnancy }\end{array}$ & $\mathrm{O} 23.401$ & $\mathrm{O} 23.403$ & $\mathrm{O} 23.409^{4}$ \\
\hline $\begin{array}{l}\text { O23.5 Infections of the genital } \\
\text { tract in pregnancy }\end{array}$ & O23.501 & $\mathrm{O} 23.503$ & $\mathrm{O} 23.509^{\star}$ \\
\hline $\begin{array}{l}\text { O23.9 Other and unspecified } \\
\text { genitourinary tract infection in } \\
\text { pregnancy } \\
\text { Includes } \\
\text { - Genitourinary tract infection in } \\
\text { pregnancy NOS }\end{array}$ & $023.901^{*}$ & $023.903^{*}$ & O23.909 \\
\hline
\end{tabular}

Source: Canadian Institute for Health Information, 2009.

\section{Procedure classification and coding}

93. The Canadian Classification of Health Intervention (CCI) is a multi-axial classification of healthrelated interventions, developed and maintained by the Canadian Institute for Health Information (CIHI) ${ }^{17}$. The tabular listing of CCI provides comprehensive coverage of diagnostic, therapeutic and other associated healthcare interventions ${ }^{18}$. It is designed to be provider and location neutral so that it may be used across the continuum of healthcare settings in Canada.

94. CCI has an alphanumeric structure with a code length of 10 characters. The main axis of CCI is the type of intervention. The first character of the code identifies whether the intervention is therapeutic, diagnostic or another type of healthcare.

95. The tabular list is divided into 8 sections (CIHI 2006):

17 CIHI is an independent, not-for-profit organization that provides essential data and analysis on Canada's health system and the health of Canadians. CIHI tracks data on health care services, health spending, health human resources, and population health.

The term intervention is used instead of procedure to reflect an expanded scope addressing application of this definition beyond traditional medical/surgical settings. 


\begin{tabular}{|c|l|c|}
\hline $\begin{array}{c}\text { Section } \\
\text { number }\end{array}$ & \multicolumn{1}{|c|}{ Section title } & Code range \\
\hline 1 & Physical/physiological therapeutic interventions & $1 . \mathrm{AA}-1 . \mathrm{ZZ}$ \\
\hline 2 & Diagnostic interventions & $2 . \mathrm{AA}-2 . \mathrm{ZZ}$ \\
\hline 3 & Diagnostic imaging interventions & 3.AA-3.ZZ \\
\hline 4 & Clinical laboratory interventions & 5.AA-4.ZZ \\
\hline 5 & Obstetrical and fetal interventions & 6.AA-6.PZ \\
\hline 6 & $\begin{array}{l}\text { Cognitive, psychosocial and sensory therapeutic } \\
\text { interventions }\end{array}$ & 7.SC-7.SP \\
\hline 7 & $\begin{array}{l}\text { Other healthcare interventions } \\
\text { Therapeutic interventions strengthening the immune } \\
\text { system and/or genetic composition }\end{array}$ & 8.AA-ZZ \\
\hline 8
\end{tabular}

96. These sections are subdivided into homogeneous ranges of groups which represent the second axis of the classification. For section 1, 2, and 3 these blocks of groups represent body systems and their specific anatomy sites. In section 5, these blocks represent stages of pregnancy and fetal development. For example, within section 1, the block 1.AA to $1 . \mathrm{BZ}$ represents the nervous system. Within that block, the group 1.AN represents the brain. The first five digits comprise the rubric, which categorizes the intervention within the group and section. Generically, the rubric describes what health intervention was performed.

97. To complete the CCI code, then the appropriate intervention qualifier should be selected. The qualifier describes how the intervention was performed. It may be broken into three separate fields, each of which has a discrete meaning. In the case of therapeutic interventions, the first two characters relate to the approach/technique used, the next two characters to devise used/implanted, and the last character to any tissue used. In other section, the second and third qualifiers could be blank.

98. As an example, the structure for the Implantation of defibrillator (1.HZ.53.^^-FS) is reported below.

Section 1, physical/physiological therapeutic interventions

Block FE-FY, therapeutic interventions on the heart (and related structures)

Group HZ, therapeutic interventions on the heart not elsewhere classified

Rubric 53, implantation of internal device, heart not elsewhere classified

Qualifier $1 \quad$ FS, cardioverter/defibrillator

Qualifier 2 GR, percutaneous transluminal approach

Code 1.HZ.53.GR-FS, Implantation of cardioverter/defibrillator using a percutaneous transluminal approach

\section{Timing and process for the revision of the coding schemata}

99. The ICD-10-CA/CCI is updated every year - with major updates every three year - under the responsibility of CIHI. The CIHI is given advise by three committee/groups:

- the ICD-10-CA/CCI National Coding Advisory Committee

- the ICD-10-CA/CCI Classification Advisory Committee

- the National ICD-10-CA/CCI Electronic Products Advisory Group 
100. The National Coding Advisory Committee provides CIHI with advice on the development and ongoing enhancement of coding standards. Standards are only incorporated into the Canadian Coding Standards for ICD-10-CA and CCI if they are applicable to all provinces and territories.

101. The Classification Advisory Committee provides CIHI with advice on the maintenance and enhancement of ICD-10-CA and CCI. In doing so, the Classification Advisory Committee will ensure the continued capability of the classifications to meet the needs of all health care providers. The purpose of the National Electronic Products Advisory Group is to provide advice on the ongoing development of new and enhancement of existing ICD-10-CA and CCI electronic products, review proposals and provide feedback on the potential impact of changes on coding, data capture and data quality, and advise on appropriate CIHI communication and educational strategies for implementation of new products or enhancements throughout the health information management community.

102. CIHI has established a process for the maintenance and enhancements of the classifications. Inputs to this process come from the following sources:

- WHO modifications to ICD-10

- $\quad$ the Coding Query Service

- $\quad$ special interest groups

- review of other international classifications (e.g. ICD-10-AM, ICD-10-CM)

- $\quad$ public submissions

\section{Tools used for data quality enhancement}

103. The CIHI publishes the Canadian Coding Standards for ICD-10-CA and CCI (CIHI 2007a). This manual guides the user through the appropriate application of current coding standards for abstracting data elements from health records to populate the Discharge Abstract Database (DAD) and the National Ambulatory Care Reporting System (NACRS). These standards are a compilation of international rules of coding as established by the World Health Organization (ICD-10, Volume 2) and the Diagnosis Typing Standard developed to denote case complexity for application in Canadian facilities. This manual uses a case-study approach to demonstrate the application of these standards. The manual is updated annually to reflect any changes in coding standards that may occur from one fiscal year to the next.

104. The coding standards are intended to supplement the classification rules inherent in ICD-10-CA and CCI by providing additional information that could not be embedded into the classifications.

105. Another tool used to enhance data quality is the CIHI's online coding query service. This service helps registered users finding answers to their ICD-10-CA/CCI coding questions.

\section{Classification system}

106. The Case Mix Groups+ (CMG+) methodology is designed to aggregate acute-care inpatients with similar clinical and resource-utilization characteristics ${ }^{19}$. The CMG+ methodology was introduced in 2007

19 In the area of day surgery, a national classification system - Day Procedure Groups (DPG) - for ambulatory hospital patients is in use. Patients are assigned to categories according to the principal or most-significant procedure recorded on the patient abstract. Patients assigned to the same DPG group represent a homogeneous cluster with similar clinical episodes and requiring similar resources. 
(CIHI 2007b), and has been updated for 2008. CMG+ was designed to take advantage of the increased clinical specificity of the ICD-10-CA and CCI classifications, and developed using multiple years of acute care inpatient activity and cost records.

107. Case Mix Groups are ordered within Major Clinical Categories (MCC) which identify either a body system (e.g. Respiratory System), or other specific types of clinical problems (e.g. Mental Disorders). $\mathrm{CMG}+$ consists of the 21 Major Clinical Categories (MCC) ${ }^{20}$ reported in the following table.

\begin{tabular}{|c|l|c|c|}
\hline MDC & \multicolumn{1}{|c|}{ Description } & $\begin{array}{c}\text { Number of } \\
\text { groups }\end{array}$ & $\begin{array}{c}\text { Relative } \\
\text { frequency } \\
(\%)\end{array}$ \\
\hline 01 & Diseases and disorders of the nervous system & 34 & 6.05 \\
\hline 02 & Diseases and disorders of the eye & 10 & 1.78 \\
\hline 03 & Diseases and disorders of the ear, nose, mouth and throat & 31 & 5.52 \\
\hline 04 & Diseases and disorders of the respiratory system & 31 & 5.52 \\
\hline 05 & Diseases and disorders of the circulatory system & 47 & 8.36 \\
\hline 06 & Diseases and disorders of the digestive system & 29 & 5.16 \\
\hline 07 & Diseases and disorders of the hepatobiliary system and pancreas & 19 & 3.38 \\
\hline 08 & $\begin{array}{l}\text { Diseases and disorders of the musculoskeletal system and } \\
\text { connective tissue }\end{array}$ & 60 & 10.68 \\
\hline 09 & Diseases and disorders of the skin, subcutaneous tissue and breast & 22 & 3.91 \\
\hline 10 & $\begin{array}{l}\text { Diseases and Disorders of the Endocrine System, Nutrition \& } \\
\text { Metabolism }\end{array}$ & 20 & 3.56 \\
\hline 11 & $\begin{array}{l}\text { Diseases and Disorders of the Kidney, Urinary Tract \& Male } \\
\text { Reproductive System }\end{array}$ & 30 & 5.34 \\
\hline 12 & Diseases and disorders of the female reproductive system & 18 & 3.20 \\
\hline 13 & Pregnancy and childbirth & 25 & 4.45 \\
\hline 14 & $\begin{array}{l}\text { Newborns and Neonates with Conditions Originating in the } \\
\text { Perinatal Period }\end{array}$ & 29 & 5.16 \\
\hline 15 & Diseases and Disorders of the Blood \& Lymphatic System & 25 & 4.45 \\
\hline 16 & Multisystemic or Unspecified Site Infections & 11 & 1.96 \\
\hline 17 & Mental Diseases \& Disorders & 35 & 6.23 \\
\hline 18 & Burns & 5 & 0.89 \\
\hline 19 & Significant Trauma, Injury, Poisoning \& Toxic Effects of Drugs & 51 & 9.07 \\
\hline 20 & Other Reasons for Hospitalization & 13 & 2.31 \\
\hline 99 & Miscellaneous CMG \& Ungroupable Data & 17 & 3.02 \\
\hline & Total & 562 & 100 \\
\hline
\end{tabular}

108. The ICD-10-CA diagnosis codes broadly categorize patients into MCC. This is based generally on the diagnosis determined to have been responsible for the greatest portion of the patient's length of stay (MRDx). The MCC is divided into two partitions. Those cases that have an abstracted CCI code from the Intervention Partition CCI Code List are assigned to the Intervention partition, while those without the presence of such an intervention are assigned to the Diagnosis partition. If a case is assigned to the Diagnosis Partition of a MCC, a list of diagnosis codes (grouped according to clinical and/or cost similarities) is used to assign the terminal cell. If a case is assigned to the Intervention Partition of a MCC, a list of intervention codes is used to assign the terminal cell. Intervention CMGs are determined by the presence of a CCI Intervention Partition Code. The grouping methodology application loops through all 
interventions recorded on the abstract to find one that is in the same MCC as the MRDx. If the application finds more than one intervention in this category the case is assigned to the CMG highest on the hierarchy. This hierarchy is referred to as the "intervention hierarchy", which is based on a decision rule that generally orders interventions from most to least resource intensive, as defined by expected resource consumption. If there are no interventions from the CCI Intervention Partition List recorded on the abstract, the case is assigned to the Diagnosis Partition of the MCC. The Diagnosis partition consists of groupings of similar diagnoses defined clinically and/or by homogeneity of costs/length of stay. In a few instances minor interventions, not on the CCI Partition code list, may be used to assign the CMG.

109. The following flowchart illustrates the high level rules of the CMG+ methodology.

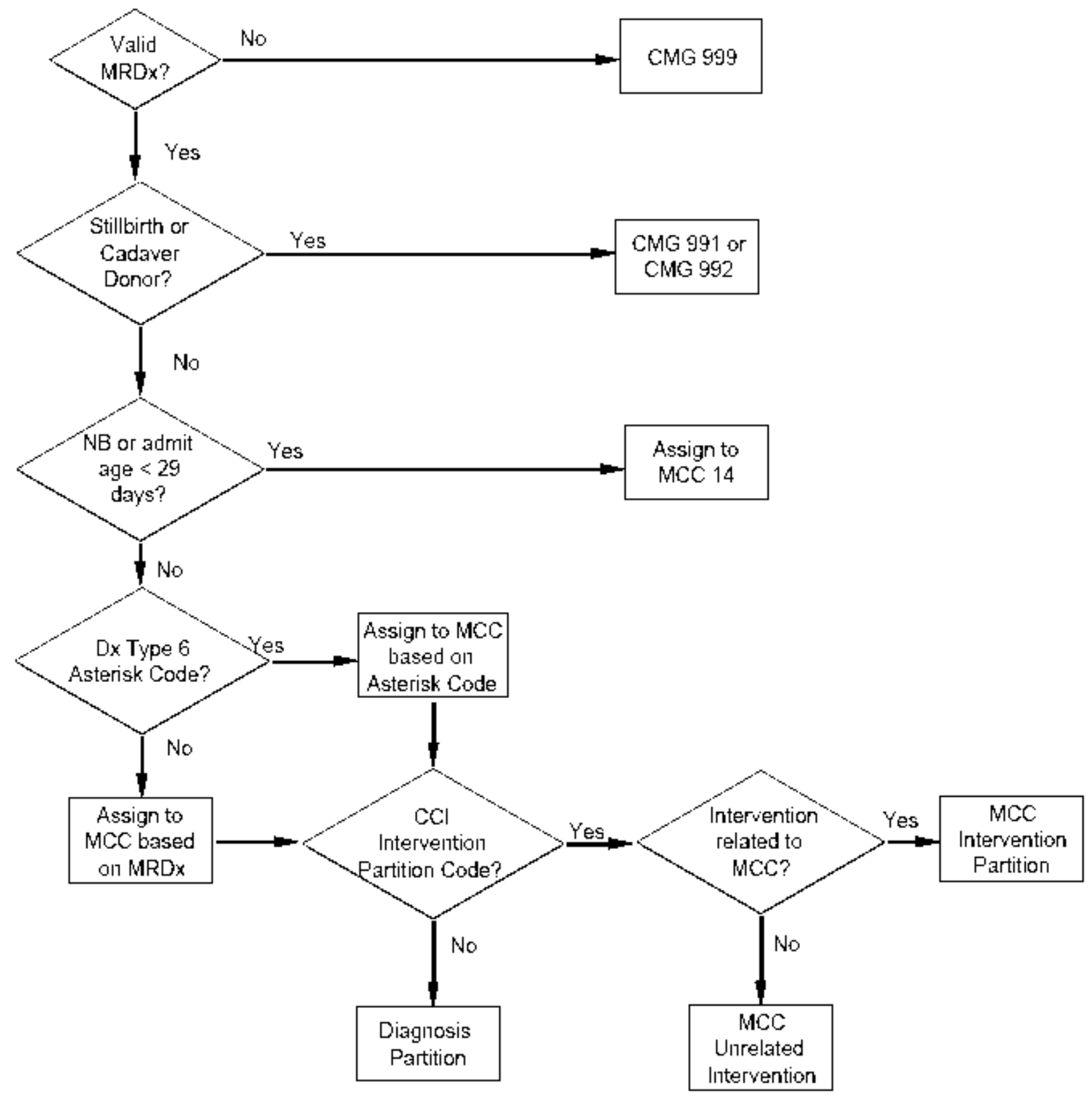

Source: Canadian Institute for Health Information, 2007b. 
110. There are $562 \mathrm{CMG}+$, including 13 groups for unrelated interventions and 4 groups for errors. The numbering system is the "classic" DRG one: three numeric digits, starting from 1 to 999 . The value increases as the MCC number increases.

111. CMG+ incorporates a new methodology that consists of five factors that are applied following CMG assignment, and are used in the assignment of the Resource Intensity Weight (RIW) and the Expected Length of Stay (ELOS) values to each case. The base CMG along with the multiplicative effect of the five factors determines the Resource Intensity Level (RIL) for the case. These factors include:

- age category

- comorbidity level

- $\quad$ flagged interventions

- intervention events

- out-of-hospital intervention

112. A brief description of each of these factors is provided below.

Age Category. There are three main age categories in CMG+: neonates, children under 18, and adults. Within each category, there are three further age group splits:

- Newborn and Neonate MCC: Newborn; 0 - 7 days; 8 - 28 days

- Paediatric Age Groups across most MCC: 29 - 364 days, 1 - 7 years, 8 - 17 years

- $\quad$ Adult Age Groups across most MCC: $18-59$ years, $60-79$ years, $80+$ years

Comorbidity Level. The Comorbidity Factor accounts for the resource utilization impact of comorbidities captured on patient abstracts using ICD-10-CA codes. Comorbid conditions are differentiated from secondary conditions through diagnosis typing. The Comorbidity Factor makes use of a list of ICD-10-CA diagnoses considered to be clinically significant and have a material impact on resources. In order for a comorbidity to be included on the Comorbidity Factor code list it must have demonstrated, through cost data and activity data analysis, to increase resource use (costs and/or LOS) by $25 \%$ or more. This Comorbidity Factor code list is specific to each MCC, i.e. a comorbidity may be relevant to some MCC but not to others, and hence will contribute to the Comorbidity Factor Level assignment for some MCC, but not for others. Each patient abstract will be assigned to a Comorbidity Factor Level, based upon the cumulative resource impact of the Comorbidity Factor list comorbidities present on that abstract:

- Level 0 (0 - 24\% impact on resource consumption)

- Level 1 (25 - 49\% impact on resource consumption)

- Level 2 (50 - 74\% impact on resource consumption)

- Level 3 (75-124\% impact on resource consumption)

- Level 4 (125+\% impact on resource consumption) 
Flagged Intervention. Certain hospital procedures, such as radiotherapy and tracheostomy, are "flagged" because they tend to be associated with higher resource consumption. Care for patients who receive "flagged" interventions typically costs more than care for similar patients who do not, even though the interventions themselves may not be costly. There are currently 14 flagged intervention categories used in the CMG+ methodology: Feeding tubes (PEG); Vascular access device; Tracheostomy; Chemotherapy; Paracentesis; Heart resuscitation; Cardioversion; Pleurocentesis; Dialysis; Radiotherapy; Mechanical ventilation no less than 96 hours; Mechanical ventilation less than 96 hours; Cell saver; and Parenteral nutrition.

Intervention Event. During the admission, a patient may require additional interventions, some of which may take place at a different time than the intervention used for CMG assignment (i.e. as separate intervention events). Cases with multiple intervention events may be more costly than those that involve only a single intervention event. Hence, the number of intervention events may provide additional explanation of resources used in treating a patient, above and beyond that provided by the CMG, age, comorbidity and flagged intervention factors. Intervention events will be factored into the RIW and ELOS assignment based on the occurrence of two or more intervention events.

Out-of-Hospital $(\mathrm{OOH})$ Intervention. $\mathrm{OOH}$ Interventions are selective interventions carried out in a health care facility other than the treating/admitting facility. As a result, the facility where the patient is eventually admitted and/or treated does not incur the cost of the intervention itself. In most of these cases, therefore, the presence of an $\mathrm{OOH}$ Intervention indicates a lower cost for the admitting facility. A negative factor is applied to adjust the RIW downward for the host facility.

\section{Variables used in the assignment process}

113. The main characteristic of the CMG+ system is the simplicity of the base CMG assignment logic. This stems from the fact that other factors are applied following CMG assignment and are used in the assignment of the resource indicators, RIW and ELOS values to each case.

114. The MCC is divided into two partitions: intervention and diagnosis. If a case is assigned to the intervention partition of a MCC, a hierarchical list of intervention codes is used to assign the CMG+ cell. If a case is assigned to the diagnosis partition of an MCC, a list of diagnosis codes is used to assign the $\mathrm{CMG}+$ cell. Very few other variables are used in the assignment process. The table below reports - as an example - the MDCs 5 and 8 categories where other (than diagnoses and procedures) variables influence the base CMG assignment process. 
DELSA/HEA/WD/HWP(2011)2

\begin{tabular}{|c|c|c|c|}
\hline MCC (type) & Category & Variables & $\begin{array}{l}\text { Number } \\
\text { of CMGs }\end{array}$ \\
\hline \multirow[t]{3}{*}{5 (intervention) } & Coronary artery bypass graft & $\begin{array}{l}\text { Cardiac catheter } \\
\text { Myocardial infarction } \\
\text { /shock/arrest } \\
\text { Cardiac pump }\end{array}$ & 7 \\
\hline & Major cardiothoracic interventions & Cardiac pump & 2 \\
\hline & Percutaneous Coronary interventions & $\begin{array}{l}\text { Myocardial } \\
\text { Infarction/shock/arrest/he } \\
\text { art failure }\end{array}$ & 2 \\
\hline \multirow[t]{5}{*}{5 (diagnosis) } & Myocardial infarction/shock/arrest & Cardiac catheter & 2 \\
\hline & Heart failure & Cardiac catheter & 2 \\
\hline & Unstable angina/Atherosclerotic Heart Disease & Cardiac catheter & 2 \\
\hline & Arrhythmia & Cardiac catheter & 2 \\
\hline & Angina (except unstable)/chest pain & Cardiac catheter & 2 \\
\hline \multirow[t]{6}{*}{8 (intervention) } & Revised hip replacement & Infection & 2 \\
\hline & Revised knee replacement & Infection & 2 \\
\hline & Resection/amputation pelvis/leg & Infection & 2 \\
\hline & Major foot intervention except soft tissue & Infection & 2 \\
\hline & Open knee intervention except fixation & Infection & 2 \\
\hline & Closed knee intervention except fixation & Infection & 2 \\
\hline
\end{tabular}

\section{Timing and process for the revision of the classification system}

115. The CMG+ classification system was developed and is maintained by the Canadian Institute for Health Information. The system is updates every two years.

\section{Cost-finding approach}

116. Canada uses a newly redeveloped methodology (CMG+) that allows for the calculation of average inpatient costs for specific patient/Case Mix Groups at national level. By introducing five factors to account for variations in patient resource consumption, the CMG+ refines the approach used to measure RIWs. The RIWs are one of the two main components needed to calculate average case costs, the other component being the Cost per Weighted Case (CPWC).

117. A RIW is an indicator representing the relative resources used by a patient. Specifically, RIWs are relative values that describe the expected resource consumption of an "average" patient within a Case Mix Group. In the CMG+ methodology, RIWs are adjusted for five factors known to affect hospital costs: age group; comorbidity level; flagged interventions; intervention events; out of hospital intervention. RIWs are calculated and updated annually based on data from the Discharge Abstract Database and from casecost data provided by hospitals in British Columbia, Alberta and Ontario.

118. The CPWC provides a measure of the average financial cost a facility incurs to treat a single inpatient. It is calculated by dividing the net total inpatient cost for a facility by the total weighted cases in that facility. The CPWC is calculated and updated annually from CIHI's Canadian MIS Database (CMDB), based on data from all hospitals in Canada that report data to the CMDB and the DAD. The CMDB contains financial and statistical information from hospitals and regional health authorities across 
Canada that can potentially be used to evaluate the cost of activities in health service organizations, among other purposes.

119. The following chart illustrates how average inpatient costs are calculated. In this example, 1,000 inpatient cases are treated in a clinical program in a hospital. To estimate average costs, CMG+ first assigns each patient case to an MCC and a CMG based on the MRDx and other information. After this, the RIW value is calculated for each case by adjusting the basic weight assigned to a CMG according to the patient's age and the rest of the five factors. By summing up all RIWs in that program, total weighted cases can be obtained for the program. In the same way, total weighted cases are calculated for all cases in that hospital by adding weighted cases for all the programs. The CPWC is then calculated by dividing the net total inpatient cost by the total weighted cases in that hospital. Finally, the expected approximate cost for that program in that hospital is calculated by multiplying the total weighted cases by the CPWC.

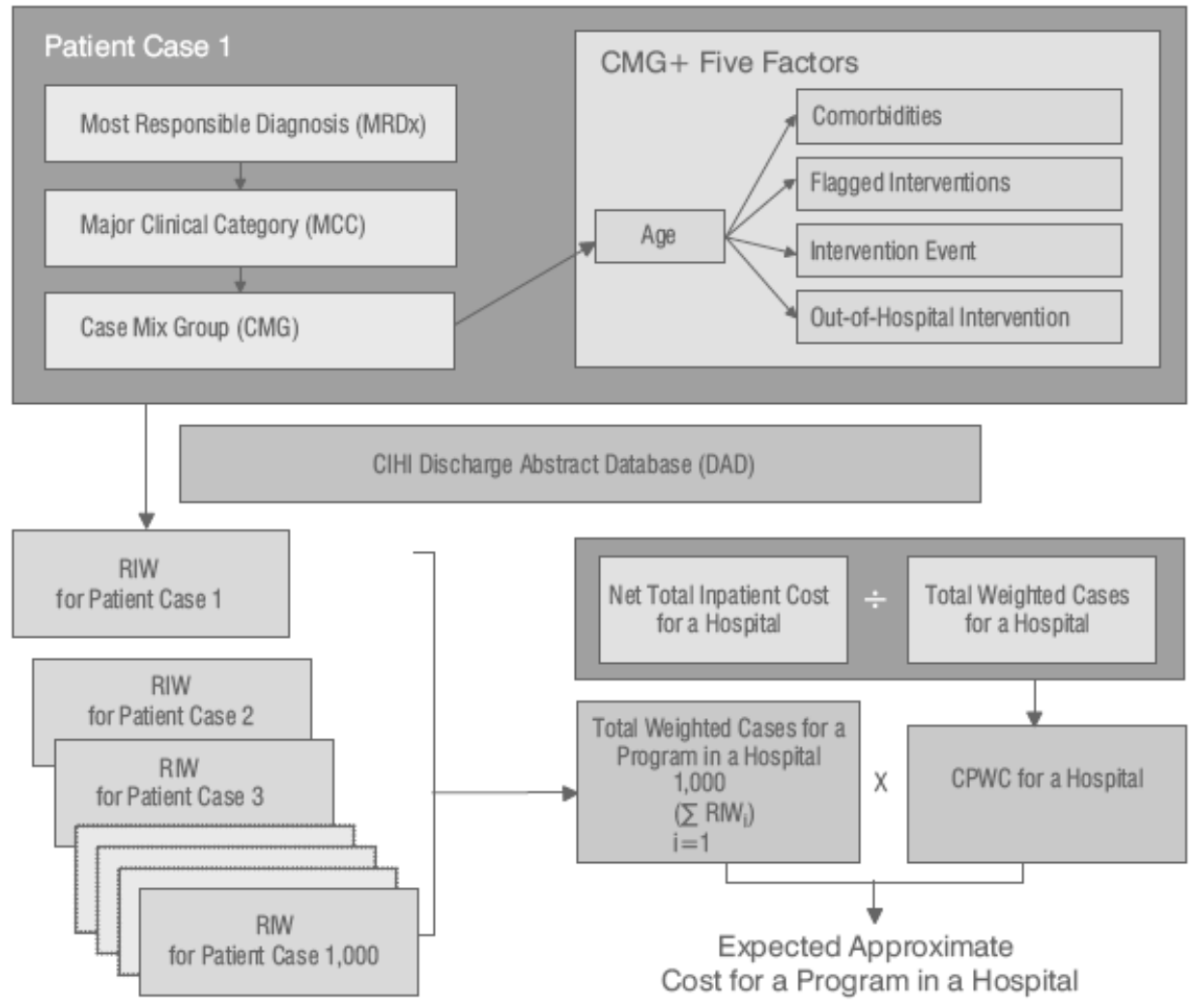

Source: Canadian Institute for Health Information, 2008.

120. The table below shows an example of the average hospitalization costs for typical patients admitted into acute care facilities categorized into CMGs by MCC. It also shows the case distribution of "typical" and "atypical" cases for all CMGs. 
MCC 01 Diseases and Disorders of the Nervous System

\begin{tabular}{|c|c|c|c|c|c|c|c|c|c|}
\hline \multirow{3}{*}{$\begin{array}{l}\text { CMG } \\
\text { Code }\end{array}$} & \multirow[b]{3}{*}{ CMG Deseription } & \multirow{3}{*}{$\begin{array}{c}\text { Total } \\
\text { Volume }\end{array}$} & \multirow{2}{*}{\multicolumn{2}{|c|}{$\begin{array}{l}\text { Typical Cases } \\
\text { Average Cost }(\$)\end{array}$}} & \multicolumn{5}{|c|}{ Cases Distribution (Percent) } \\
\hline & & & & & \multirow{2}{*}{$\begin{array}{l}\text { Typical } \\
\text { Cases }\end{array}$} & \multicolumn{3}{|c|}{ Atypical Cases } & \multirow{2}{*}{$\begin{array}{l}\text { Long-Stay } \\
\text { Outliers }\end{array}$} \\
\hline & & & Mean & Median & & Transfers & Sign-Outs & Deaths & \\
\hline \multirow{7}{*}{\multicolumn{2}{|c|}{$\begin{array}{l}001 \text { Intracranial Vessel Intervention } \\
\text { Except Extraction, Open Approach } \\
002 \text { Intracranial Vessel Intervention Except } \\
\text { Extraction, Percutaneous Approach } \\
003 \text { Other Vascular Intervention With } \\
\text { Nervous System Diagnosis } \\
004 \text { Craniotomy for Drainage }\end{array}$}} & & & & & & & & \\
\hline & & 777 & 28,122 & 14,098 & 62.7 & 23.8 & 0.3 & 9.5 & 3.7 \\
\hline & & & & & & & & & \\
\hline & & 487 & 11,129 & 9,272 & 67.6 & 23.6 & 0.2 & 5.3 & 3.3 \\
\hline & & & & & & & & & \\
\hline & & 978 & 8,165 & 6,089 & 87.3 & 5.9 & 0.1 & 1.5 & 5.1 \\
\hline & & 235 & 20,627 & 8,863 & 41.3 & 40.4 & 0.0 & 13.2 & 5.1 \\
\hline \multicolumn{2}{|c|}{$\begin{array}{l}\text { CMG code and description refer } \\
\text { to the illnesses or conditions } \\
\text { used in classifying similar } \\
\text { patients into a group, which is } \\
\text { assigned a specific code. }\end{array}$} & $\begin{array}{l}\text { me refers } \\
\text { f typical, a } \\
\text { outlier cas } \\
\text { CMGs. }\end{array}$ & $\begin{array}{l}\text { e total } \\
\text { cal and } \\
n \text { the }\end{array}$ & \multicolumn{3}{|c|}{$\begin{array}{l}\text { The average (mean and median) } \\
\text { cost of typical acute care cases } \\
\text { is calculated using data from the } \\
\text { Discharge Abstract Database } \\
\text { and the Canadian MIS Database, } \\
\text { and applying the RIWs and the } \\
\text { CPWC to the respective CMGs. } \\
\text { Data do not include physician } \\
\text { compensation. }\end{array}$} & \multicolumn{3}{|c|}{$\begin{array}{l}\text { Cases in the DAD used here } \\
\text { are classified as typical, } \\
\text { atypical and long-stay outliers, } \\
\text { and their distribution is given } \\
\text { as percentages of the total } \\
\text { volume of cases. Atypical } \\
\text { cases are further subdivided } \\
\text { into patient transfers, sign- } \\
\text { outs and deaths. }\end{array}$} \\
\hline
\end{tabular}

Source: Canadian Institute for Health Information, 2008.

121. The following section describes how case-cost data are estimated in Ontario, one of the sources from which the RIWs are calculated.

\section{Ontario}

122. The hospital production function model shown in the Figure below represents patient-specific costing. The model illustrates how a hospital uses a number of inputs (labour equipment, etc.) to produce services (for example x-ray, laboratory tests, and nursing services) that a patient receives from the hospital. The challenge of case costing is to accurately identify the costs of these services and then to distribute the costs to each patient reflecting the cost of the care delivered.

123. The production function model shows that the output of a hospital is a mix of services, or intermediate products, specific for each patient. These intermediate products for patient care are produced by a number of departments (e.g., Nursing, Pharmacy, etc.). Each department produces a range of intermediate products by combining inputs such as labour and capital. For example, an x-ray would be considered an intermediate product of the Diagnostic Imaging department. 


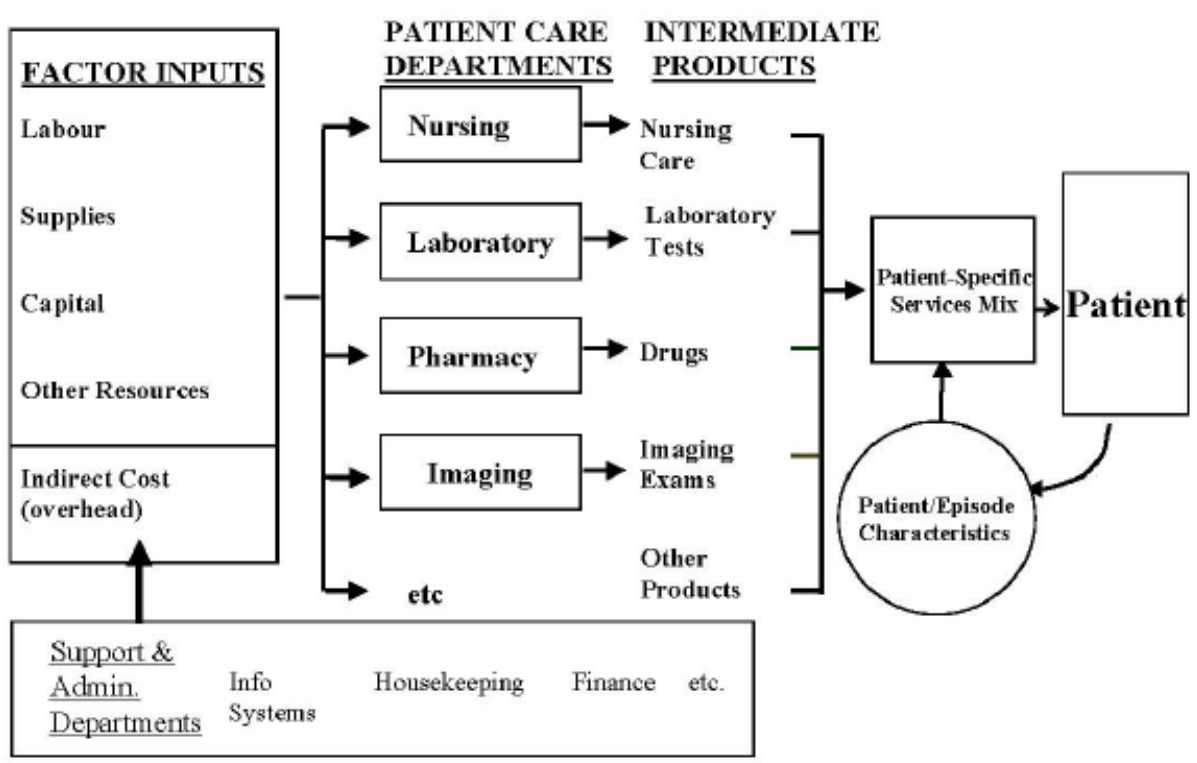

Source: Ontario Ministry of Health and Long-Term Care, 2006.

124. Based on this conceptual model, the goal of the costing methodology is to apportion total hospital costs incurred by both the direct patient care and overhead functional centres to individual patients within a given costing period. This means distributing the costs of the inputs to each patient visit based on the mix of intermediate products received. To accomplish this, the Ontario Case Cost Initiative (OCCI) has developed a case costing methodology based largely on the Canadian Institute for Health Information's MIS Standards (Guidelines for Management Information Systems in Canadian Health Service Organizations).

125. The OCCI has summarized the case costing methodology into four steps:

- $\quad$ gather the data

- $\quad$ allocate indirect costs

- calculate functional centre unit or intermediate product costs

- distribute costs to patients

Step 1 Gather the data

The MIS Standards provide a framework to standardize the collection, processing and reporting of information. An important feature of the MIS Standards is that this standardization allows for comparison of costs across hospitals. The Functional Centre Framework of the MIS Standards organizes hospital activity into functional centres. Generally, functional centres reflect the various departments normally found in hospitals (e.g., Operating Room, Diagnostic Imaging and Pharmacy). Within each functional centre, the Chart of Accounts standardizes how functional centre expenses and statistics are to be tracked. It goes as far as identifying the detailed individual accounts found in the General Ledger. Based on the information collected through the Chart of Accounts, total expenses for each functional centre can be calculated. 


\section{Step 2. Allocate indirect costs}

Functional centres are categorized as either transient cost centres (TCCs) or absorbing cost centres (ACCs). TCCs are generally the support and administrative, or overhead, departments within a hospital. ACCs are generally the patient care departments. Once each functional centre is designated as either a TCC or ACC, a methodology is required which allocates a portion of each TCCs expenses to each ACC. The resulting allocated expenses are referred to as indirect costs. The original ACC costs are referred to as direct costs. The direct costs and the allocated indirect costs make up the full costs of the ACC. The cost-finding process uses the simultaneous equation allocation methodology to allocate the indirect costs. Each TCCs costs are allocated to each of the ACCs based on a system of linear equations.

\section{Step 3 Calculate functional centre unit costs or intermediate product costs}

The third step of the case costing process can be accomplished using two methods. The first method involves calculating unit costs for services provided by each nursing functional centre. This approach is referred to as the Functional Centre Unit Cost (FCUC) method. The other method is the Intermediate Product Costing method (ICP), which is typically used in the Diagnostic and Laboratory functional centres. Both methods produce acceptable and valid results and - in fact - both yield the same results when the same Relative Value Units are used to distribute costs. The main difference between the two methods is that the FCUC method tracks patient-specific unit costs whereas the ICP method tracks patient-specific utilization of products.

\section{Step 4 Distributing costs to patients}

Once all the costs are in the appropriate ACC, relative value units (RVUs) are used to determine the appropriate portion of costs to be distributed to each patient. In general, RVUs measure the relative amounts of resources consumed in producing the specific service/product for patients, and may be specific to each functional centre. These RVUs are tracked on a patient-by-patient basis within each ACC that delivers patient care. Workload units are the RVUs usually used to distribute most costs to patients, whereas RVUs other than workload are used to distribute the remaining costs to patients. Each patient visit is costed by multiplying the cost per RVU by the total number of RVUs the patient received from that ACC. 


\section{England}

\section{Diagnoses classification and coding}

126. The clinical information on illnesses, diseases and injuries are currently recorded for the Hospital Episode Statistics (HES) using the ICD-10, published by WHO.

\section{Procedures classification and coding}

127. The Office of Population, Censuses and Surveys Classification of Interventions and Procedures, 4th Revision (OPCS-4) is used for coding information on procedures in the HES (Department of Health 2007). OPCS-4 codes consist of a letter followed by three characters. The letters denote the twenty four anatomically based chapters of the classification - most of which relate to the whole or part of a system of the body. There are more than 6,000 codes altogether.

128. The list of OPCS-4 chapters and three digit categories range are reported below.

\begin{tabular}{|c|l|c|}
\hline Chapter & \multicolumn{1}{|c|}{ Description } & Categories range \\
\hline A & Nervous System & A01-A84 \\
\hline B & Endocrine System and Breast & B01-B40 \\
\hline C & Eye & C01-C90 \\
\hline D & Ear & D01-D28 \\
\hline E & Respiratory Tract & E01-E98 \\
\hline F & Mouth & F01-F63 \\
\hline G & Upper Digestive Tract & G01-G82 \\
\hline H & Lower Digestive Tract & H01-H70 \\
\hline J & Other Abdominal Organs - principally digestive & K01-J77 \\
\hline K & Heart & L01-L99 O01- \\
\hline L & Arteries and Veins & O05, O15 \\
\hline M & Urinary & M01-M86 \\
\hline N & Male Genital Organs & N01-N35 \\
\hline P & Lower Female Genital Tract & P01-P32 \\
\hline Q & Upper Female Genital Tract & Q01-Q56 \\
\hline R & Female Genital Tract associated with pregnancy and childbirth and & R01-R43 \\
\hline P & Skin & S01-S70 \\
\hline T & Soft Tissue & T01-T97 \\
\hline U & Diagnostic Imaging, Testing and Rehabilitation & U01-U54 \\
\hline V & Bones and Joints of Skull and Spine & V01-V63 \\
\hline W & Other Bones and Joints & W01-W99 O06- \\
& \multicolumn{1}{|c|}{ O10 } \\
\hline X & Miscellaneous Operations & X01-X97 \\
\hline Y & Subsidiary Classification of Methods of Operation & Y01-Y99 \\
\hline Z & Subsidiary Classification of Sites of Operation & \\
\hline & & Z01-Z99 O1-O14 \\
\hline
\end{tabular}

129. Chapter Y provides "methods of operation" codes which are intended for the incorporation of otherwise unclassifiable detail in a far wider range of procedures. For example, Y08 covers different types of laser procedure and identifies the use of this form of treatment when associated with a particular 
operation, while Y14 indicates the type of stent placed in organ. It is not intended that the additional codes derived from this chapter be used in a primary position.

130. Chapter $\mathrm{Z}$ gives a series of site codes for the identification of intra-organ anatomical detail. For example, Z15 delineates the various quadrant of the breast, while Z32 identifies the valve of heart. It is not intended that the additional codes derived from this chapter be used in a primary position.

131. Once a chapter is full, then alpha-numeric categories are assigned using the free alpha $\mathrm{O}$. This has occurred within chapters L, W, and Z. Codes created in this way still form part of an existing chapter even though they have a different alpha prefix to the rest of that chapter. Such new codes will logically sit at the end of the body system chapter.

132. An example of valid codes follows.

\section{Chapter K, heart}

Group K52-K78, other parts of heart and pericardium

Category K59, cardioverter defibrillator introduced through vein

K59.1, implantation of cardioverter defibrillator using one electrode lead

K59.2, implantation of cardioverter defibrillator using two electrode leads

K59.3, resiting of lead of cardioverter defibrillator

$\mathrm{K} 59.4$, renewal of cardioverter defibrillator

K59.5, removal of cardioverter defibrillator

133. It is important to note that the use of high cost drugs is now required to be coded. In the miscellaneous operation chapter, the following categories are available for that purpose: hypertension drugs (X82); other cardiovascular drugs (X83); respiratory drugs (X84); neurology drugs (X85); antiinfective drugs (X86); endocrinology drugs (X87); reproductive and urinary tract drugs (X88); immunosuppressant drugs (X89); haematology and nutrition drugs (X90); metabolic drugs (X91); musculoskeletal drugs (X92); ophthalmology drugs (X93); ear, nose, and throat drugs (X94); dermatology drugs (X95); immunology drugs (X96); and anaesthesia drugs (X97).

\section{Timing and process for the revision of the coding schemata}

134. The development of OPCS-4.4 is informed by direct feedback from the NHS to ensure the needs of stakeholders are met. The NHS Classifications Service (NCS) of NHS Connecting for Health ${ }^{21}$ has responsibility for the support, maintenance, development and licensing of the OPCS-4, which is Crown copyright.

135. The role of the NCS as the national resource responsible for clinical classifications and associated products includes:

- develop, issue and maintain the standards relating to all clinical classification data in use in the NHS (ICD-10 and OPCS-4) promoting the consistency of classification as a key part of delivering a patient-centered health service Health formed with the primary role of delivering the National Programme for IT. NHS Connecting for Health is now responsible for all nationally coordinated major IT programmes across the NHS. These include business critical NHS IT systems and services which were formerly delivered by the NHS Information Authority. 
- $\quad$ provide the centre of expertise and a point of contact for international coding classifications work

- deliver the National Clinical Classifications Helpdesk giving official resolution to all clinical coding queries

- develop and maintain an extensive portfolio of associated products (including cross maps from SNOMED CT and Read codes to ICD-10 and OPCS-4)

- drive data quality by developing and delivering clinical coding audit methodology

- provide an education, training and accreditation programme for clinical coders to support an individual coder's continuous professional development

136. The NCS released OPCS-4.4 on 1 April 2007, following final approval from the NHS Information Standards Board.

\section{Tools used for data quality enhancement}

137. The UK Coding Review Panel aims to maintain and improve the quality of coded clinical data. The panel is managed by NHS Connecting for Health and provides a collaborative focus for the coding and classification of morbidity data in England, Scotland, Wales and Northern Ireland.

138. The panel determines national clinical coding policy and practice and changes to national UK clinical coding standards, reviews important coding issues - including those that require communication with clinicians and specified experts, develops clinical coding standards, and identifies ICD issues that need to be addressed by WHO Collaborating Centres.

139. The Coding Clinic Collection is a supplement to the Clinical Coding Instruction Manual for ICD10 and OPCS-4. It incorporates changes to clinical coding national standards, best coding practice or educational/technical theory, and practical examples of clinical coding.

140. The Coding Clinic aims to provide:

- $\quad$ standards on coding issues which need nationwide clarification, modification or development to ensure consistent application of coding across the NHS

- $\quad$ information on new diagnoses and procedures which have a significant impact on data users

- additional information and updates to the Clinical Coding Instruction Manual

- educational and technical theory, and practical examples of classification conventions - including national clinical coding standards (and changes to these standards for input and output users).

141. Coding queries are sent into the National Clinical Coding Helpdesk using the National Clinical Coding Query Mechanism accompanied by all relevant supporting documentation. If the nature of the query requires a review by the UK Coding Review Panel it will be submitted at the next scheduled meeting. These meetings are held every eight weeks, and the originator of the query will be notified of the status of the query as this will delay resolution being issued. 
142. The UK Coding Review Panel contributes to the regular revision of the ICD-10, providing reports to the advisory board for the UK WHO Collaborating Centre for the Classification of Diseases.

\section{Classification system}

143. One of the features of the Healthcare Resource Groups (HRG) classification system is the setting independence (The Information Centre 2008). To avoid perverse incentives associated with providing the same care in a different setting (for example Primary care, Outpatient, Daycase), HRGs describe care on the basis of what is done rather than where. Patients that can be appropriately treated in more than one setting should be grouped to the same HRG.

144. In this version of the system, another new characteristic relates to the fact that some significant elements of cost and activity have been "unbundled" from core HRGs. That is, the "unbundled component" becomes an HRG in its own right as an addition to a core $\mathrm{HRG}^{22}$. "Unbundled" elements of care can be identified as additional, exceptional, high-cost treatments. Unbundled HRGs have been developed for Chemotherapy (regimen and delivery), Radiotherapy (planning and treatment), Interventional Radiology, Diagnostic Imaging (e.g. MRIs/ CT), Rehabilitation, Renal Dialysis, Critical Care, Specialist Palliative Care, and High cost drugs.

145. The HRGs version 4.4 improves differentiation between routine and complex care (that is, increases granularity), and extends the areas covered by the classification to the following activity types: admitted patient care; non-admitted patients; emergency medicine; and adult critical care.

146. The HRGs system contains 1389 groups $^{23}$. 511 groups (36.79\%) are not differentiated (base HRGs). For the remaining groups, a set of 459 rules is used to specify the classification logic.

147. The following table reports the number and relative frequency of HRGs by chapter will be unbundled.

The Audit Commission in its "The right results? Payment by results 2003-2007" report recognises that "It will be important to monitor early experience with the new payment classification and be prepared to simplify it if necessary" (The Audit Commission, 2008). 
DELSA/HEA/WD/HWP(2011)2

\begin{tabular}{|c|c|c|c|}
\hline Chapter & Description & $\begin{array}{c}\text { Number of } \\
\text { groups }\end{array}$ & $\begin{array}{c}\text { Relative } \\
\text { frequency } \\
(\%)\end{array}$ \\
\hline A & Nervous System & 37 & 2.66 \\
\hline B & Eyes and Periorbita & 35 & 2.52 \\
\hline $\mathrm{C}$ & Mouth Head Neck and Ears & 73 & 5.26 \\
\hline $\mathrm{D}$ & Respiratory System & 96 & 6.91 \\
\hline $\mathrm{E}$ & Cardiac Surgery and Primary Cardiac Condition & 62 & 4.46 \\
\hline $\mathrm{F}$ & Digestive System & 94 & 6.77 \\
\hline G & Hepatobiliary and Pancreatic System & 51 & 3.67 \\
\hline $\mathrm{H}$ & Musculoskeletal System & 192 & 13.82 \\
\hline $\mathrm{J}$ & Skin, Breast and Burns & 92 & 6.62 \\
\hline K & Endocrine and Metabolic System & 35 & 2.52 \\
\hline $\mathrm{L}$ & Urinary Tract and Male Reproductive System & 122 & 8.78 \\
\hline M & Female Reproductive System and Assisted Reproduction & 42 & 3.02 \\
\hline $\mathrm{N}$ & Obstetrics & 19 & 1.37 \\
\hline $\mathrm{P}$ & Diseases of Childhood and Neonates & 92 & 6.62 \\
\hline Q & Vascular System & 31 & 2.23 \\
\hline $\mathrm{R}$ & Diagnostic Imaging and Interventional Radiology & 43 & 3.10 \\
\hline S & $\begin{array}{l}\text { Haematology, Chemotherapy, Radiotherapy and Specialist } \\
\text { Palliative Care }\end{array}$ & 101 & 7.27 \\
\hline $\mathrm{U}$ & Undefined Groups & 1 & 0.07 \\
\hline $\mathrm{V}$ & Multiple Trauma, Emergency and Urgent Care and Rehabilitation & 42 & 3.02 \\
\hline $\mathrm{W}$ & $\begin{array}{l}\text { Immunology, Infectious Diseases and other contacts with Health } \\
\text { Services }\end{array}$ & 69 & 4.97 \\
\hline $\mathrm{X}$ & Critical Care, High Cost Drugs and Devices & 59 & 4.25 \\
\hline \multirow[t]{2}{*}{$\mathrm{Z}$} & Unbundled & 1 & 0.07 \\
\hline & Total & 1389 & 100 \\
\hline
\end{tabular}


148. Each chapter is subdivided into sub-chapters. As an example of the sub-chapter structure, the table below reports the sub-chapter labels for "Musculoskeletal System" and "Critical Care, High Cost Drugs and Devices" chapters, with the related number of HRGs.

\begin{tabular}{|c|c|l|c|}
\hline Chapter & $\begin{array}{c}\text { Sub- } \\
\text { chapter }\end{array}$ & \multicolumn{1}{|c|}{ Description } & $\begin{array}{c}\text { Number of } \\
\text { HRGs }\end{array}$ \\
\hline H & A & Orthopedic Trauma Procedures & 61 \\
\hline H & B & Orthopedic Non-Trauma Procedures & 55 \\
\hline H & C & Spinal Surgery and Disorders & 43 \\
\hline H & D & Musculoskeletal Disorders & 33 \\
\hline
\end{tabular}

\begin{tabular}{|c|c|l|c|}
\hline Chapter & $\begin{array}{c}\text { Sub- } \\
\text { chapter }\end{array}$ & \multicolumn{1}{|c|}{ Description } & $\begin{array}{c}\text { Number of } \\
\text { HRGs }\end{array}$ \\
\hline X & A & Neonatal Critical Care & 6 \\
\hline X & B & Pediatric Critical Care & 8 \\
\hline X & C & Adult Critical Care & 7 \\
\hline X & D & High Cost Drugs & 38 \\
\hline
\end{tabular}

149. The HRGs code structure is presented below.

$H R G$ Chapter. The two character alphanumeric code retains the current HRG chapters, with the addition of a chapter dedicated to generic (i.e. cross-chapter) groupings. Making this code two characters allows for sub-chapter splits, e.g. Renal Procedures and Disorders (LA), Urinary Tract and Male Reproductive System Procedures and Disorders (LB), and Renal Dialysis (LC) within chapter L.

$H R G$ Number. A two digit numeric code which identifies the HRG within the Chapter: the lower the HRG number, the higher the expected resource use of that HRG, relative to other HRGs.

Split. A single character alpha numeric code is an indication of the presence of splits such as age, length of stay or complications. The character will have no information associated with its value. For example, it is not the case that a value of ' $A$ ' always represents an age split. 'No split' is indicated by ' $Z$ ' in this field

150. Complication and comorbidity splits are a way of incorporating varying severity and complexity levels within the design of the HRGs. An HRG is split by complication and comorbidity (CC) by use of a $\mathrm{CC}$ list. In HRG, a radical overhaul of both the underlying $\mathrm{CC}$ system and the $\mathrm{CC}$ list was completed. Complex elderly HRGs were removed and the levels of CC were extended to create three levels rather than simply 'with' and 'without CC' (as in version 3.5):

Level 1 - Not a significant complication

Level 2 - Intermediate complication

Level 3 - Major complication 
151. It is important to note that a particular diagnosis may be a major complication for some diagnoses whilst not being a relevant complication for others. The relevance and ranking of complications and comorbidities has therefore been assessed at chapter level to ensure that CCs are appropriately allocated and ranked. CC splits were used in particular in the medical HRGs as a way of indicating varying illness severity for patients with the same primary diagnosis.

152. Several examples of HRGs split are shown below.

LB04A Kidney Major Endoscopic Procedure with CC

LB04B Kidney Major Endoscopic Procedure without CC

LB38A Unspecified Haematuria with major CC

LB38B Unspecified Haematuria without major CC

LB02A Kidney Major Open Procedure, 19 years and over with major CC

LB02B Kidney Major Open Procedure, 19 years and over with intermediate CC

LB02C Kidney Major Open Procedure, 19 years and over without CC

\section{Variables used in the assignment process}

153. HRG assignment is based on patients' clinical conditions, treatment strategies, and age for admitted patient care. Clinical conditions are defined by patients' discharge diagnoses, including the principal diagnosis and up to thirteen secondary diagnoses, indicating other conditions that were present at admission (comorbidities) or developed during the hospital stay (complications). The (eventual) treatment strategy is defined by the reporting of a principal procedure and up to eleven procedures performed during the stay.

154. For non-admitted patient care, HRGs assignment is based on:

- $\quad$ principal procedure and up to eleven procedures performed during the encounter

- $\quad$ specialty

- $\quad$ first or follow up attendance

- face-to-face contact or telephone/telemedicine consultation

155. It is worth noting that - for several diseases and interventions - specific categories were identified. Hence the groups are not directly identifiable from the descriptions. As an example, below it is reported the assignment logic for the five HRGs that describe the Oculoplastic ${ }^{24}$. For the surgical HRGs, the OPCS codes assigned to each group are reported.

$24 \quad$ The HRGs definitions manual from which those examples were extracted remain the sole and exclusive property of The Information Centre, NHS. 


\section{BZ05Z Oculoplastics category 3}

C10.2 Hair bearing flap to eyebrow, C10.3 Hair bearing graft to eyebrow, C11.3 Correction of epicanthus, C11.4 Correction of telecanthus, C14.2 Graft of skin to eyelid, C14.3 Graft of cartilage to eyelid, C14.4 Graft of skin and fat to eyelid, C14.8 Other specified reconstruction of eyelid, C40.1 Mucosal graft to conjunctiva, C40.2 Amniotic graft to conjunctiva, C40.3 Sliding graft to conjunctiva, C40.4 Prosthetic replacement of conjunctiva

\section{BZ06A Oculoplastics category 2: 19 years and over}

BZ06B Oculoplastics category 2: 18 years and under

C09.3 Replacement of medial canthal tendon using periosteal strip, C11.1 Excision of lesion of canthus, C11.5 Graft of skin to canthus, C11.7 Biopsy of lesion of canthus, C11.8 Other specified operations on canthus, C13.1 Blepharoplasty of both eyelids, C13.2 Blepharoplasty of upper eyelid, C13.3 Blepharoplasty of lower eyelid, C13.4 Blepharoplasty NEC, C14.1 Flap of skin to eyelid, C14.5 Graft of fascia to eyelid, C14.9 Unspecified reconstruction of eyelid, C15.4 Correction of cicatrical ectropion, C15.5 Correction of cicatrical entropion, C16.5 Revision of tarsorrhaphy, C18. Correction of ptosis of eyelid, C19._ Incision of eyelid, C22.1 Avulsion of nerve of eyelid, C43.1 Division of adhesions of conjunctiva, C43.6 Creation of hood of conjunctiva, C43.7 Transplantation of conjunctiva, C43.8 Other specified other operations on conjunctiva

\section{BZ07A Oculoplastics category 1: 19 years and over}

BZ07B Oculoplastics category 1: 18 years and under

C10.1 Excision of lesion of eyebrow, C10.4 Suture of eyebrow, C10.5 Incision of lesion of eyebrow, C10.8 Other specified operations on eyebrow, C11.2 Destruction of lesion of canthus, C11.6 Canthotomy, C12. Extirpation of lesion of eyelid, C13.8 Other specified excision of redundant skin of eyelid, C13.9 Unspecified excision of redundant skin of eyelid, C15.1 Correction of ectropion NEC, C15.2 Correction of entropion NEC, C15.3 Correction of trichiasis, C15.8 Other specified correction of deformity of eyelid, C15.9 Unspecified correction of deformity of eyelid, C16.1 Central tarsorrhaphy, C16.2 Lateral tarsorrhaphy, C16.3 Medial tarsorrhaphy, C16.4 Tarsorrhaphy NEC, C16.8 Other specified other plastic repair of eyelid, C16.9 Unspecified other plastic repair of eyelid, C17._ Other repair of eyelid, C20. Protective suture of eyelid, C22.2 Biopsy of lesion of eyelid, C22.3 Removal of foreign body from eyelid, C22.4 Injection into eyelid, C22.5 Exploration of eyelid, C22.6 Epilation of eyelash, C22.8 Other specified other operations on eyelid, C39.1 Excision of lesion of conjunctiva, C39.2 Cauterisation of lesion of conjunctiva, C39.3 Cryotherapy to lesion of conjunctiva, C39.4 Curettage of lesion of conjunctiva, C39.8 Other specified extirpation of lesion of conjunctiva, C39.9 Unspecified extirpation of lesion of conjunctiva, C40.5 Suture of conjunctiva, C40.8 Other specified repair of conjunctiva, C40.9 Unspecified repair of conjunctiva, C41._ Incision of conjunctiva C43.2 Biopsy of lesion of conjunctiva, C43.3 Removal of foreign body from conjunctiva, C43.4 Subconjunctival injection, C43.5 Exploration of conjunctiva

\section{Timing and process for the revision of the classification system}

156. The Casemix Service of the NHS Information centre develops clinical grouping methodologies and software products that enable the NHS to record clinical activity. The Service is responsible for the revision/update of the system. The revision process is not systematic.

\section{Cost-finding approach}

157. The costing of all services delivered by the NHS providers is governed by the following principles. Costs should be (Department of Health 2008):

- calculated on a full absorption basis to identify the full cost of services delivered 
- allocated and apportioned accurately by maximising direct charging and where this is not possible using standard methods of apportionment

- matched to the services that generate them to avoid cross subsidisation

158. It is acknowledged that configurations of cost centres differ across NHS providers. To address this apparent tension, NHS providers should identify cost centres which best reflect their service delivery for internal management purposes. These cost centres should however be able to clearly map to the treatment function/programme/service ${ }^{25}$ definitions required in the Reference Cost Collection guidance.

159. There are three key elements which are required in the costing methodology:

- a "high level control total" based on actual costs by services identifying direct, indirect and overhead costs in line with the national minimum standards

- a continuous reconciliation process at all stages of the costing process is required to ensure all costs are recovered, and that costs can be matched to relevant services and final accounts

- a "resource profile" analysis of the key conditions which represent a minimum of $80 \%$ of the high level control total in both activity and cost terms

160. These profiles or pathways allow clinical audit and financial monitoring to be undertaken as part of the ongoing internal performance monitoring. Effort should be focused on the smallest number of procedures and activities within each function which together represent a high proportion of the total cost.

161. There are four steps in the costing exercise:

- establish control totals for costing

- production of high level control totals

- establish control totals at point of delivery

- costing inpatient and day case activity

162. The costing process begins with the general ledger. At the first level, the purpose is that a control total for costing should be established. This should be the full cost of providing services for NHS patients. The aggregate (quantum) of costs used in their production is reconciled to the financial accounts of the provider for the previous financial year (1st April to 31st March). In aggregate, they comprise operating expenses, including depreciation, plus finance costs such as repayment of public-sector loans, and are net of non-patient related income which is matched against corresponding expenditure.

163. At the second level, the objective is to attribute all costs to the services which generate them. To meet this objective, as many costs as possible should be allocated directly to the function/patient to which they relate. Costs that cannot be attributed directly are allocated and apportioned using appropriate work or other measures. Where costs have not been directly attributed to the patient, costing pools should be constructed so that the costs included can be allocated or apportioned using the same method. The costing

25 The terms service/programme/treatment function tend to be used interchangeably. In costing they are separately identifiable groups of patient related activities that can be quantified. In this document they will be referred to as functions. 
methodology requires hospital facilities to be grouped together into one of three types of cost pool: direct; indirect; overhead.

164. In some cases (direct costs), it will be known precisely how expenditure in that cost pool has been incurred. These costs can be directly allocated to the services which used them, for example, it may be known which specialty used certain drugs. In other cases (indirect costs), it is assumed that a single basic key work activity can be identified which influences expenditure in this cost pool. Expenditure in the cost pool can then be allocated to other services proportionately to use of this activity. For example, hospital pharmacists' costs can be allocated to specialties according to the number of items dispensed to that service. For some cost pools (overheads), there will be no reliable single work activity statistic, and these costs are apportioned to other cost pools and patient-level specialties on a more discretionary basis.

165. For all services not attributed directly to patients, the high level control totals should be analysed between the points of delivery e.g. day cases, outpatients, direct access. This may involve some further disaggregation of costs e.g. the fully absorbed costs of a support department will be distributed as an element in the cost of a range of surgical and medical interventions, outpatient attendances, but also as a direct access service. The amount of work involved at this stage will be determined by the approach taken to the allocation and apportionment of costs through costing pools. The point of delivery control totals must reconcile to the high level control totals and provide the basis of resource profiles which will be established for a range of services.

166. For inpatient and day case activity, the costs are then further disaggregated to HRGs. This is done in a number of steps:

- the main HRGs used by the provider are identified within each specialty

- the main conditions or procedures used by the provider are identified within each HRG

- a resource profile is estimated for each condition or procedure ${ }^{26}$. This involves identifying the main cost drivers for each procedure, e.g. time-based costs such as spent on ward, time spent in surgical theatre, or event based costs such as use of high cost prostheses

- unit costs are identified for each cost driver. For event-based costs such as the unit cost of prostheses, this might be available from the hospital purchasing system. For time-based costs, this will be an average unit cost per - for example - bed day or theatre minute derived from the appropriate cost pool

- the weighted average HRG cost is estimated as the total costs for each of the procedures/conditions costed, added together and divided by the total number of episodes for the costed codes within the HRG

167. A National Schedule of Reference Costs 2008-09 for NHS Trusts is publicly available (Department of Health 2010). It reports figures on:

- elective inpatient HRG data

- non elective inpatient HRG data 
DELSA/HEA/WD/HWP(2011)2

- non elective inpatient excess bed day HRG data

- $\quad$ day cases HRG data

168. The following table contains the available figures for selected elective inpatient products/HRGs. 
DELSA/HEA/WD/HWP(2011)2

\begin{tabular}{|c|c|c|c|c|c|c|c|c|}
\hline HRG code & HRG label & Activity & $\begin{array}{c}\text { National Average } \\
\text { Unit Cost }\end{array}$ & $\begin{array}{l}\text { Lower Quartile Unit } \\
\text { Cost }\end{array}$ & $\begin{array}{c}\text { Upper Quartile Unit } \\
\text { Cost }\end{array}$ & No. of Bed Days & \begin{tabular}{|c|} 
Average Length of \\
Stay - Days
\end{tabular} & $\begin{array}{c}\text { No. Data } \\
\text { Submissions }\end{array}$ \\
\hline $\mathrm{AA} 02 \mathrm{Z}$ & Intracranial Procedures for Trauma with Intermediate Diagnosis & & $\varepsilon 5,550$ & $£ 3,325$ & $\{7,863$ & & & 18 \\
\hline AAO3Z & \begin{tabular}{|l} 
Intracranial Procedures for Trauma with Minor Diagnosis \\
\end{tabular} & 108 & $£ 5,473$ & $\varepsilon 3,134$ & $\varepsilon 7,425$ & 688 & 6.37 & 47 \\
\hline AA04Z & $\begin{array}{l}\text { Intracranial Procedures Except Trauma with Non-Transient Stroke or Cerebrovascular Accident, Nervous } \\
\text { system infections or Encephalopathy - category } 4\end{array}$ & 23 & $\varepsilon 11,174$ & $£ 5,930$ & $£ 13,418$ & 445 & 19.35 & 17 \\
\hline AA05Z & Intracranial Procedures Except Trauma with Haemorrhagic Cerebrovascular Disorders - category 4 & 790 & $£ 5,967$ & $£ 5,809$ & $£ 5,809$ & 2,422 & 3.07 & 2 \\
\hline AA06Z & Intracranial Procedures Except Trauma with Brain Tumours or Cerebral Cysts - category 4 & 1,773 & $£ 7,936$ & $\{6,283$ & $\{9,510$ & 13,654 & & 57 \\
\hline AA07Z & $\begin{array}{l}\text { Intracranial Irocedures Except Trauma with Cerebral Degenerations or Miscellaneous Disorders of } \\
\text { Nergous S Pstem - category } 4\end{array}$ & 481 & $£ 7,451$ & $£ 5,352$ & $£ 8,386$ & 2,614 & 5.43 & 43 \\
\hline AA08Z & $\begin{array}{l}\text { Intracranial Procedures Except Trauma with Muscular, Balance, Cranial or Peripheral Nerve disorders, } \\
\text { Epilepsy or Head Injury - category } 4\end{array}$ & 615 & $£ 5,487$ & $£ 3,938$ & $£ 6,443$ & 2,842 & 4.62 & 44 \\
\hline AA09Z & Intracranial Procedures Except Trauma with Other Diagnoses - category 4 & 52 & $£ 4,22$ & $\varepsilon 1,734$ & $£ 6,402$ & 2,031 & 3.89 & 106 \\
\hline AA10Z & $\begin{array}{l}\text { Intracranial Procedures Except Trauma with Non-Transient Stroke or Cerebrovascular Accident, Nervous } \\
\text { system infections or Encephalopathy - category } 3\end{array}$ & 18 & $£ 6,756$ & $£ 3,208$ & $£ 8,407$ & 103 & 5.72 & 15 \\
\hline AA11Z & Intracranial Procedures Except Trauma with Haemorrhagic Cerebrovascular Disorders - category 3 & 35 & $£ 8,993$ & $£ 6,249$ & $\varepsilon 12,104$ & 395 & 11.29 & 19 \\
\hline AA12Z & Intracranial Procedures Except Trauma with Brain Tumours or Cerebral Cysts - category 3 & 1,658 & $\{5,838$ & $\{4,356$ & $\{7,023$ & 9,399 & 5.67 & 46 \\
\hline AA13Z & $\begin{array}{l}\text { Intracranial Procedures Except Trauma with Cerebral Degenerations or Miscellaneous Disorders of } \\
\text { Nervous System - category } 3\end{array}$ & 579 & $£ 5,653$ & $\{3,781$ & $£ 6,308$ & 3,445 & 5.95 & 61 \\
\hline AA14Z & $\begin{array}{l}\text { Intracranial Procedures Except Trauma with Muscular, Balance, Cranial or Peripheral Nerve disorders; } \\
\text { Epilepsy; Head Injury - category } 3\end{array}$ & 389 & $£ 4,143$ & $\{1,666$ & $£ 5,284$ & 1,422 & 3.66 & 33 \\
\hline AA15Z & Intracranial Procedures Except Trauma with Other Diagnoses - category 3 & 475 & $£ 5,045$ & $£ 3,517$ & $£ 5,955$ & 2,614 & 5.50 & 82 \\
\hline AA16Z & $\begin{array}{l}\text { Intracranial Procedures Except Trauma with Non-Transient Stroke or Cerebrovascular Accident, Nervous } \\
\text { system infections or Encephalopathy - category } 1 \text { or } 2\end{array}$ & 97 & $£ 6,688$ & $£ 3,032$ & $£ 9,728$ & 1,016 & 10.47 & 43 \\
\hline AA17Z & Intracranial Procedures Except Trauma with Haemorrhagic Cerebrovascular Disorders - category 1 or 2 & 126 & $\varepsilon 7,465$ & $£ 4,073$ & $\varepsilon 9,124$ & 730 & 5.79 & 31 \\
\hline AA18Z & Intracranial Procedures Except Trauma with Brain Tumours or Cerebral Cysts - category 1 or 2 & 1,002 & $£ 4,854$ & $£ 3,793$ & $\{6,293$ & 5,364 & 5.35 & 84 \\
\hline AA19Z & $\begin{array}{l}\text { Intracranial Procedures Except Trauma with Cerebral Degenerations or Miscellaneous Disorders of } \\
\text { Nervous System - category } 1 \text { or } 2\end{array}$ & 1,202 & $£ 4,414$ & $£ 2,705$ & $£ 5,352$ & 5,111 & 4.25 & 124 \\
\hline AA20Z & $\begin{array}{l}\text { Intracranial Proceddures Except Trauma with Muscular, Balance, Cranial or Peripheral Nerve disorders; } \\
\text { Epplepsy; Head Injury - category } 1 \text { or } 2\end{array}$ & 3,061 & $£ 2,704$ & $£ 2,064$ & $£ 2,906$ & 11,086 & 3.62 & $\overline{06}$ \\
\hline AA21Z & Intracranial Procedures Except Trauma with Other Diagnoses - category 1 or 2 & 11,774 & $£ 1,550$ & $£ 408$ & $£ 2,204$ & 19,232 & 1.63 & 475 \\
\hline AA22Z & Non-Transient Stroke or Cerebrovascular Accident, Nervous system infections or Encephalopathy & 2,002 & $\varepsilon 3,101$ & $\{1,066$ & $\{3,849$ & 17,285 & 8.63 & 520 \\
\hline
\end{tabular}




\section{France}

\section{Diagnoses classification and coding}

169. ICD-10 is used in France. On a yearly basis, several codes are added to that classification to provide a higher clinical detail. The Agence Technique de 1'Information sur 1'Hospitalisation (ATIH) ${ }^{27}$ is responsible for those addenda to the ICD-10 codes.

170. As an example, for Obesity (E66) a fifth character is added to the ICD-10 structure to specify the body mass index:



\section{Procedure classification and coding}

171. The Classification Commune des Actes Médicaux (CCAM) is a framework for the multiaxial classification of procedures according to anatomical site, action, and approach/method (Agence Technique de l'Information sur l'Hospitalisation, 2008). It is used in France since 2002. The CCAM contains an analytical listing of procedure descriptions, with their corresponding code. Explanations of conditions of use for certain descriptions or of the meaning of specific terms are provided in the form of symbols or notes. These indications are an integral part of the CCAM.

172. The CCAM analytical volume is organised into four different levels: chapters, sub-chapters, paragraphs and sub-paragraphs. CCAM descriptions are broken down into eighteen chapters, the first classification level. These chapters are identified using 2-character Arabic numerals. Chapters 01 to 16 are defined by the anatomo-physiological system, the anatomical system or the topography, which is acted upon during the described procedure, regardless of practitioner specialty, qualification or working method, or procedure objective.

173. Among these chapters, two have a particularity: chapter 09, concerning procreation, pregnancy and newborn babies, groups together procedures based on the notion of physiological proximity; chapter 15 describes procedures involving the osteoarticular and muscular system that specifically concern neither the head (chapter 11), nor the neck or trunk (chapter 12), nor the upper (chapter 13) or lower limb (chapter 14). Along with these chapters by system, some special chapters do not follow this classification logic.

174. Chapter 17 groups together all procedures for which no specifications are given as to the system or tract. Chapter 18 includes separate lists of additional acts as well as modifiers.

27 Created in December 2000, the Agency is a public administrative institution under the supervision of the Health and Social Security ministers. ATIH is co-funded by the government and the national health insurance. 
175. The table below reports the CCAM chapters and their descriptions.

\begin{tabular}{|c|l|}
\hline Chapter & \multicolumn{1}{c|}{ Description } \\
\hline 01 & Système nerveux central, périphérique et autonome \\
\hline 02 & Oeil et annexes \\
\hline 03 & Oreille \\
\hline 04 & Appareil circulatoire \\
\hline 05 & Système immunitaire et système hématopoiétique \\
\hline 06 & Appareil respiratoire \\
\hline 07 & Appareil digestif \\
\hline 08 & Appareil urinaire et génital \\
\hline 09 & Actes concernant la procréation, la grossesse er le nouveau-né \\
\hline 10 & Glandes endocrine et métabolisme \\
\hline 11 & Appareil ostéoarticulaire et musculaire de la tête \\
\hline 12 & Appareil ostéoarticulaire et musculaire du cou et du tronc \\
\hline 13 & Appareil ostéoarticulaire et musculaire du membre supérieur \\
\hline 14 & Appareil ostéoarticulaire et musculaire du membre inférieur \\
\hline 15 & Appareil ostéoarticulaire et musculaire, sans précision topographique \\
\hline 16 & Système tégumentaire-glance mammaire \\
\hline 17 & Actes sans précision topographique \\
\hline 18 & Gestes complémentaires et modificateurs \\
\hline
\end{tabular}

176. The chapters are subdivided into sub-chapters numbered using 2-character Arabic numerals. These distinguish between diagnostic and therapeutic procedures. Therefore there are always at least two sub-chapters for each chapter. In order to make the classification as clear and as easy to use as possible, these two major groups have often been separated into several sub-chapters. This is more common for therapeutic procedures, classified under sub-chapters by subsystem, topography or organ.

177. The sub-chapters are then subdivided into paragraphs. Some are segmented into sub-paragraphs (this level may be empty).

178. Diagnostic procedures from the same sub-chapter are grouped together into paragraphs according to procedure type or technique (functional explorations, $\mathrm{x}$-ray, scintigraphy, etc.); the order of presentation, but not the numbering, is identical from one chapter to the next. Sub-chapters concerning therapeutic procedures are subdivided into paragraphs compiled according to a guiding principle that is usually topographical. Thus, the presentation follows an anatomical order: listing of organs or sites in a craniocaudal or, for limbs, proximodistal direction. For systems or organs with circulation or peristalsis, the order follows the direction of flow: this is why venous procedures are listed in a centripetal topographical order, contrary to the centrifugal classification for arterial procedures. When a procedure concerns several precisely described anatomical sites, whether in the same system or not, it was decided that it would be classified according to the first site mentioned in the description; hence, acquired rectovaginal fistula drainage is found in the chapter on digestive system procedures, in the paragraph concerning interventions involving the rectum. This approach stems from the rule that a description must only appear in the CCAM once, which excludes the possibility of repeating descriptions.

179. The second classification principle is the action performed: excision, plastic surgery, osteosynthesis, etc. When several descriptions concern the same action on the same organ or same site using different accesses or techniques, they are placed adjacently. They are written to distinguish as easily as possible the differentiating element or elements. Thus, the user has all the different ways of performing the same type of intervention, in the same area, under the same subdivision. 
180. CCAM main codes are seven characters semi-structured alphanumerical codes: an initial segment of four capital alphabetical characters ${ }^{28}$; a final segment, identified by three Arabic numerals. There are no separators between these segments; thus, code composition is AAAA000. The first two alphabetical characters indicate the anatomical location of a procedure, the third indicates the action performed, and the fourth the access mode or technique utilised. Thus, code structure corresponds to distinct description axes: simply reading them identifies, to a certain extent, procedure performance method.

181. To distinctly identify such descriptions, a numerical 3-digit counter follows these four alphabetical characters. Contrary to the alphabetical segment, the counter has no structure. Counter value does not indicate the occurrence order of descriptions within the CCAM; this solution enables the CCAM to evolve without interrupting initial presentation and coding logic. Numbers between 900 and 999 are reserved for codes of procedures that the French National Authority for Health has classified "under clinical research", thus enabling them to be easily identified by the user.

182. The first letter of the code segment designates the system, tract or structure which the action concerns; therefore, it is understood that there is a similarity with the CCAM chapter plan. A letter may correspond to an entire chapter. As an example, A for chapter 01 on the nervous system, B for chapter 02 on the eye. Due to the large number of procedures it contains, chapter 04 uses two letters: D for Heart and major vessels and E for Peripheral vessels. Conversely, one letter may be shared by two chapters: thus, the letter $\mathbf{J}$ is shared by chapters 08 on procedures concerning the urinary system and male and female genital tracts, and 09 describing fertility interventions. The letter $\mathrm{Z}$ is reserved for large topographical areas, with no specification as to system or organ.

183. The second letter of this code segment provides additional detail. Combined with the letter indicating the system or tract, it identifies:

- $\quad$ an organ. For example, in the digestive system (letter H), the letter L designates the liver (HL), J the rectum $(\mathrm{HJ})$, and $\mathrm{N}$ the pancreas $(\mathrm{HN})$.

- a topographic region: for example, in the skin and subcutaneous tissue $(\mathrm{Q})$, letter $\mathrm{B}$ is used for the trunk $(\mathrm{QB})$, and letter $\mathrm{B}$ for the breast $(\mathrm{QB})$.

- a function, associated by convention to the affected system or organ: for example, AL for Memory in the nervous system (letter A).

184. The $\mathrm{Z}$ letter is used when no location is given as to a system or organ (without topographic specification). For example, GZ designates the respiratory system without specifications. In the case where a procedure concerns several locations, it was decided that the deepest location or the closest to the cephalic extremity should be coded first; in case of difficulties, the first location given in the description is coded.

185. The action terms is coded using a single letter for simplicity, and the same code is often allocated to several action verbs, grouped together because of their technical similarity. Thus, the letter $\mathrm{G}$ has been allocated to the verbs remove, extract, and empty. Even when identically coded, the verbs retain their different meanings and the corresponding actions must continue to be differentiated in the process used.

186. When a procedure description includes several actions, the code used is that which refers to the main action or the first one mentioned. 
187. A single letter is also used to code the information on access mode. The notion of "access mode" must be differentiated from that of "access route", commonly known as "approach" in surgery. The access mode is determined by the way instruments penetrate into the body and the technique used (for example, use or non-use of an endoscopic device). Procedures with instrumental penetration are identified by letters A-J. They indicate both the access method and/or the technique (transparietal access, B; transparietal endoscopic access, C). Procedures without instrumental penetration into the body are called non-access, and are identified by the characters $\mathrm{K}, \mathrm{L}, \mathrm{M}, \mathrm{N}$ and $\mathrm{P}$ in the coding system for access modes, depending on the technique used.

188. As an example, a scintigraphy of the thyroid gland is identified by the following code under paragraph 10.01.02, Scintigraphie des glandes endocrines:

\section{KCQL003}
$\mathrm{K}$ : système endocrinien
C: glande thyrö̈de
Q: examiner
L: acte par agent ionisant

189. The last part of the code (003) is a counter. There are two additional procedures that have the same basic root: Scintigraphie de la glande thyroïde avec mesure radio-isotopique de la fixation (KCQL001); and Mesure radio-isotopique de la fixation thyroïdienne de l'iode (KCQL002).

190. The following example relates to the therapeutic interventions on hearth and its vessels.

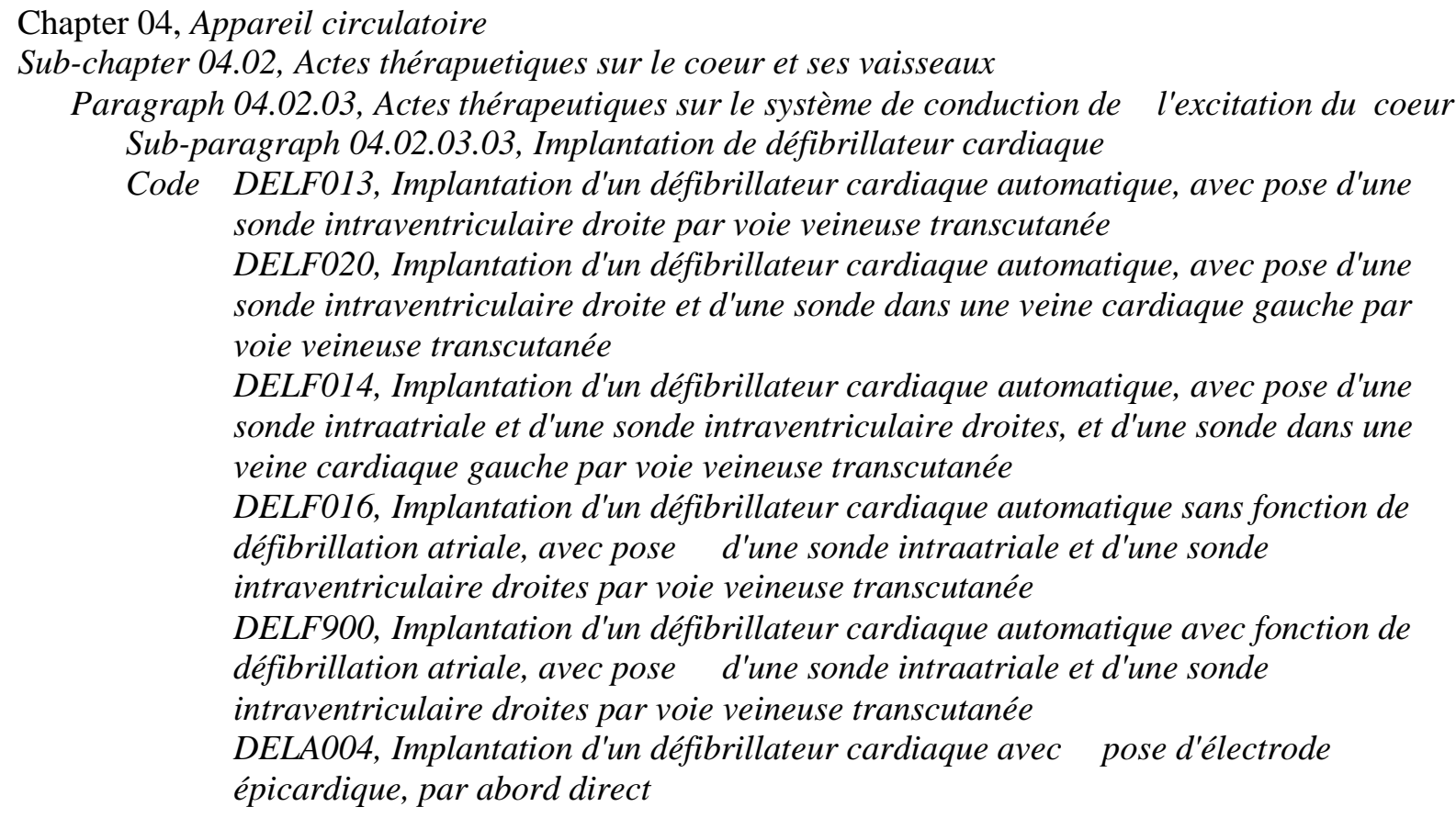

The CCAM classification system contains approximately 8000 codes.

\section{Timing and process for the revision of the coding schemata}

191. The ATIH is responsible for the regular update of both the diagnosis and the procedure classification systems. 


\section{Classification system}

192. The Groupes Homogènes de Malades (GHM) is a classification system that measures acute hospitalizations (médecine, chirurgie, obstétrique: MCO). It has been developed to classify inpatient, day care, and outpatient hospital-based services.

193. The GHM version 11.b contains 2368 groups $^{29}$. The distribution of those groups by Major Diagnostic Category (MDC) ${ }^{30}$ is reported in the following table. of 4 severity level (instead of 3 for selected GHM). Malades). In the rest of this paragraph, we will refer to GHM and MDC in general terms. 
DELSA/HEA/WD/HWP(2011)2

\begin{tabular}{|c|c|c|c|}
\hline $\begin{array}{c}\text { MDC } \\
\text { number }\end{array}$ & Description & $\begin{array}{c}\text { Number of } \\
\text { groups }\end{array}$ & $\begin{array}{c}\text { Relative } \\
\text { frequency } \\
(\%)\end{array}$ \\
\hline 28 & Séances & 16 & 0.7 \\
\hline 27 & Transplantations d'organes & 30 & 1.3 \\
\hline 26 & Traumatismes multiples graves & 8 & 0.3 \\
\hline 25 & Maladies dues à une infection par le VIH & 13 & 0.5 \\
\hline 01 & Affections du système nerveux & 193 & 8.2 \\
\hline 02 & Affections de l'oeil & 81 & 3.4 \\
\hline 03 & $\begin{array}{l}\text { Affections des oreilles, du nez, de la gorge, de la bouche et des } \\
\text { dents }\end{array}$ & 156 & 6.6 \\
\hline 04 & Affections de l'appareil respiratoire & 124 & 5.2 \\
\hline 05 & Affections de l'appareil circulatoire & 208 & 8.8 \\
\hline 06 & Affections du tube digestif & 165 & 7.0 \\
\hline 07 & Affections du système hépatobiliaire et du pancréas & 91 & 3.8 \\
\hline 08 & $\begin{array}{l}\text { Affections et traumatismes de l'appareil musculosquelettique et } \\
\text { du tissu conjonctif }\end{array}$ & 327 & 13.8 \\
\hline 09 & Affections de la peau, des tissus sous-cutanés et des seins & 105 & 4.4 \\
\hline 10 & Affections endocriniennes, métaboliques et nutritionnelles & 104 & 4.4 \\
\hline 11 & Affections du rein et des voies urinaires & 109 & 4.6 \\
\hline 12 & Affections de l'appareil génital masculin & 78 & 3.3 \\
\hline 13 & Affections de l'appareil génital féminin & 99 & 4.2 \\
\hline 14 & $\begin{array}{l}\text { Grossesses pathologiques, accouchements et affections du post- } \\
\text { partum }\end{array}$ & 24 & 1.0 \\
\hline 15 & Nouveau-nés, prématurés et affections de la période périnatale & 20 & 0.8 \\
\hline 16 & Affections du sang et des organes hématopoïétiques & 60 & 2.5 \\
\hline 17 & $\begin{array}{l}\text { Affections myéloprolifératives et tumeurs de siège imprécis ou } \\
\text { diffus }\end{array}$ & 71 & 3.0 \\
\hline 18 & Maladies infectieuses et parasitaires & 47 & 2.0 \\
\hline 19 & Maladies et troubles mentaux & 76 & 3.2 \\
\hline 20 & $\begin{array}{l}\text { Troubles mentaux organiques liés à l'absorption de drogues ou } \\
\text { induits par celles-ci }\end{array}$ & 23 & 1.0 \\
\hline 21 & Traumatismes, allergies et empoisonnements & 75 & 3.2 \\
\hline 22 & Brûlures & 19 & 0.8 \\
\hline 23 & $\begin{array}{l}\text { Facteurs influant sur l'état de santé et autres motifs de recours } \\
\text { aux services de santé }\end{array}$ & 41 & 1.7 \\
\hline 90 & Error & 5 & 0.2 \\
\hline Total & & 2368 & 100 \\
\hline
\end{tabular}

194. The GHM numbering uses six characters that can be broken down as follows:

- the first two are numerical and indicate the MDC number;

- the third is alphabetical and characterizes the GHM according to the classification logic with the following conventions:

○ C, surgical group with classifying operating procedure

$\circ \mathrm{K}$, group with classifying non-operating procedure

$\circ \mathrm{M}$, medical group without classifying procedure

$\circ \mathrm{Z}$, undifferentiated group with or without classifying operating procedure

- H, group in CM 90 excluding "Procedures unrelated to main diagnosis" group

- the fourth and fifth are numerical and are used as a counter 
195. The sixth GHM character is alphabetical, and indicates the severity level or the "type" of the GHM:

○ 1 , severity level 1

○ 2, severity level 2

○ 3 , severity level 3

○ 4, severity level 4

- T, short stay

○ J, outpatient

$\circ \mathrm{Z}$, not differentiated by severity

○ E, died

- A, sans problème significatif

- $\mathrm{B}$, avec autre problème significatif

- $\mathrm{C}$, avec problème severe

$\circ \mathrm{D}$, avec problème majeur

196. Case severity is identified through a list of complication ou morbidité associée (CMA). Each code included in this list has a severity level assigned. An example is given below.

\begin{tabular}{|l|l|l|}
\hline \multicolumn{1}{|c|}{ Code } & \multicolumn{1}{|c|}{ Description } & Severity level \\
\hline $\mathrm{J} 70.0$ & Affections pulmonaires aiguës dues à une irradiation & 2 \\
\hline $\mathrm{J} 70.1$ & Affections pulmonaires chroniques et autres dues à une irradiation & 2 \\
\hline $\mathrm{J} 70.2$ & Affections pulmonaires interstitielles aiguës, médicamenteuses & 3 \\
\hline $\mathrm{J} 70.3$ & Affections pulmonaires interstitielles chroniques, médicamenteuses & 3 \\
\hline $\mathrm{J} 70.4$ & Affection pulmonaire interstitielle, médicamenteuse, sans précision & 3 \\
\hline $\mathrm{J} 80$ & Syndrome de détresse respiratoire de l'adulte & 4 \\
\hline
\end{tabular}

197. There are length of stay (LOS) thresholds specific to each severity level: 3 days of stay for level 2; 4 days for level 3; and 5 days for level 4 . If the minimum LOS is not reported, then the case is assigned to the severity level immediately below (if the LOS matches the threshold).

198. Age could influence the severity level assignment too. For specific groups, if age $>79$ years then severity is increased by one level for levels 1,2 , and 3. For specific groups, if age $>69$ years then severity is increased by one level for levels 1 , and 2 . If age $<2$ years, then the minimum severity level is 2 .

\section{Variables used in the assignment process}

199. First, cases are assigned to MDC 28, Séance. For a case to be assigned to that MDC, two criteria should be met:

- the principal diagnosis should be one of the following: Z49.1 Dialyse extra-corporelle, Z49.2 Autres dialyses, Z49.20 Séance de dialyse péritonéale automatisée [DPA], Z49.21 Séance de dialyse péritonéale continue ambulatoire [DPCA], Z51.00 Séance de préparation à une irradiation, Z51.01 Séance d'irradiation, Z51.1 Séance de chimiothérapie pour tumeur, Z51.3 Transfusion sanguine, sans mention de diagnostic, Z51.80 Séance d'oxygénothérapie hyperbare.

- the admission and the discharge dates should be the same, or if not the number of séances should be greater than 0 .

200. The following graph reports the assignment tree for MDC 28. 


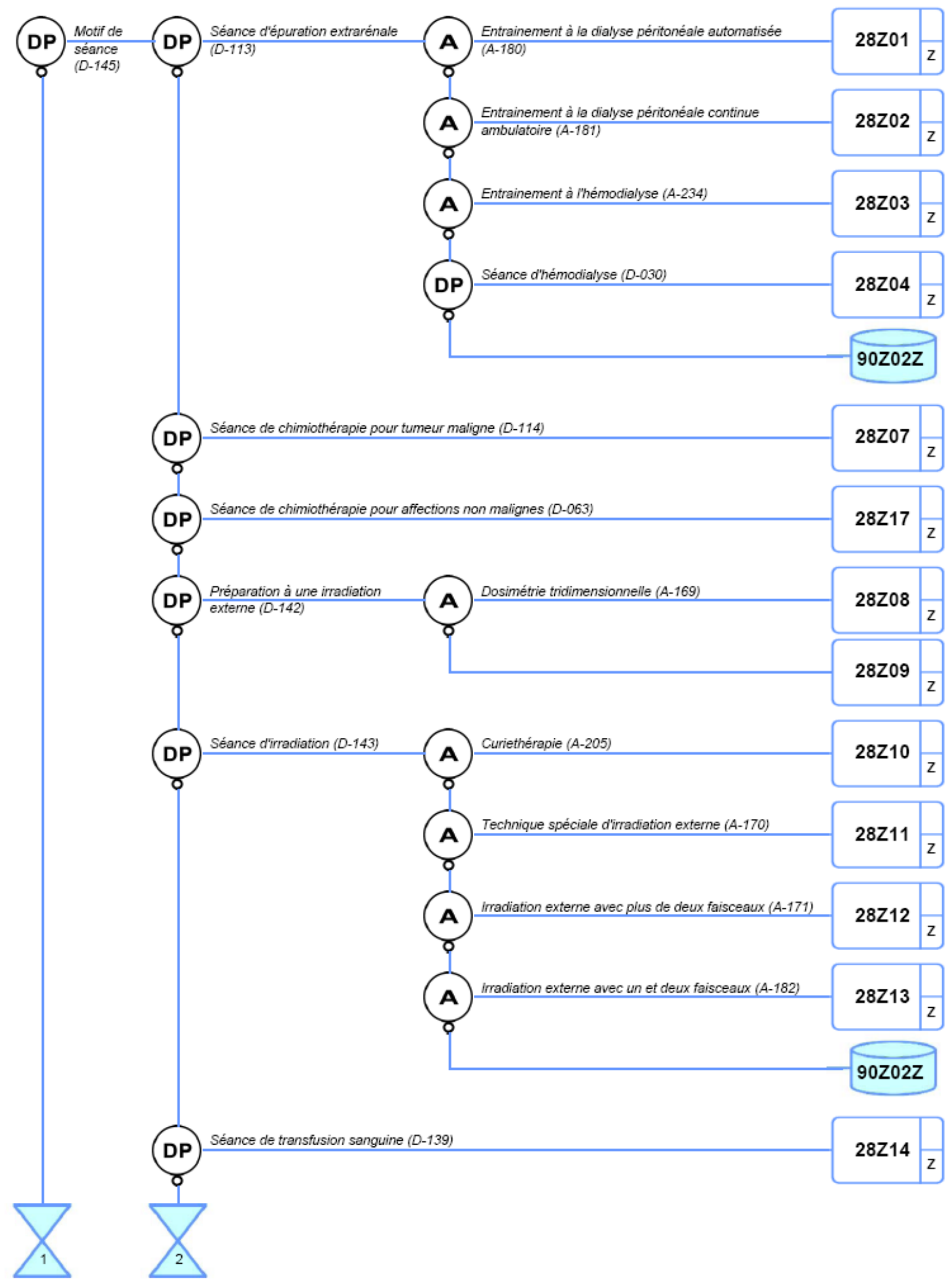




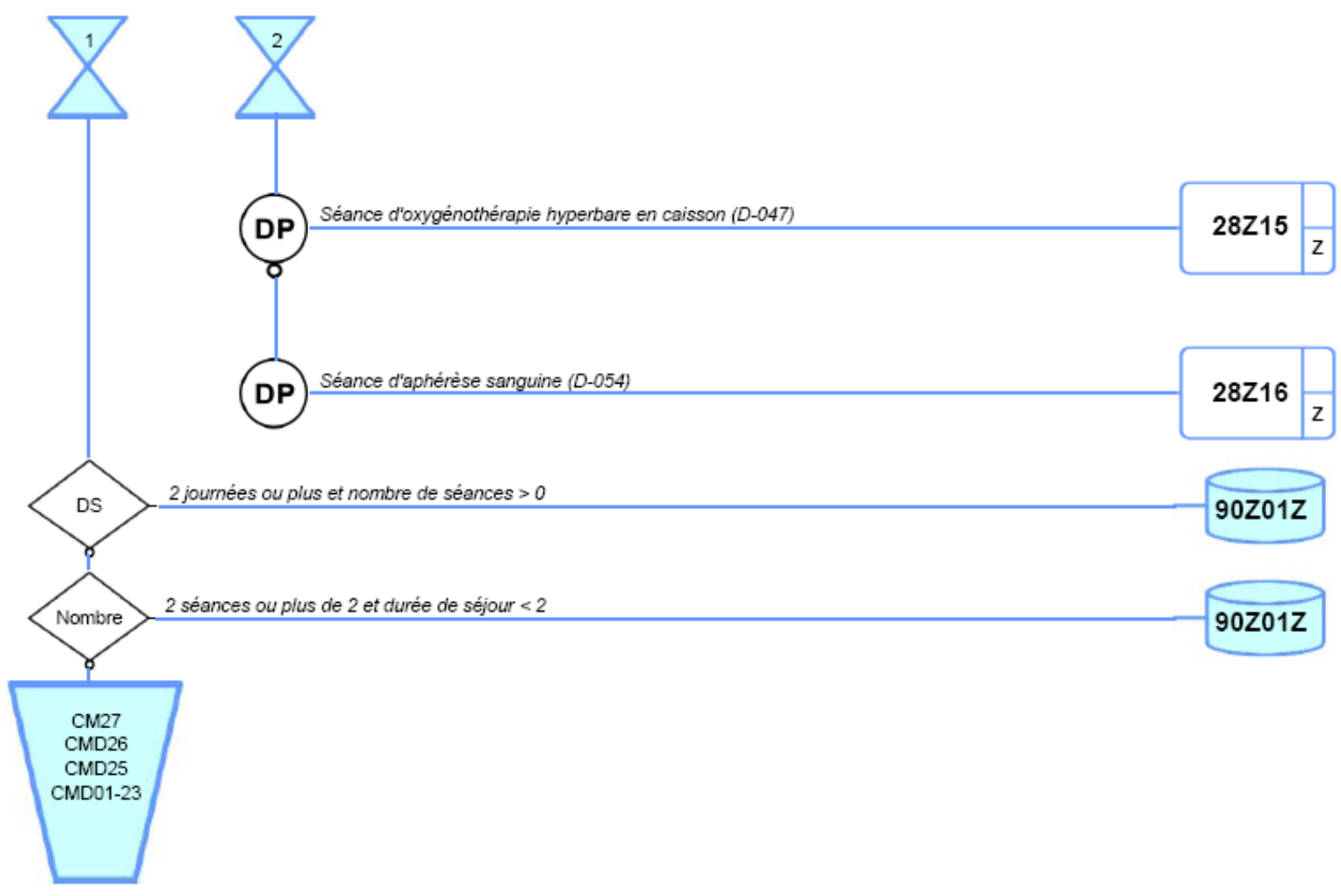

DP: principal diagnosis

A: operating room procedure

DS: length of stay

Source: Ministère de la Santé et des Sports, 2009.

201. Cases are then assigned to one of the remaining MDC. The following figure reports an example of the surgical partitioning of MDC 1, Disease and disorders of the nervous system. 


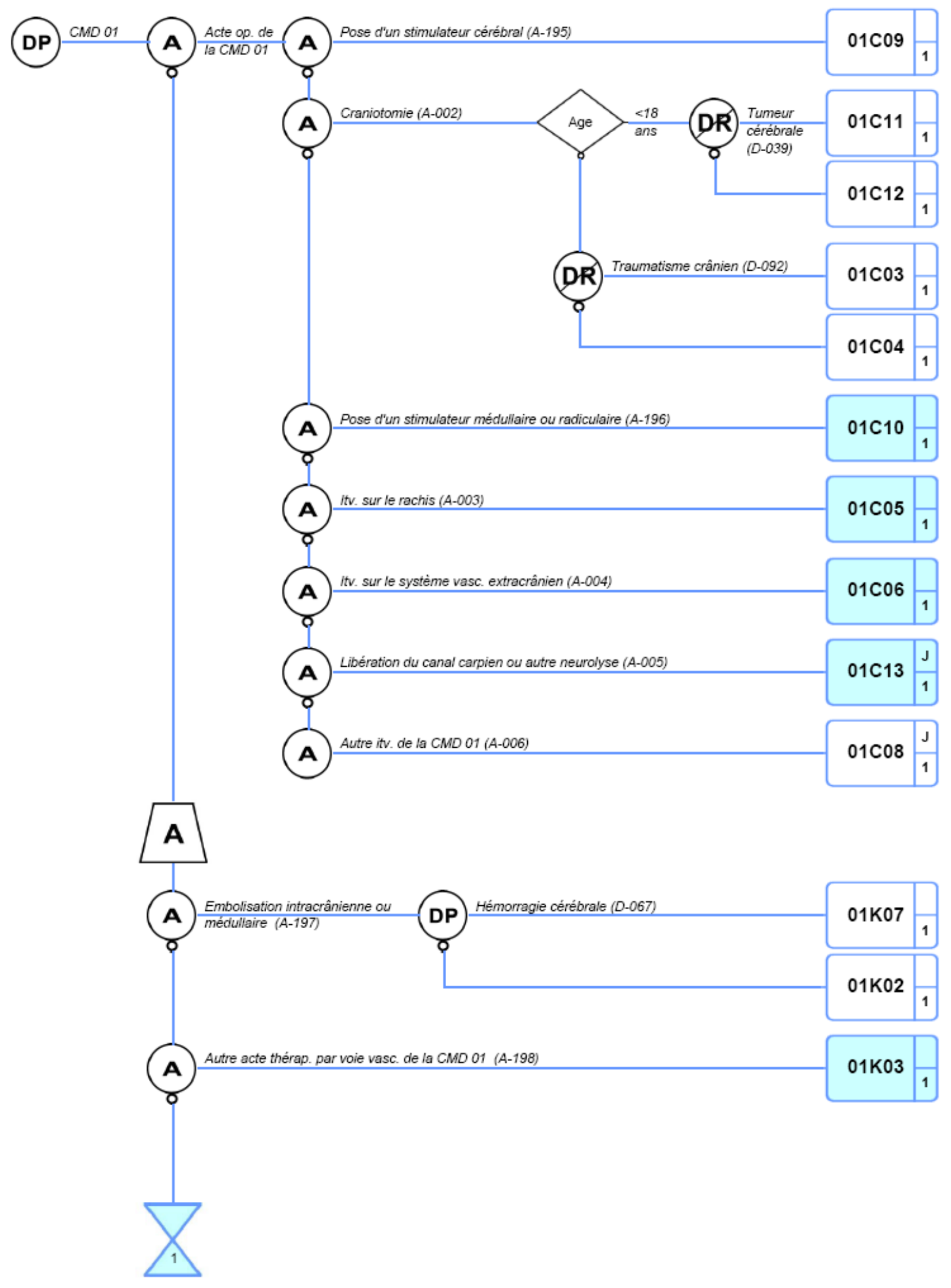




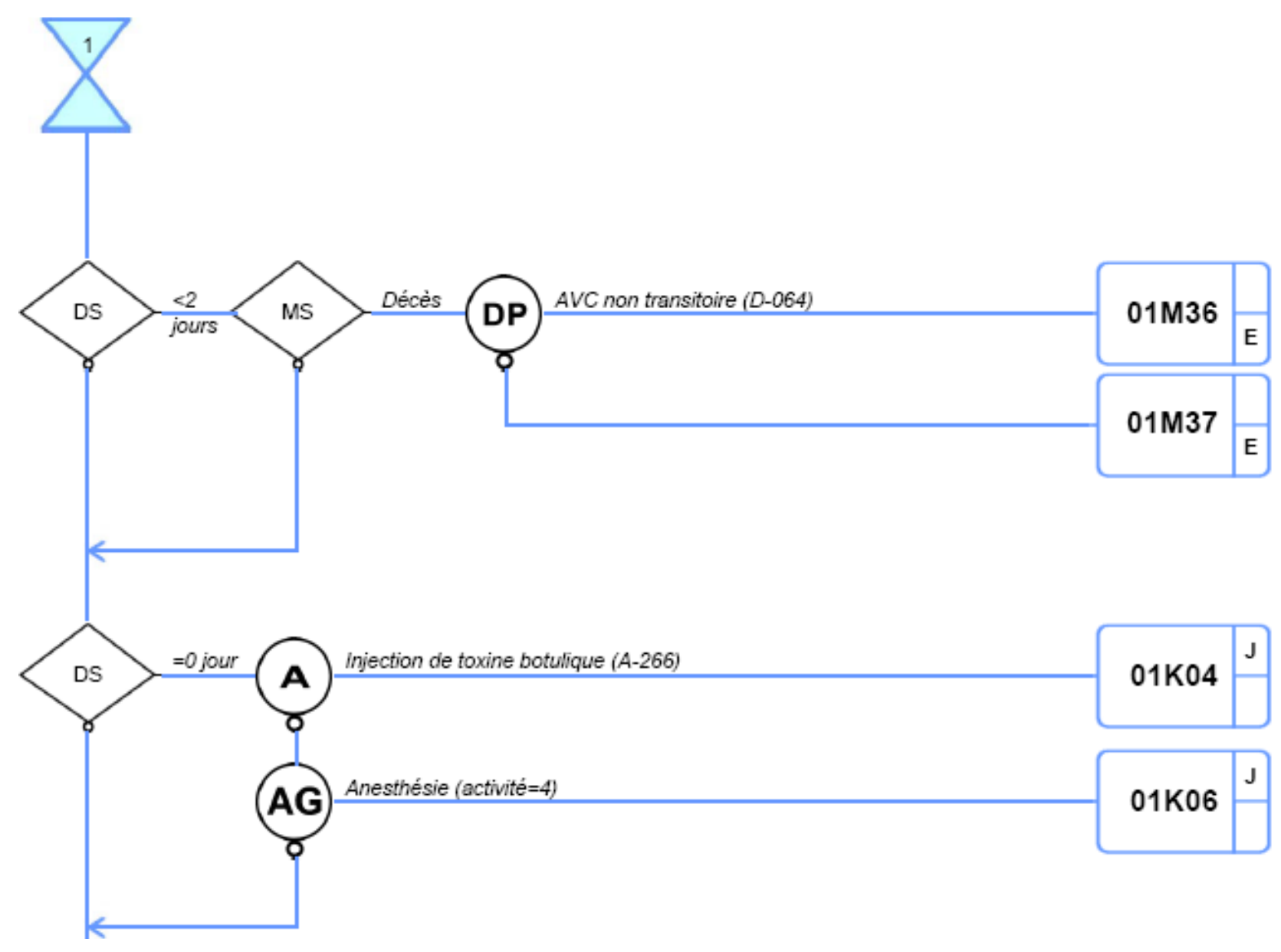

DAS: at least one of the secondary diagnoses

CMA: complication or comorbidity

Source: Ministère de la Santé et des Sports, 2009

\section{Timing and process for the revision of the classification system}

202. The ATIH is responsible for the revision/update of the system. The revision process is not systematic.

\section{Cost-finding approach}

203. Hospital costs per hospitalization are computed through the Étude Nationale de Coûts à Méthodologie Commune (ENCC). The ENCC is an annual survey carried out by the Agence Technique de l'Information sur l'Hospitalisation in a sample of hospitals that uses a top-down cost-finding approach and identifies the hospitalizations (sejours) as cost object (Or et al 2009). The 2006 ENCC data relate to a sample of 41 public hospitals that completed the survey ${ }^{31}$, and refer to $1,373,167$ hospitalizations: 508,114 séances (cases with 0 length of stay); 359,907 day cases (length of stay less than 2 days and not 0); and 505,146 inpatient cases ( $36.8 \%$ of the total).

$31 \quad$ At the beginning, 63 public and 41 private hospitals expressed their interest and willingness to take part in the study. 
204. The main steps of the ENCC are (Bellanger et al 2006; Agence Technique de l'Information sur l'Hospitalisation, 2007):
i. $\quad$ Les principes de découpage analytique de l'ENCC
ii. Les règles d'affectation des charges
iii. La ventilation des fonctions logistiques
iv. La valorisation des séjours

\section{i. Les principes de découpage analytique de l'ENCC}

205. The analytical principle that underlies the rules to allocate expenditures is that of homogeneous sections. This principle consists of subdividing a structure into sections, each section being characterized by a group of resource items used for the same purpose, and by activity that can be measured in physical units named workload units (unités d'oeuvre, UO) ${ }^{32}$. Coherently with the principle of homogeneous sections, hospitals should subdivide their activity into resource areas/cost centers (sections d'analyse, SA). The SA is a group of expenditures relating to a homogeneous activity. It should therefore facilitate the link between clearly identified resources and precisely measured activities.

206. The following is a list of the main SA.

\section{Fonction clinique (SAC)}

Fonction médico-technique (SAMT)

Sections d'analyse mixtes (SAMX)

Fonction logistique médicale (LM)

Fonction logistique et gestion générale (LGG)

Structure (STR)

\section{ii. Les règles d'affectation des charges}

207. The simplified accounting plan identified in the ENCC aims at two main objectives:

- provide hospitals with a common basis for identifying and classifying expenditures and products

- facilitate the assignment of expenditures and products to SA

208. All expenditures should be assigned to the relevant SA that is consuming the resources. Once the assignment process has been completed, expenditures will be regrouped in a limited number of categories identified by the type of cost. These groups, differentiated by type of SA, are reported below.

For SAC, SAMT, and SAMX :

- Personnel médical

- Personnel soignant

- Personnel autre

- Spécialités pharmaceutiques

32

Unite d'oeuvre : unit of measure of the production of a section of analysis. It is a function of the nature of the activity of the section; this means that it is necessary to identify the variable that can better describe the production of the section and the consumption made of that production. 
- Médicaments

- Produits sanguins labiles

- Dispositifs médicaux implantables

- Autres consommables médicaux

- Sous-traitance à caractère médical - imagerie, laboratoires, laboratoires hors nomenclature, hospitalisation à l'extérieur, autre

- Entretien et maintenance du matériel médical

- Amortissement et location du matériel médical

- Honoraires intégrés des praticiens hospitaliers à temps complet

For the logistic sections:

- Personnel médical

- Personnel soignant

- Personnel autre

- Autres dépenses

For all the other sections, a total expenditure figure is computed.

209. The ENCC method foresees, in parallel to the assignment of expenditures to sections, the direct assignment of the following expenditures to cases: drugs; prosthesis; and blood.

iii. La ventilation des fonctions logistiques

210. The objective of this step is firstly to assign the expenditure of the logistic functions (LM, LGG and STR) to the different type of activities using ad hoc allocation keys; then secondly, to assign the LM expenditures on acute care to the hospital sections (SAC, SAMT, and SAMX) ${ }^{33}$.

211. The table below reports the allocation keys by SA that the ENCC approach suggests using. 
DELSA/HEA/WD/HWP(2011)2

\begin{tabular}{|c|c|}
\hline Section & Allocation key \\
\hline Pharmacie & Euro de charges de dépenses médicales gérées par la pharmacie \\
\hline Stérilisation & Mètre cube stérilisé \\
\hline Génie biomédical & Montant d'actif brut médical immobilisé \\
\hline Hygiène hospitalière et vigilances & Euro de charges de dépenses médicales gérées par la pharmacie \\
\hline $\begin{array}{l}\text { Les autres sections de logistique } \\
\text { médicale }\end{array}$ & Euro de charges brutes \\
\hline Restauration & Nombre de repas servis aux patients \\
\hline Blanchisserie & Nombre de kilos de linge \\
\hline $\begin{array}{l}\text { Services administratifs à caractère } \\
\text { général }\end{array}$ & Euro de charges brutes \\
\hline $\begin{array}{l}\text { Services administratifs liés au } \\
\text { personnel }\end{array}$ & Effectifs \\
\hline Accueil et gestion des malades & Nombre de dossiers créés \\
\hline Services hôteliers & $\begin{array}{l}\text { Mètre carré des services de soins et des plateaux médico- } \\
\text { techniques }\end{array}$ \\
\hline Entretien/maintenance & $\begin{array}{l}\text { Mètre carré des services de soins et des plateaux médico- } \\
\text { techniques }\end{array}$ \\
\hline DSIO & Nombre de postes informatiques \\
\hline$\overline{D I M}$ & Nombre de résumés PMSI \\
\hline $\begin{array}{l}\text { Brancardage et transport pédestre } \\
\text { des patients }\end{array}$ & Nombre de courses de brancardage \\
\hline Transport motorisé des patients & Nombre de courses motorisées \\
\hline Structure-immobilier & $\begin{array}{l}\text { Mètre carré des services de soins et des plateaux médico- } \\
\text { techniques }\end{array}$ \\
\hline Structure-financier & Euro de charges brutes \\
\hline
\end{tabular}

iv. La valorisation des séjours

212. For each SAC, SAMT and SAMX section it is necessary to collect:

- the total number of workload units (UO) produced in one year, the so-called «UO administratives»

- the total number of UO consumed by each case

213. For a given section, the unit cost is computed by subdividing the section "total expenditures" by the number of $U O$ administrative produced during a year. The cost per case in the SA is computed by multiplying the unit UO cost by the number of UO consumed during the hospitalisation.

214. The SAC cost driver is the length of stay (in days). The unit per diem cost is computed for each SAC by subdividing the total expenditure by the total number of days. 
215. The list of the cost drivers for the SAMT is reported in the following table.

\begin{tabular}{|l|l|}
\hline \multicolumn{1}{|c|}{ SAMT type } & \multicolumn{1}{c|}{ Cost driver } \\
\hline Urgences & Passage \\
\hline Service médical d'urgence et de réanimation terrestre & $1 / 2$ heure de transport \\
\hline Service médical d'urgence et de réanimation aérien & Minute de transport \\
\hline Laboratoires d'anatomo-pathologie & ICR \\
\hline Laboratoires de biologie médicale & $I C R$ \\
\hline Blocs opératoires & $I C R$ \\
\hline Imagerie & $I C R$ \\
\hline Anesthésiologie & $I C R$ \\
\hline Explorations fonctionnelles & $I C R$ \\
\hline Autres activités médico-techniques & UO selon activité concernée \\
\hline
\end{tabular}

216. The unit cost for each SAMT is computed by subdividing the expenditures by the total number of UO produced.

217. The list of the cost drivers for the SAMX is reported in the following table.

\begin{tabular}{|l|l|}
\hline \multicolumn{1}{|c|}{ SAMX type } & \multicolumn{1}{c|}{ Cost driver } \\
\hline Réanimation & Oméga CCAM ${ }^{34}$ et Journée \\
\hline Radiothérapie & ICR \\
\hline Dialyse & $I C R$ \\
\hline Chirurgie ambulatoire & ICR \\
\hline
\end{tabular}

218. Relative cost index (ICR) represents a work unit based statistic. Computing technical costs on an ICR value is far from simple. The method adopted consists in defining a composite index to assign costs to each type of resource relative to other resources, e.g., doctors, nurses, and equipment. This index is expressed in "points" and contains three components: a medical activity index (IAM), a nursing staff activity index (IAS) and an index for measuring material resource consumption (ICRM).

219. The ICRs were adapted for the CCAM in 2004. Medical bodies provided information about the resources consumed by each procedure in each medical specialty and the National Centre for Hospital Expertise (CNEH) determined the costs of the resources estimated by the medical experts. The CNEH interviewed hospitals to confirm that the information was consistent, and then transferred the assessment to the ATIH.

220. The total cost of a stay is the sum of the daily costs incurred at each clinical cost centre, the directly attributable costs, the costs of the technical cost centres in proportion to the total number of ICRs used and the laundry, catering, infrastructure and structural costs, pro rata for the total acute care length of stay.

221. As an example of the publicly available information, the following table reports the components for which an average cost by product/Groupe Homogène de Malades (GHM) is estimated. Each row of the downloadable Excel format table represents a product/GHM and includes a detailed breakdown of unit average cost by cost element/bucket ${ }^{35}$. The last column to the right reports the average cost by GHM (coût complet).

34 L'oméga CCAM (Classification Commune des Actes Médicaux) is the result of a formula that takes into account the length of stay in reanimation and the relative cost index of the reanimation specific interventions. 
DELSA/HEA/WD/HWP(2011)2

\begin{tabular}{|c|c|c|c|c|c|c|c|c|c|}
\hline GHM V11 & Libellé GHM & $\begin{array}{c}\text { Nombre } \\
\text { de } \\
\text { séjours } \\
\text { ENCC } \\
2008\end{array}$ & $\left|\begin{array}{c}\text { Dépenses } \\
\text { clinique }+ \\
S I+S C+ \\
R E A\end{array}\right|$ & $\begin{array}{l}\text { Dépenses } \\
\text { MT }\end{array}$ & $\begin{array}{c}\text { Dépenses } \\
\text { LGG }\end{array}$ & $\begin{array}{c}\text { Dépenses } \\
L M\end{array}$ & $\begin{array}{c}\text { Charges directes } \\
\text { y compris } \\
\text { honoraires et } \\
\text { rémunération à } \\
\text { l'acte }\end{array}$ & Structure & $\begin{array}{c}\text { Coût } \\
\text { complet }\end{array}$ \\
\hline $01 \mathrm{C} 031$ & Craniotomies pour traumatisme, âge supérieur à 17 ans, niveau 1 & 638 & 1,925 & 1,249 & 895 & 176 & 903 & 168 & 5,316 \\
\hline $01 \mathrm{C032}$ & Craniotomies pour traumatisme, âge supérieur à 17 ans, niveau 2 & 414 & 5,550 & 2,014 & 1,836 & 345 & 2,166 & 377 & 12,288 \\
\hline $01 \mathrm{C033}$ & Craniotomies pour traumatisme, âge supérieur à 17 ans, niveau 3 & 248 & 10,771 & 2,760 & 2,849 & 500 & 2,910 & 569 & 20,358 \\
\hline $01 \mathrm{C034}$ & Craniotomies pour traumatisme, âge supérieur à 17 ans, niveau 4 & 174 & 21,802 & 4,526 & 5,430 & 1,065 & 6,551 & 1,059 & 40,434 \\
\hline total & Craniotomies pour traumatisme, âge supérieur à 17 ans & 1,474 & 6,802 & 2,114 & 2,034 & 385 & 2,286 & 402 & 14,024 \\
\hline $01 C 041$ & $\begin{array}{l}\text { Craniotomies en dehors de tout traumatisme, âge supérieur à } 17 \text { ans, } \\
\text { niveau } 1\end{array}$ & 3,530 & 1,777 & 2,562 & 973 & 321 & 1,280 & 181 & 7,094 \\
\hline $01 \mathrm{C} 042$ & $\begin{array}{l}\text { Craniotomies en dehors de tout traumatisme, âge supérieur à } 17 \text { ans, } \\
\text { niveau } 2\end{array}$ & 1,233 & 4,620 & 2,803 & 1,843 & 465 & 2,176 & 371 & 12,278 \\
\hline $01 \mathrm{C} 043$ & $\begin{array}{l}\text { Craniotomies en dehors de tout traumatisme, âge supérieur à } 17 \text { ans, } \\
\text { niveau } 3\end{array}$ & 633 & 9,122 & 3,612 & 2,944 & 603 & 3,625 & 559 & 20,465 \\
\hline $01 \mathrm{C} 044$ & $\begin{array}{l}\text { Craniotomies en dehors de tout traumatisme, âge supérieur à } 17 \text { ans, } \\
\text { niveau } 4\end{array}$ & 571 & 17,139 & 5,414 & 4,940 & 984 & 6,226 & 1,013 & 35,716 \\
\hline total & Craniotomies en dehors de tout traumatisme, âge supérieur à 17 ans & 5,967 & 4,527 & 2,978 & 1,720 & 441 & 2,159 & 336 & 12,160 \\
\hline $01 C 051$ & $\begin{array}{l}\text { Interventions sur le rachis et la moelle pour des affections } \\
\text { neurologiques, niveau } 1\end{array}$ & 1,513 & 1,392 & 1,722 & 861 & 303 & 1,429 & 155 & 5,861 \\
\hline $01 \mathrm{C} 052$ & $\begin{array}{l}\text { Interventions sur le rachis et la moelle pour des affections } \\
\text { neurologiques, niveau } 2\end{array}$ & 636 & 2,808 & 2,295 & 1,538 & 387 & 1,738 & 285 & 9,052 \\
\hline $01 C 053$ & $\begin{array}{l}\text { Interventions sur le rachis et la moelle pour des affections } \\
\text { neurologiques, niveau } 3\end{array}$ & 188 & 7,750 & 2,996 & 3,025 & 612 & 3,172 & 605 & 18,159 \\
\hline $01 C 054$ & $\begin{array}{l}\text { Interventions sur le rachis et la moelle pour des affections } \\
\text { neurologiques, niveau } 4\end{array}$ & 103 & 15,410 & 4,345 & 3,770 & 889 & 4,888 & 851 & 30,153 \\
\hline total & $\begin{array}{l}\text { Interventions sur le rachis et la moelle pour des affections } \\
\text { neurologiques }\end{array}$ & 2,440 & 2,921 & 2,096 & 1,342 & 377 & 1,808 & 257 & 8,801 \\
\hline \begin{tabular}{|l|}
$01 \mathrm{C} 061$ \\
\end{tabular} & Interventions sur le système vasculaire précérébral, niveau 1 & 1,437 & 1,387 & 1,867 & 654 & 257 & 1,068 & 133 & 5,366 \\
\hline $01 \mathrm{C062}$ & Interventions sur le système vasculaire précérébral, niveau 2 & 576 & 2,327 & 2,192 & 1,017 & 303 & 1,366 & 208 & 7,414 \\
\hline $01 \mathrm{C063}$ & Interventions sur le système vasculaire précérébral, niveau 3 & 117 & 4,622 & 2,725 & 1,890 & 427 & 2,171 & 389 & 12,224 \\
\hline $01 \mathrm{C064}$ & Interventions sur le système vasculaire précérébral, niveau 4 & 26 & 8,664 & 5,107 & 3,543 & 801 & 4,069 & 728 & 22,913 \\
\hline
\end{tabular}




\section{Germany $^{36}$}

\section{Diagnoses classification and coding}

222. The German Institute of Medical Documentation and Information (DMDI) issues the German version on ICD-10 (ICD-10-GM) on behalf of the Federal Ministry of Health (BMG). This classification is revised annually.

\section{Procedure classification and coding}

223. DIMDI issues the "Operationen-schlussel" (Classification of Surgical and Medical Procedures, OPS) on behalf of the BMG. Originally, OPS included only surgical procedures for statistics in hospitals and for the definition of case based lump sums and procedural rates in the billing of in-patient benefits. Since the introduction of the German DRG, all expense-related medical procedures in hospitals are coded.

224. The structure of the classification is reported below. The classification contains approximately 24000 codes (German Institute for Medical Documentation and Information 2008).

\begin{tabular}{|c|c|l|}
\hline Chapter & Code range & \multicolumn{1}{|c|}{ Title } \\
\hline 1 & $1-101-99$ & Diagnostic procedures (Diagnostische Massnahmen) \\
\hline 3 & $3-003-99$ & Diagnostic imaging (Bildgebende Diagnostik) \\
\hline 5 & $5-015-99$ & Operations (Operationen) \\
\hline 6 & $6-006-00$ & Drugs (Medikamente) \\
\hline 8 & $8-018-99$ & $\begin{array}{l}\text { Non-surgical therapeutic procedures (Nichtoperative Therapeutische } \\
\text { Massnahmen) }\end{array}$ \\
\hline 9 & $9-26$ 9-99 & $\begin{array}{l}\text { Miscellaneous diagnostic and therapeutic procedures (Erganzende } \\
\text { Massnahmen) }\end{array}$ \\
\hline
\end{tabular}

36 The majority of the publicly available information is in German. Thus the description of the coding schemata contained in this chapter is poor. 
OPERATIONS (5-01...5-99)

\begin{tabular}{|c|l|}
\hline $5-01-5-05$ & Operationen am Nervensystem \\
\hline $5-06-5-07$ & Operationen an endokrinen Drüsen \\
\hline $5-08-5-16$ & Operationen an den Augen \\
\hline $5-18-5-20$ & Operationen an den Ohren \\
\hline $5-21-5-22$ & Operationen an Nase und Nasennebenhöhlen \\
\hline $5-23-5-28$ & Operationen an Mundhöhle und Gesicht \\
\hline $5-29-5-31$ & Operationen an Pharynx, Larynx und Trachea \\
\hline $5-32-5-34$ & Operationen an Lunge und Bronchus \\
\hline $5-35-5-37$ & Operationen am Herzen \\
\hline $5-38-5-39$ & Operationen an den Blutgefäßen \\
\hline $5-40-5-41$ & Operationen am hämatopoetischen und Lymphgefäßsystem \\
\hline $5-42-5-54$ & Operationen am Verdauungstrakt \\
\hline $5-55-5-59$ & Operationen an den Harnorganen \\
\hline $5-60-5-64$ & Operationen an den männlichen Geschlechtsorganen \\
\hline $5-65-5-71$ & Operationen an den weiblichen Geschlechtsorganen \\
\hline $5-72-5-75$ & Geburtshilfliche Operationen \\
\hline $5-76-5-77$ & Operationen an Kiefer- und Gesichtsschädelknochen \\
\hline $5-78-5-86$ & Operationen an den Bewegungsorganen \\
\hline $5-87-5-88$ & Operationen an der Mamma \\
\hline $5-89-5-92$ & Operationen an Haut und Unterhaut \\
\hline $5-93-5-99$ & Zusatzinformationen zu Operationen \\
\hline
\end{tabular}


225. Within the category that relates to the Operation on cardiovascular system, the following table contains the codes that describe the implantation of a cardiac pacemaker and defibrillator.

\begin{tabular}{|c|c|}
\hline $5-377$ & Implantation eines Herzschrittmachers und Defibrillators \\
\hline $5-377.0$ & Schrittmacher, n.n.bez. \\
\hline $5-377.1$ & Schrittmacher, Einkammersystem \\
\hline $5-377.2$ & Schrittmacher, Zweikammersystem, mit einer Schrittmachersonde \\
\hline $5-377.3$ & Schrittmacher, Zweikammersystem, mit zwei Schrittmachersonden \\
\hline $5-377.30$ & Ohne antitachykarde Stimulation \\
\hline $5-377.31$ & Mit antitachykarder Stimulation \\
\hline $5-377.4$ & Schrittmacher, Dreikammersystem (biventrikuläre Stimulation) \\
\hline $5-377.5$ & Defibrillator mit Einkammer-Stimulation \\
\hline $5-377.6$ & Defibrillator mit Zweikammer-Stimulation \\
\hline $5-377.7$ & Defibrillator mit biventrikulärer Stimulation \\
\hline $5-377.8$ & Ereignis-Rekorder \\
\hline $5-377.9$ & Synchronisationssystem, linksventrikuläres Pacing, Zweikammersystem \\
\hline 5-377.a & Synchronisationssystem, linksventrikuläres Pacing, Dreikammersystem \\
\hline $5-377 . b$ & System zur nichtinvasiven Überwachung von Abstoßungsreaktionen nach Herztransplantation \\
\hline 5-377.c & Isolierte Sondenimplantation, offen chirurgisch \\
\hline $5-377 . c 0$ & Epikardial, linksventrikulär \\
\hline $5-377 . c 1$ & Epikardial, rechtsventrikulär \\
\hline $5-377 . c 2$ & Epithorakal \\
\hline $5-377 . d$ & $\begin{array}{l}\text { Verwendung von Herzschrittmachern oder Defibrillatoren mit automatischem } \\
\text { Fernüberwachungssystem }\end{array}$ \\
\hline 5-377.f & Verwendung von Defibrillatoren mit zusätzlicher Messfunktion \\
\hline 5-377.f0 & Mit zusätzlicher Messfunktion für das Lungenwasser \\
\hline 5-377.f1 & Mit zusätzlichem Drucksensor zur nichtinvasiven Messung des rechtsventrikulären Druckes \\
\hline 5-377.x & Sonstige \\
\hline 5-377.y & N.n.bez. \\
\hline
\end{tabular}




\section{Timing and process for the revision of the coding schemata}

226. The $\mathrm{DMDI}^{37}$ is responsible for the updating of both the diagnosis and the procedure classification systems. The updates are publicly available on their website.

\section{Classification system}

227. The German DRG system (G-DRG) measures inpatient and day care acute hospital services (German Institute for the Hospital Remuneration System 2008).

228. The following table reports the distribution of the 1151 groups valid for 2011 by Major Diagnostic Category (MDC).

37 DIMDI was founded in 1969 and is an institute within the scope of the German Federal Minsitry of Health. DIMDI's main task is to provide information in all fields of the life sciences to the interested public. DIMDI has 118 employees in three different departments and associated working groups: 43 in the "Medical information" department; 51 in the "Data Processing and Information Systems" department and 24 in the Administration Department. 


\begin{tabular}{|c|c|c|c|}
\hline$M D C$ & Description & $\begin{array}{l}\text { Number of } \\
\text { groups }\end{array}$ & $\begin{array}{c}\text { Relative } \\
\text { frequency } \\
(\%)\end{array}$ \\
\hline Pre & & 60 & 5.2 \\
\hline 01 & Krankheiten und Störungen des Nervensystems & 104 & 9.0 \\
\hline 02 & Krankheiten und Störungen des Auges & 33 & 2.9 \\
\hline 03 & $\begin{array}{l}\text { Krankheiten und Störungen des Ohres, der Nase, des Mundes und } \\
\text { des Halses }\end{array}$ & 54 & 4.7 \\
\hline 04 & Krankheiten und Störungen der Atmungsorgane & 61 & 5.3 \\
\hline 05 & Krankheiten und Störungen des Kreislaufsystems & 143 & 12.4 \\
\hline 06 & Krankheiten und Störungen der Verdauungsorgane & 80 & 7.0 \\
\hline 07 & Krankheiten und Störungen an hepatobiliärem System und Pankreas & 38 & 3.3 \\
\hline 08 & $\begin{array}{l}\text { Krankheiten und Störungen an Muskel-Skelett-System und } \\
\text { Bindegewebe }\end{array}$ & 133 & 11.6 \\
\hline 09 & Krankheiten und Störungen an Haut, Unterhaut und Mamma & 52 & 4.5 \\
\hline 10 & Endokrine, Ernährungs- und Stoffwechselkrankheiten & 36 & 3.1 \\
\hline 11 & Krankheiten und Störungen der Harnorgane & 62 & 5.4 \\
\hline 12 & Krankheiten und Störungen der männlichen Geschlechtsorgane & 27 & 2.3 \\
\hline 13 & Krankheiten und Störungen der weiblichen Geschlechtsorgane & 37 & 3.2 \\
\hline 14 & Schwangerschaft, Geburt und Wochenbett & 29 & 2.5 \\
\hline 15 & Neugeborene & 43 & 3.7 \\
\hline 16 & $\begin{array}{l}\text { Krankheiten des Blutes, der blutbildenden Organe und des } \\
\text { Immunsystems }\end{array}$ & 16 & 1.4 \\
\hline 17 & Hämatologische und solide Neubildungen & 51 & 4.4 \\
\hline $18 \mathrm{~A}$ & $H I V$ & 7 & 0.6 \\
\hline $18 \mathrm{~B}$ & Infektiöse und parasitäre Krankheiten & 21 & 1.8 \\
\hline 19 & Psychische Krankheiten und Störungen & 7 & 0.6 \\
\hline 20 & $\begin{array}{l}\text { Alkohol- und Drogengebrauch und alkohol- und drogeninduzierte } \\
\text { psychische Störungen }\end{array}$ & 7 & 0.6 \\
\hline $21 \mathrm{~A}$ & Polytrauma & 10 & 0.9 \\
\hline $21 \mathrm{~B}$ & $\begin{array}{l}\text { Verletzungen, Vergiftungen und toxische Wirkungen von Drogen und } \\
\text { Medikamenten }\end{array}$ & 15 & 1.3 \\
\hline 22 & Verbrennungen & 8 & 0.7 \\
\hline 23 & $\begin{array}{l}\text { Faktoren, die den Gesundheitszustand beeinflussen, und andere } \\
\text { Inanspruchnahme des Gesundheitswesens }\end{array}$ & 8 & 0.7 \\
\hline Other & Fehler-DRGs und sonstige DRGs & 9 & 0.8 \\
\hline & Total & 1151 & 100.0 \\
\hline
\end{tabular}

229. The G-DRG numbering follows the following 4-digit structure:

- $\quad$ First character: MDC

- $\quad$ Second and third: DRG number

- $\quad$ Fourth: severity/complexity level (Z, not differentiated)

230. For example, B75A stands for the DRG "febrile seizures, age of patient $<1$ year". B refers to the major diagnosis category, in this case it is the major diagnosis category 01 "Diseases and disorders of the nervous system", 75 is the number of the DRG. The last letter, in this case "A" stands for the economic complexity of the diagnosis. "A" means a very complex and therefore expensive treatment, "I" means least complexity. "Z" means no further stratification applied. 
231. 256 G-DRGs are not differentiated according to severity/complexity. For the remaining groups, there could be up to nine levels (from 1 to 9) of severity/complexity based mainly on age and complications and/or comorbidities (CC). As an example, the table below reports the nine groups that define the Other type of Acute Leukemia (Andere akute Leukämie), differentiated on the basis of age, major CC (äußerst schweren CC), procedures performed (chemotherapy, dialysis), and other diagnoses (sepsis, agranulocitosis).

\begin{tabular}{|c|c|}
\hline $\begin{array}{c}\text { DRG } \\
\text { number }\end{array}$ & Description \\
\hline R63A & Andere akute Leukämie mit hochkomplexer Chemotherapie \\
\hline R63B & $\begin{array}{l}\text { Andere akute Leukämie mit intensiver Chemotherapie, mit Dialyse oder Sepsis oder mit } \\
\text { Agranulozytose oder Portimplantation, Alter }<6 \text { Jahre oder mit äußerst schweren CC }\end{array}$ \\
\hline $\mathrm{R} 63 \mathrm{C}$ & $\begin{array}{l}\text { Andere akute Leukämie mit intensiver Chemotherapie, mit Dialyse oder Sepsis oder mit } \\
\text { Agranulozytose oder Portimplantation, Alter > } 5 \text { Jahre, ohne äußerst schwere CC }\end{array}$ \\
\hline R63D & $\begin{array}{l}\text { Andere akute Leukämie mit mäßig komplexer Chemotherapie, mit Dialyse oder Sepsis oder } \\
\text { mit Agranulozytose oder Portimplantation oder mit lokaler Chemotherapie, mit Dialyse } \\
\text { od. Sepsis od. mit Agranulozytose od. Portimplantation oder mit äußerst schweren CC }\end{array}$ \\
\hline R63E & $\begin{array}{l}\text { Andere akute Leukämie mit intensiver oder mäßig komplexer Chemotherapie, ohne } \\
\text { Dialyse, ohne Sepsis, ohne Agranulozytose, ohne Portimplantation, mit äßßerst schweren } \\
\text { CC }\end{array}$ \\
\hline R63F & $\begin{array}{l}\text { Andere akute Leukämie ohne Chemotherapie, mit Dialyse oder Sepsis oder mit } \\
\text { Agranulozytose oder Portimplantation oder mit äußerst schweren CC }\end{array}$ \\
\hline R63G & $\begin{array}{l}\text { Andere akute Leukämie mit intensiver Chemotherapie, ohne Dialyse, ohne Sepsis, ohne } \\
\text { Agranulozytose, ohne Portimplantation, ohne äußerst schwere CC }\end{array}$ \\
\hline $\mathrm{R} 63 \mathrm{H}$ & $\begin{array}{l}\text { Andere akute Leukämie mit mäßig komplexer Chemotherapie, ohne Dialyse, ohne Sepsis, } \\
\text { ohne Agranulozytose, ohne Portimplantation, ohne äußerst schwere CC }\end{array}$ \\
\hline R63I & $\begin{array}{l}\text { Andere akute Leukämie mit lokaler Chemotherapie oder ohne Chemotherapie, ohne } \\
\text { Dialyse, ohne Sepsis, ohne Agranulozytose, ohne Portimplantation, ohne äußerst schwere } \\
\text { CC }\end{array}$ \\
\hline
\end{tabular}

\section{Timing and process for the revision of the classification system}

232. The Institute for the Hospital Remuneration System is responsible for the annual update of the GDRG system.

\section{Cost-finding approach}

233. The InEK provides the organizational structure to maintain and further develop the German DRG reimbursement system and, among its other duties, is responsible for calculating cost weights. For deriving DRG classifications, InEK relies on retrospective cost and claims data collected in German hospitals and case-related claims data annually. The case related cost data are calculated using a sampling of data from hospitals participating in a voluntary data sharing programme. As of February 2006, a total of 284 hospitals have agreed to participate in the data sharing programme and thus serve as the calculating base 
for cost weights in the G-DRG system. This corresponds to roughly $16 \%$ of the approximately 1,800 hospitals using DRGs in Germany. They have to calculate costs per case according to the full cost method using actual costs derived from the hospitals' audited annual accounts.

234. Psychiatry, psychosomatic medicine, and psychotherapy services are excluded from remuneration. In addition, when calculating costs per case the following cost elements are excluded:

- extraordinary expenses and expenses relating to other periods

- capital costs (exception: depreciation of fixed assets)

- core business expenses, insofar as these are not related to general inpatient services (e.g. costs of scientific research/teaching and costs of outpatient services are excluded)

- taxes, charges, insurance for operational sections of the hospital that do not provide general inpatient services, as well as tax on profits

- specific and long-term allowance for bad debts

- interest payable, insofar as this is not related to capital loans

- imputed costs (e.g. hospital building)

235. The process of calculating costs per case is based on a modular approach. It entails arranging each set of case-related data in the calculation results according to cost-element groups and cost-centre groups. Aggregating costs across cost element groups and cost centre groups makes it possible to pinpoint the costs per patient or per patient group (DRGs) in a concise manner.

236. The process of calculating raw costs per case is based on a modular approach which entails arranging each set of case-related data in the calculation results according to cost element groups and cost centre groups. Aggregating costs across cost element groups and cost centre groups makes it possible to show the costs per patient or per patient group (DRGs) in a concise manner.

237. After cost centre accounting has been completed, the cost items are separated into the following cost element groups:

- group 1: Labour costs of the clinical staff

- group 2: Labour costs of the nursing staff

- group 3: Labour costs of the administrative and technical staff

- group 4a: Drug costs

- group 4b: Drug costs (individual costs/actual consumption)

- group 5: Costs of implants and grafts

- group 6a: Material costs (without drugs, implants or grafts)

- group 6b: Material costs (individual costs/actual consumption; without drugs, implants or grafts)

- group 7: Medical infrastructure costs

- group 8: Non-medical infrastructure costs

238. To ensure the comparability of the data sets from different hospitals, the cost centres in each set of case-related data are aggregated across cost centre groups:

Hospital units with beds:

- group 1: Standard care unit

- group 2: Intensive care unit

- group 3: Dialysis unit 
Diagnostic and treatment areas:

- group 4: Operating rooms

- group 5: Anaesthesia

- group 6: Maternity room

- group 7: Cardiac diagnostics/therapy

- group 8: Endoscopic diagnostics/therapy

- group 9: Radiology

- group 10: Laboratories

- group 11: Other diagnostic and therapeutic areas

- group 12: Central cost centre ${ }^{38}$

\section{Cost element accounting}

239. Direct costs for cost-intensive drugs, implants, and other material goods are matched with the cost centre where they occurred or the cost unit for whose production they were incurred. The Calculation Manual lists individual products for which direct cost allocation is mandatory according to the actual consumption. If this is not possible, then allocation can be performed on the basis of hospital-specific clinical allocation model. Indirect costs are apportioned across the individual treatment cases via cost centre accordingly and, subsequently, using cost rates in the context of the cost unit accounting.

\section{Cost centre accounting}

240. Cost centres are categorized as direct (final), indirect (intermediate), mixed (DRG and non-DRG related services), and non-DRG. The latter are excluded from the calculations. For the mixed cost centres, the non-DRG costs are excluded on the basis of the percentage they comprise of the total number of services performed at that cost centre (possibly weighted by value). The indirect cost centres are assigned to final cost centres according to allocation rates/keys. The final cost centres are assigned to cases on the basis of allocation bases cost-centre specific set by the Manual.

241. As an example of the publicly available information, the following table reports the variables for which an average cost by product/GHM is estimated. Each row of the table represents a product/GHM and includes a detailed breakdown of unit average cost by cost element/bucket.

242. The column headings are the following:

1) German DRG number

2) surgical $(\mathrm{O})$ versus medical $(\mathrm{M})$ partitioning

3) German DRG description

4) Relative weight

6) Average length of stay (in days)

7) lower trim point

8) per diem relative weight within lower trim point

9) upper trim point

10) per diem relative weight above upper trim point

38 Only non-medical infrastructure costs from cost element group 8 may be assigned to the central cost centre. The central cost centre is thus irrelevant for all of the other cost element groups. 
DELSA/HEA/WD/HWP(2011)2

\begin{tabular}{|c|c|c|c|c|c|c|c|c|c|}
\hline \multirow[b]{2}{*}{ DRG } & \multirow[b]{2}{*}{$\begin{array}{c}\text { Parti- } \\
\text { tion }\end{array}$} & \multirow[b]{2}{*}{ Bezeichnung } & \multirow[b]{2}{*}{$\begin{array}{l}\text { Bewertungsrelation bei } \\
\text { Hauptabteilung }\end{array}$} & \multirow{2}{*}{$\begin{array}{l}\text { Bewertungsrelation } \\
\text { bei Hauptabteilung und } \\
\text { Beleghebamme }\end{array}$} & \multirow{2}{*}{$\begin{array}{l}\text { Mittlere } \\
\text { Verweil- } \\
\text { dauer }^{1)} \\
\end{array}$} & \multicolumn{2}{|c|}{ Untere Grenzverweildauer } & \multicolumn{2}{|c|}{ Obere Grenzverweildauer } \\
\hline & & & & & & $\begin{array}{l}\text { Erster Tag mit } \\
\text { Abschlag 2), 5) }\end{array}$ & $\begin{array}{l}\text { Bewertungs- } \\
\text { relation/Tag }\end{array}$ & $\begin{array}{c}\text { Erster Tag zus. } \\
\left.\text { (ntgelt }{ }^{3,5}, 5\right)\end{array}$ & $\begin{array}{l}\text { Bewertungs- } \\
\text { relation/Tag }\end{array}$ \\
\hline 1 & 2 & 3 & 4 & 5 & 6 & 7 & 8 & 9 & 10 \\
\hline $\mathrm{A} 01 \mathrm{~A}$ & $\mathrm{O}$ & Lebertransplantation mit Beatmung > 179 Stunden & 31.636 & & 58.0 & 18 & 1.384 & 76 & 0.540 \\
\hline A01B & 0 & $\begin{array}{l}\text { Lebertransplantation mit Beatmung }>59 \text { und }<180 \text { Stunden } \\
\text { oder mit Transplantatabstoßung oder mit kombinierter } \\
\text { Nierentransplantation }\end{array}$ & 15.545 & & 34.7 & 11 & 1.030 & 53 & 0.360 \\
\hline A01C & 0 & $\begin{array}{l}\text { Lebertransplantation ohne Beatmung > } 59 \text { Stunden, ohne } \\
\text { Transplantatabstoßung, ohne kombinierte Nierentransplantation }\end{array}$ & 11.898 & & 26.9 & 8 & 1.034 & 45 & 0.345 \\
\hline $\mathrm{A} 02 \mathrm{Z}$ & $\mathrm{O}$ & Transplantation von Niere und Pankreas & 10.197 & & 26.8 & 8 & 0.821 & 45 & 0.287 \\
\hline A03A & $\mathrm{O}$ & Lungentransplantation mit Beatmung > 179 Stunden & 45.397 & & 72.5 & 23 & 1.629 & 91 & 0.539 \\
\hline A03B & $\mathrm{O}$ & Lungentransplantation ohne Beatmung > 179 Stunden & 14.008 & & 27.0 & 8 & 1.209 & 45 & 0.403 \\
\hline
\end{tabular}




\section{Norway}

\section{Diagnoses classification and coding}

ICD-10 is in use to code diagnoses as from 1999.

\section{Procedures classification and coding}

243. In 1989 the Nordic medico-statistical committee (NOMESCO) decided to start a project on the definition of a common Nordic classification of surgical procedures. For this purpose, a special working group was established, who proposed the principles of classification and the structure of codes at the beginning of 1991. For each chapter, the working group appointed one or two responsible editors, who prepared the final proposals in cooperation with the national groups. The final classification proposal was translated into English and first published in 1996 as NOMESCO Classification of surgical procedures (NCSP). The English version is the common reference version for the national versions ${ }^{39}$.

244. The NCSP consists of fifteen main chapters (A-H, J-N, P-Q) of surgical procedures arranged according to functional-anatomic body system, four subsidiary chapters $(T, U, X, Y)$ containing therapeutic and investigative procedures associated with surgery and one supplementary chapter $(\mathrm{Z})$. The procedure codes of the main and subsidiary chapters A-Y are basic procedure codes, each assigned as a unique identifier to a uniquely defined procedure. The basic procedure codes include and represent all accepted surgical procedures. The supplementary codes of chapter $\mathrm{Z}$ serve as general procedure qualifiers, providing additional information to the basic procedure codes. They are always appended to basic procedure codes, and may never be used alone.

245. The table below reports the description of the structure of the common classification by anatomical chapter and anatomical area. This common classification contains 7436 codes. 


\begin{tabular}{|c|l|}
\hline $\begin{array}{c}\text { Anatomical } \\
\text { chapter }\end{array}$ & \multicolumn{1}{c|}{ Description } \\
\hline A & Nervous system \\
\hline B & Endocrine system \\
\hline C & Eye and adjacent structures \\
\hline D & Ear, nose and larynx \\
\hline E & Teeth, jaws, mouth and pharynx \\
\hline F & Heart and major thoracic vessels \\
\hline G & Chest wall, pleura, mediastinum, diaphragm, trachea, bronchus and lung \\
\hline H & Mammary gland \\
\hline J & Digestive system and spleen \\
\hline K & Urinary system, male genital organs and retroperitoneal space \\
\hline L & Female genital organs \\
\hline M & Obstetric procedures \\
\hline N & Musculoskeletal system \\
\hline P & Peripheral vessels and lymphatic system \\
\hline Q & Skin \\
\hline T & Minor surgical procedures \\
\hline U & Transluminal endoscopy \\
\hline X & Investigative procedures connected with surgery \\
\hline Y & Procurement of organs or tissue for transplantation \\
\hline Z & General qualifiers pertaining to all other chapters \\
\hline
\end{tabular}

246. The NCSP codes consist of three alphabetic characters (positions 1-3 of the code) and two numeric characters (positions 4-5 of the code). All upper-case characters of the English alphabet are permitted as alphabetic characters, except I and $\mathrm{O}$. The procedure codes are independent of surgical specialty. Diagnostic information is excluded from procedure codes as a matter of principle, except in procedures that are unique to the diagnosis, and where the diagnostic information is necessary to achieve a concise procedure designation. The basic procedure codes will be found at only one place in the classification. The way in which a procedure is related to the functional-anatomical axis determines the position of the code within the classification. In the case of exclusions cross-references to the appropriate codes, code groups or chapters will generally be given.

247. In the main chapters, the codes are composed as follows:

- The first level (position 1) of the code denotes the chapter, representing in the fifteen main chapters the functional-anatomical body system group

- The second level (position 2) denotes the functional-anatomical region within the body system in question

- The third level (position 3) denotes the general method of the procedure (procedure group)

248. The numeric characters of the code, (positions 4 and 5), identify the specific procedure within the procedure group, including surgical technique and precise anatomical location.

249. With this structure, the sequence of character positions within the code has a uniform significance throughout the fifteen main chapters of the classification. 
250. In the subordinate chapters, the body system, corresponding to a main chapter, and body region, corresponding to a main chapter body region group, are denoted by positions 2 and 3 of the code, e.g.: UD - Transluminal endoscopy of ear, nose and larynx corresponding to chapter D - Ear, nose and larynx, and UDQ - Laryngoscopy corresponding to DQ - Larynx. In these chapters positions 4-5 are used to characterise method and technique (procedure) in a manner suitable to the contents of the chapter. The supplementary codes of chapter $\mathrm{Z}$ are general qualifiers, applicable in principle to all main and subordinate chapters. The basic procedure codes are not changed in definition or code designation by the addition of one or more supplementary codes.

251. The character $Z$ in position 1 of the code denotes the chapter as in all other chapters. Characters $\mathrm{X}, \mathrm{Z}$ and $\mathrm{S}$ in position 2 of the code denote unspecified region. The codes are available to characterize procedures of all other chapters. In case a group of codes is specific to a main or subsidiary chapter, the second character identifies the corresponding chapter.

252. In all chapters except chapter $\mathrm{Z}$, the use of certain characters in certain positions of the code carries particular significance in the following manner:

- $\mathrm{X}$ in position 2 denotes unspecified region within the body system in question.

- $\mathrm{W}$ in position 2 denotes reoperations, without specification of region within the body system in question.

- $\mathrm{W}$ in position 3 denotes possible procedure groups not presently found in the classification ("Other procedure" groups).

- 9 in position 4 represents possible "other procedures" in the same manner as $\mathrm{W}$ in position 3 represents "other procedure groups".

253. In the main chapters relating to the major body cavities -that is $G$ (Chest wall, pleura, mediastinum, diaphragm, trachea, bronchus and lung), J (Digestive system and spleen), K (Urinary system, male genital organs and retroperitoneal space), L (Female genital organs) and M (Obstetric procedures) the position 5 numeric character describes the procedure approach in the following manner:

- 0,3 or 6 denotes an Open or otherwise conventional approach (including blind percutaneous approach)

- 1, 4 or 7 denotes an Endoscopic approach through incision or stab (including percutaneous, transvaginal)

- 2,5 or 8 denotes a Transluminal endoscopic approach (through natural or artificial body orifice).

254. In chapter $\mathrm{F}$ (Heart and major thoracic vessels), the same applies, with the exception that numeric characters 2, 5 and 8 are used for percutaneous transluminal procedures, with or without endoscopy.

255. In Chapter B (Endocrine system), where transluminal endoscopy is not an option, the position 5 numerals 1, 4 and 7 are reserved for percutaneous endoscopic procedures in the same manner. These are found only in group BC (Adrenal gland). Position 5 numerals $0,2,3,5,6$ and 8 all denote a conventional approach as described above.

256. In chapters $\mathrm{F}, \mathrm{G}, \mathrm{J}, \mathrm{K}, \mathrm{L}$ and $\mathrm{M}$, the same position 5 numeric character is used to denote the approach for "other" procedures with the position 4 numeric character 9. In chapters or procedure groups 
where this use of position 5 to describe the approach does not apply, "other" procedures are described by numeric characters 99 in position 4-5.

257. In chapter $U$ (Transluminal endoscopy), and in the anatomical groups of chapters $\mathrm{T}$ and $\mathrm{X}$ relating to main chapters F, G and J-M, wherever appropriate, arrangement of the position 4-5 numeric characters is the same as for the corresponding main chapters.

258. An example of the classification structure for the implantation of permanent defibrillator is reported below.

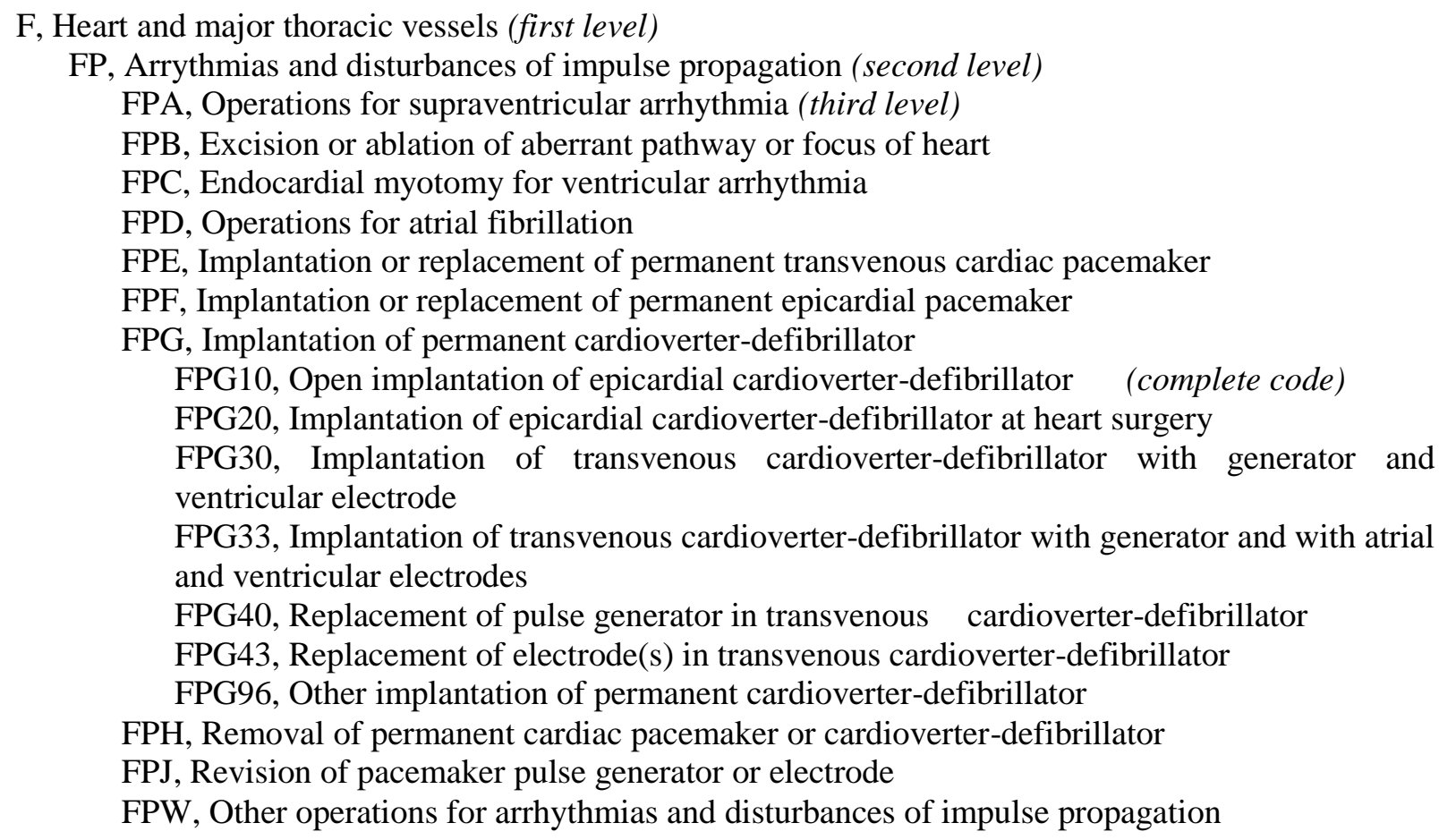

\section{Timing and process for the revision of the coding schemata}

259. The responsibility for maintenance of the classifications is with the Nordic Centre for Classification in Health Care ${ }^{40}$.

260. Changes and amendments to the classifications are made annually and are valid from 1 January. The changes are made to the common English reference version, and then reported to the authorities in each of the Nordic countries so that they can be incorporated into the national versions from the time of validity. Requests for changes and amendments are discussed first in an electronic forum, where views are obtained from experts and from members of the Reference group for Nordic classification issues, and second at a meeting of the reference group which prepares a recommendation to the board of the Nordic centre about which changes to the classification should be approved.

261. The Nordic reference group requires the following for taking update proposals into consideration:

$40 \quad$ The Centre is an independent organization funded by the Nordic countries. It was instituted in 1987 and financed by the Nordic Council of Ministries during 1987-1994. As of 1995 it is financed directly by the Nordic health administrations. 
- $\quad$ proposals should be approved and submitted by a responsible national classification body

- the proposal should include a description of the new method and an account of its indications

- the proposal should also include a rough estimate of how many procedures that are performed per year in the country submitting the proposal, or the expected annual number in the near future

- references should be included to relevant literature documenting that proposed new codes represent established procedures and not purely experimental procedures

\section{Classification system}

262. The NordDRG classification system is used to measure inpatient and short therapy cases, the latter defined as those cases with a length of stay of less than 2 days.

263. The NordDRG system consists of 793 groups, which include 213 groups (26.9\%) for short therapy. The following table reports the number of DRG by MDC. 


\begin{tabular}{|c|c|c|c|}
\hline$M D C$ & Description & $\begin{array}{l}\text { Number of } \\
\text { groups }\end{array}$ & $\begin{array}{c}\text { Relative } \\
\text { frequency } \\
(\%)\end{array}$ \\
\hline Pre & & 10 & 1.26 \\
\hline 01 & Diseases of nervous system & 48 & 6.05 \\
\hline 02 & Diseases and disorders of the eye & 24 & 3.03 \\
\hline 03 & Diseases and disorders of the ear, nose, mouth and throat & 51 & 6.43 \\
\hline 04 & Diseases and disorders of the respiratory system & 38 & 4.79 \\
\hline 05 & Diseases and disorders of the circulatory system & 65 & 8.20 \\
\hline 06 & Diseases and disorders of the digestive system & 60 & 7.57 \\
\hline 07 & Diseases and disorders of the hepatobiliary system and pancreas & 34 & 4.29 \\
\hline 08 & $\begin{array}{l}\text { Diseases and disorders of the musculoskeletal system and connective } \\
\text { tissue }\end{array}$ & 80 & 10.09 \\
\hline 09 & Diseases and disorders of the skin and subcutaneous tissue & 32 & 4.04 \\
\hline 10 & Endocrine, nutritional and metabolic diseases and disorders & 28 & 3.53 \\
\hline 11 & Diseases and disorders of the kidney and urinary tract & 41 & 5.17 \\
\hline 12 & Diseases and disorders of the male reproductive system & 27 & 3.40 \\
\hline 13 & Diseases and disorders of the female reproductive system & 30 & 3.78 \\
\hline 14 & Pregnancy, childbirth and puerperium & 24 & 3.03 \\
\hline 15 & $\begin{array}{l}\text { Newborns and other neonates with conditions originating in the } \\
\text { perinatal period }\end{array}$ & 11 & 1.39 \\
\hline 16 & $\begin{array}{l}\text { Diseases and disorders of the blood and blood forming organs and } \\
\text { immunological disorders }\end{array}$ & 12 & 1.51 \\
\hline 17 & $\begin{array}{l}\text { Myeloproliferative diseases and disorders, poorly differentiated } \\
\text { neoplasms }\end{array}$ & 26 & 3.28 \\
\hline 18 & Infectious and parasitic diseases & 14 & 1.77 \\
\hline 19 & Mental diseases and disorders & 30 & 3.78 \\
\hline 21 & Injuries, poisonings and toxic effects of drugs & 24 & 3.03 \\
\hline 22 & Burns & 11 & 1.39 \\
\hline 23 & $\begin{array}{l}\text { Factors influencing health status and other contacts with health } \\
\text { services }\end{array}$ & 46 & 5.80 \\
\hline 24 & Multiple significant trauma & 7 & 0.88 \\
\hline 30 & Breast problem & 14 & 1.77 \\
\hline \multirow[t]{2}{*}{99} & Unspecific or erroneous information & 6 & 0.76 \\
\hline & Total & 793 & 100 \\
\hline
\end{tabular}

264. DRG are numbered using 3 or 4 digits. The basic first three digits are a progressive number. The fourth digit is eventually used to better identify the DRG (from A-F), or to identify a short therapy $(\mathrm{O}, \mathrm{P})$. Below are two examples of the DRG numbering. 


\begin{tabular}{|c|c|l|}
\hline $\begin{array}{c}\text { DRG } \\
\text { number }\end{array}$ & MDC & \multicolumn{1}{c|}{ DRG description } \\
\hline 112A & 05 & Coronary dilatation with contrast cardiography \\
\hline 112B & 05 & Percutaneuous ablations for cardiac arrhythmia \\
\hline 112C & 05 & $\begin{array}{l}\text { PCI without myocardial infarction, without complications and/or comorbidities } \\
\text { (CC) }\end{array}$ \\
\hline 112D & 05 & PCI without myocardial infarction, with CC \\
\hline 112E & 05 & PCI with myocardial infarction, without CC \\
\hline 112F & 05 & PCI with myocardial infarction, with CC \\
\hline 112O & 05 & Percutaneous cardiovascular procedures, short therapy \\
\hline
\end{tabular}

\begin{tabular}{|c|c|l|}
\hline $\begin{array}{c}D R G \\
\text { number }\end{array}$ & $M D C$ & \\
\hline 242A & 08 & Infectious arthritis or bursitis \\
\hline 242B & 08 & Specific inflammatory arthropathy with CC \\
\hline 242C & 08 & Specific inflammatory arthropathy without CC \\
\hline 242D & 08 & Other arthritis \\
\hline 242E & 08 & Arthrosis with CC \\
\hline 242F & 08 & Arthrosis without CC \\
\hline
\end{tabular}

265. Severity is classified using secondary diagnoses that identify complications or comorbidities. It could be either in the three-digit progressive number as in the example below, or an additional four character as in the examples above.

\begin{tabular}{|c|c|l|}
\hline $\begin{array}{c}\text { DRG } \\
\text { number }\end{array}$ & $M D C$ & DRG description \\
\hline 244 & 08 & Bone diseases \& specific arthropathies with CC \\
\hline 245 & 08 & Bone diseases \& specific arthropathies without CC \\
\hline
\end{tabular}

\section{Variables used in the assignment process}

266. In the first step, a case is assigned to DRG 469 and 470 on the basis of the validity of diagnosis and procedure codes, and the coherence of the reported codes with age and sex. Then neonatal (MDC 15) groups are assigned, both short therapy and "classic". Finally, a case is assigned to pre-MDC and other MDC. A distinction is made between short therapy DRGs and "classic" inpatient DRGs.

267. As an example of the NordDRG logic, below is reported the assignment tree for MDC 30, Breast problems ("classic" DRGs). 


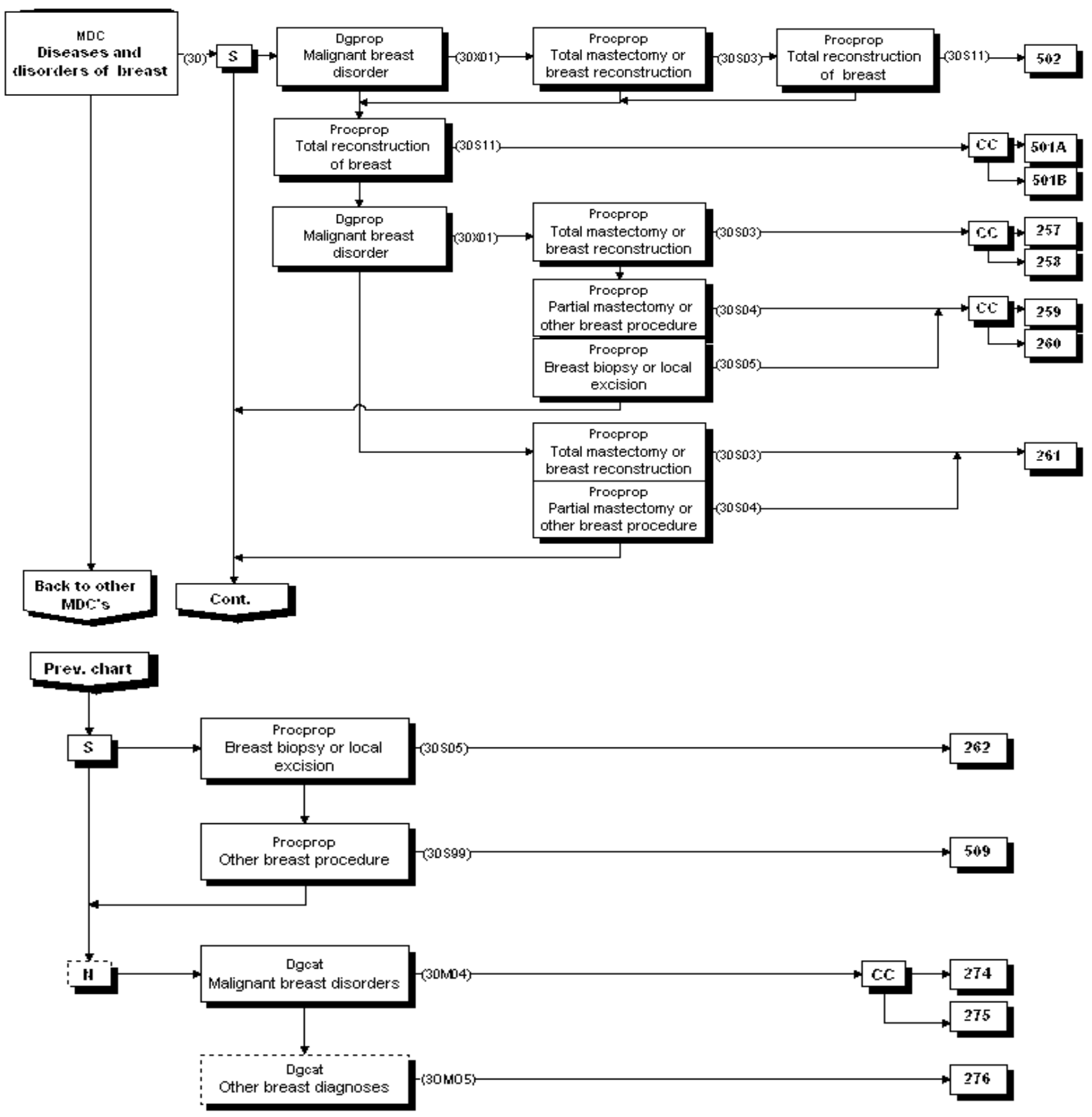

Source: Nordic Casemix Centre, 2011.

\section{Timing and process for the revision of the classification system}

268. NordDRG system is updated annually by Nordic Casemix Centre ${ }^{41}$. All NordDRG products - i.e. definition tables, manuals, handbooks and groupers - are produced in different versions. At present there

41 The Nordic Casemix Centre was instituted from 2008 by the Nordic healthcare organisations to promote Casemix co-operation. It is located in Helsinki (Finland). 
are national versions for Denmark, Finland, Norway and Sweden and a 'Common Nordic' version which isn't use as such anywhere but it is the master version for all the other versions.

269. The NordDRG Definitions are owned by the national health authorities in the Nordic countries. The responsibility for the NordDRG system lies with a Steering group representing the owners. The Steering group supervises the medical development and maintenance work on NordDRG performed at the Nordic Casemix Centre. The Nordic Casemix Centre maintains an edited electronic discussion forum to allow for broader input from expert DRG users. The NordDRG Discussion Forum is the main source of information on current discussions regarding performance, updates and developmental issues. Accepted and rejected proposals for updates of NordDRG are documented in the Forum. New proposals and questions about NordDRG can be put to the NordDRG Forum.

\section{Cost-finding approach}

270. The Norwegian health care system is organized on three levels, i.e. national, regional and local levels. Overall responsibility for the health care sector rests at the national level, with the Ministry of Health and Care Services. The regional level is represented by five regional health authorities, who have responsibility for specialist health care; and the local level represented by 434 municipalities has responsibility for primary health care (including nursing care). Resource allocation does not vary among the regional health authorities and the municipalities. The regional health authorities are financed by basic grants, earmarked means and activity-based funding (based on the DRG system and other fee-for-service for somatic care from the state). The municipalities' health care services and nursing care are financed by basic grants, earmarked means, fee-for-service, and local taxes.

271. In 1997, Norway introduced activity-based funding based on the DRG system for somatic inpatient activity. This measure was further expanded in 1999 to include day surgery. The activity-based funding system is built on active information from the hospitals. Information on patients consists of data on illnesses and procedures according to the international classification systems (ICD-10 and NCSP). This data is then transferred to the Norwegian Patient Register three times a year. The collated information is then transferred to the Ministry of Health and Care Services, which also supervises this system. A Nordic DRG system is used to classify the patients and DRG weights are based on national average costs.

272. The Ministry of Health and Care Services pays the regional health authorities the amount their activity level requires. DRG weights are equal for all hospitals irrespective of cost structure, case mix and the type of hospital. A current national set of cost weights is estimated on the basis of costs in selected hospitals. The price of a DRG point is equal throughout the country and hence also reimbursement is equal. But the regional health authorities are allowed to change these reimbursement rates to their health enterprises.

273. Cost data are collected from a sample of hospital every year. In 2007, twenty-one hospitals were included in the sample. To estimate a cost by DRG, a top-down allocation method is used to allocate costs - excluding capital costs - to products. Length of stay and specific bases/keys that reflect the most recent clinical practice are used in this allocation process. 


\section{United States $^{42}$}

\section{ICD-9-CM}

274. The International Classification of Diseases, Ninth Revision, Clinical Modification (ICD-9-CM) is based on the WHO ICD-9 classification. ICD-9-CM is the official system of assigning codes to diagnoses and procedures associated with hospital utilization in the United States.

275. The ICD-9-CM consists of:

- a tabular list containing a numerical list of the disease code numbers in tabular form

- an alphabetical index to the disease entries

- a classification system for surgical, diagnostic, and therapeutic procedures (alphabetic index and tabular list)

276. The following table reports the number of diagnosis and procedure codes by fiscal year of validity for selected years.

\begin{tabular}{|c|c|c|c|c|c|c|}
\cline { 2 - 7 } \multicolumn{1}{c|}{} & \multicolumn{2}{c|}{ Diagnosis codes } & \multicolumn{2}{c|}{ Procedure codes } & \multicolumn{2}{c|}{ Total codes } \\
\hline $\begin{array}{c}\text { Fiscal } \\
\text { Year }\end{array}$ & Number & \% change & Number & \% change & Number & \% change \\
\hline 2011 & 13141 & 0.89 & 3859 & 0.55 & 17000 & 0.81 \\
\hline 2010 & 13025 & 0.98 & 3838 & 0.37 & 16863 & 0.84 \\
\hline 2009 & 12899 & 2.72 & 3824 & 1.49 & 16723 & 2.44 \\
\hline 2008 & 12557 & 1.01 & 3768 & 0.94 & 16325 & 0.99 \\
\hline 2007 & 12432 & 1.49 & 3733 & 0.86 & 16165 & 1.34 \\
\hline 2006 & 12250 & 1.31 & 3701 & 0.87 & 15951 & 1.21 \\
\hline 2005 & 12091 & 1.23 & 3669 & 1.49 & 15760 & 1.29 \\
\hline 2004 & 11945 & 0.61 & 3615 & 0.22 & 15560 & 0.52 \\
\hline 2003 & 11873 & 1.09 & 3607 & 0.73 & 15480 & 1.00 \\
\hline 2002 & 11745 & & 3581 & & 15326 & \\
\hline
\end{tabular}

\section{Diagnoses classification and coding}

277. The first major subdivision of volume 1, Classification of Diseases and Injuries, contains seventeen chapters that classify conditions according to etiology (cause of disease) or by a specific anatomical (body) system. The chapters in this subdivision are:

42 This chapter describes the coding schemata used in the Medicare programme. Medicare is a health insurance program for people age 65 or older, people under age 65 with certain disabilities, and people of all ages with End-Stage Renal Disease (permanent kidney failure requiring dialysis or a kidney transplant). 


\begin{tabular}{|c|l|c|}
\hline Chapter & \multicolumn{1}{|c|}{ Description } & Code range \\
\hline I & Infectious and parasitic diseases & $001-139$ \\
\hline II & Neoplasms & $140-239$ \\
\hline III & Endocrine, nutritional and metabolic diseases, and immunity disorders & $240-279$ \\
\hline IV & Diseases of the blood and blood-forming organs & $280-289$ \\
\hline V & Mental disorders & $290-319$ \\
\hline VI & Diseases of the nervous system & $320-389$ \\
\hline VII & Diseases of the circulatory system & $390-459$ \\
\hline VIII & Diseases of the respiratory system & $460-519$ \\
\hline IX & Diseases of the digestive system & $520-579$ \\
\hline X & Diseases of the genitourinary system & $580-629$ \\
\hline XI & Complications of pregnancy, childbirth, and the puerperium & $630-677$ \\
\hline XII & Diseases of the skin and subcutaneous tissue & $680-709$ \\
\hline XIII & Diseases of the musculoskeletal system and connective tissue & $710-739$ \\
\hline XIV & Congenital anomalies & $740-759$ \\
\hline XV & Certain conditions originating in the perinatal period & $760-779$ \\
\hline XVI & Symptoms, signs, and ill-defined conditions & $780-799$ \\
\hline XVII & Injury and poisoning & $800-999$ \\
\hline
\end{tabular}

278. Each chapter is structured into the following subdivisions:

- Sections

- Categories

- Subcategories

- Subclassifications

279. A section consists of a group of three-digit categories that represents a single disease entity or a group of similar or closely related conditions (for example, Disorders of the Thyroid Gland 240-246). An individual three-digit category represents a single disease entity or a group of similar or closely related conditions (as an example, 520, Disorders of tooth development and eruption). The fourth-digit subcategory provides more specificity or information regarding the etiology (cause), site, or manifestation (characteristic signs, symptoms, or secondary processes) of an illness. Fourth-digit subcategories are collapsible to the three-digit level. In some cases, fourth-digit subcategories have been expanded to the fifth-digit level to provide even greater specificity.

280. Residual subcategories are codes with titles of "other" and "unspecified". They were developed to classify conditions not assigned to a separate subcategory to ensure that every disease always has a code. Residual subcategories titled "other" are easily distinguished because the fourth digit is often the number 8 . Those codes describing "unspecified" conditions are usually assigned a fourth digit of 9. For example: 003.8, Other specified salmonella infections; 003.9, Salmonella infection, unspecified.

281. Two supplementary classifications exist in addition to the main classification for diseases and injuries: Supplementary Classification of Factors Influencing Health Status and Contact with Health Services (V01-V84) and Supplementary Classification of External Causes of Injury and Poisoning (E800E999). Unlike the numeric codes in the disease classification, the supplementary classifications contain alphanumeric codes. The codes in the Supplementary Classification of Factors Influencing Health Status and Contact with Health Services are known as V codes and consist of the letter V followed by two 
numeric digits, a decimal point, a fourth digit, and (where applicable) a fifth digit. As an example, Vaccination not carried out because of allergy to vaccine or component (V64.04) or Surgical or other procedure not carried out because of patient's decision (V64.2).

282. The codes in the Supplementary Classification of External Causes of Injury and Poisoning are known as E codes and consist of the letter $\mathrm{E}$ followed by three numeric digits, a decimal point, and a fourth digit. For example, Suicide and self-inflicted injury by hanging (E953.0).

\section{Procedure classification and coding}

283. The ICD-9-CM Procedure Classification is a modification of WHO's Fascicle V, "Surgical Procedures", of the ICD-9 Classification of Procedures in Medicine. It is published as Volume 3 of ICD-9CM. It contains both a Tabular List and an Alphabetic Index. Greater detail has been added to the ICD-9CM Procedure Classification necessitating expansion of the codes from three to four digits. Approximately $90 \%$ of the rubrics refer to surgical procedures with the remaining $10 \%$ accounting for other investigative and therapeutic procedures. The list of chapters is reported below.

\begin{tabular}{|c|l|c|}
\hline Chapter & \multicolumn{1}{|c|}{ Description } & Blocks range \\
\hline 0 & Procedures and interventions, not elsewhere classified & 00 \\
\hline 1 & Operations on the nervous system & $01-05$ \\
\hline 2 & Operations on the endocrine system & $06-07$ \\
\hline 3 & Operations on the eye & $08-16$ \\
\hline 4 & Operations on the ear & $18-20$ \\
\hline 5 & Operations on the nose, mouth, and pharynx & $21-29$ \\
\hline 6 & Operations on the respiratory system & $30-34$ \\
\hline 7 & Operations on the cardiovascular system & $35-39$ \\
\hline 8 & Operations on the hematopoietic and lymphatic system & $40-41$ \\
\hline 9 & Operations on the digestive system & $42-54$ \\
\hline 10 & Operations on the urinary system & $55-59$ \\
\hline 11 & Operations on the male genital organs & $60-64$ \\
\hline 12 & Operations on the female genital organs & $65-71$ \\
\hline 13 & Obstetrical procedures & $72-75$ \\
\hline 14 & Operations on the musculoskeletal system & $76-84$ \\
\hline 15 & Operations on the integumentary system & $85-86$ \\
\hline 16 & Miscellaneous diagnostic and therapeutic procedures & $87-99$ \\
\hline
\end{tabular}

As an example, below is reported the classification structure for the implantation of permanent defibrillator.

37 Other operations on heart and pericardium

37.9 Other operations on heart and pericardium

37.94 Implantation or replacement of automatic cardioverter/defibrillator, total system [AICD]

37.95 Implantation of automatic cardioverter/defibrillator lead(s) only

37.96 Implantation of automatic cardioverter/defibrillator pulse generator only

37.97 Replacement of automatic cardioverter/defibrillator lead(s) only 


\section{Timing and process for the revision of the coding schemata}

284. The National Center for Health Statistics (NCHS) and the Centers for Medicare and Medicaid Services (CMS) are the U.S. governmental agencies responsible for overseeing all changes and modifications to the ICD-9-CM.

285. Recognizing the ICD-9-CM as a dynamic statistical tool that must be flexible to meet expanding classification needs, the ICD-9-CM Coordination and Maintenance Committee was created as a forum for proposals to update ICD-9-CM. A representative from the NCHS and one from the CMS co-chair the ICD-9-CM Coordination and Maintenance Committee meetings. Responsibility for maintenance of the ICD-9-CM is divided between the two agencies, with classification of diagnoses (volumes 1 and 2) by NCHS and of procedures (volume 3) by CMS.

286. Although the ICD-9-CM Coordination and Maintenance Committee is a Federal Committee, suggestions for modifications come from both the public and private sectors. Interested parties are asked to submit recommendations for modification prior to a scheduled meeting. Proposals for a new code should include a description of the code being requested, and rationale for why the new code is needed. Supporting references and literature may also be submitted. Proposals should be consistent with the structure and conventions of the classification.

287. These meetings are open to the public; comments are encouraged both at the meetings and in writing. Recommendations and comments are carefully reviewed and evaluated before any final decisions are made. No decisions are made at the meetings. The ICD-9-CM Coordination and Maintenance Committee's role is advisory. All final decisions are made by the Director of NCHS and the Administrator of CMS. Final decisions are made after the December meeting and become effective October 1 of the following year. Official code revision packages, which are referred to as addenda, are public available.

\section{Tools used for data quality enhancement}

288. CMS and NCHS provide guidelines for coding and reporting using the ICD-9-CM. These guidelines should be used as a companion document to the official version of the ICD-9-CM and have been approved by the four organizations that make up the Cooperating Parties for the ICD-9-CM: the American Hospital Association (AHA), the American Health Information Management Association (AHIMA), CMS, and NCHS.

289. The guidelines are a set of rules that have been developed to accompany and complement the official conventions and instructions provided within the ICD-9-CM itself. They are based on the coding and sequencing instructions in Volumes I, II and III of ICD-9-CM, but provide additional instruction. Adherence to these guidelines when assigning ICD-9-CM diagnosis and procedure codes is required under the Health Insurance Portability and Accountability Act (HIPAA). The guidelines are organized into sections. Section I includes the structure and conventions of the classification and general guidelines that apply to the entire classification, and chapter-specific guidelines that correspond to the chapters as they are arranged in the classification. Section II includes guidelines for selection of principal diagnosis for nonoutpatient settings. Section III includes guidelines for reporting additional diagnoses in non-outpatient settings. Section IV is for outpatient coding and reporting.

290. Coding Clinic for ICD-9-CM is a quarterly newsletter published by AHA's Central Office on ICD-9-CM to facilitate greater dissemination of clearinghouse information to hospitals and other involved parties on the use of ICD-9-CM and uniform data sets for reporting purposes. Its major functions follow: 
- $\quad$ to provide ICD-9-CM coding advice and official guidelines relative to uses for hospital-based inpatient and outpatient coding, physician-based coding, as well as internal and external reporting needs of hospitals

- to answer questions on code assignments and sequencing of codes

- to serve as an important, current reference on regulatory and other requirements for reporting diagnostic and procedural information from patient health records

- to present topics and articles that provide practical information, improve technical skills in coding, and address issues facing health information management professionals on the various uses of ICD-9-CM, data reporting requirements, data edits, health record documentation and authentication, and other related matters

\section{The future: ICD-10-CM and ICD-10-PCS}

291. On the $16^{\text {th }}$ January 2009, the Department of Health and Human Services issued a final rule that adopts modifications to the standard medical data code sets for coding diagnoses and inpatient hospital procedures by concurrently adopting the International Classification of Diseases, 10th Revision, Clinical Modification (ICD-10-CM) for diagnosis coding, and the International Classification of Diseases, 10th Revision, Procedure Coding System (ICD-10-PCS) for inpatient hospital procedure coding (Department of Health and Human Services 2009). These new codes replace the International Classification of Diseases, 9th Revision, Clinical Modification, Volumes 1, 2, and 3. The compliance date for the regulation is October 1, 2013.

\section{ICD-10-CM}

292. The NCHS has developed a clinical modification of the classification for morbidity purposes. The new ICD-10-CM would be used for the reporting of diseases and conditions of patients treated in the United States healthcare system. ICD-10-CM is intended to be the replacement for ICD-9-CM, volumes 1 and 2. ICD-10 is copyrighted by the WHO, which owns and publishes the classification. WHO authorized the development of the adaption of ICD-10 for use in the United States.

293. ICD-10-CM was developed following a thorough evaluation by a Technical Advisory Panel and extensive additional consultation with physician groups, clinical coders, and others to ensure clinical accuracy and utility.

294. The current draft of ICD-10-CM contains significantly more codes than exist in ICD-9-CM and offers many additional advantages. Some of these features include:

- ICD-10-CM has the same hierarchical structure as ICD-9-CM, but the codes are all alphanumeric and all letters except $U$ are used

- the codes corresponding to ICD-9-CM V and E codes are incorporated into the main classification and are not separated into supplementary classifications as in ICD-9-CM

- new diseases and conditions not uniquely identified in ICD-9-CM have been given codes. In addition, conditions with newly discovered etiology or treatment protocols have been reclassified to a more appropriate chapter

- injuries are grouped by body part instead of by categories of injury 
- excludes notes are expanded to provide guidance on the hierarchy of chapters and to clarify priority of code assignment

- combination codes have been created, such as arteriosclerotic heart disease with angina

- the concept of laterality (right-left) has been added

- the codes for postoperative complications have been expanded, and a distinction has been made between intraoperative complications and postprocedural disorders

- the obstetric codes indicate which trimester the patient is in and no longer identify whether the patient has delivered

- the diabetes codes indicate insulin-requiring and non-insulin-requiring types

- information relevant to ambulatory and managed care encounters has been added

An updated 2010 release of ICD-10-Clinical Modifications (CM) is available for public viewing on the NCHS website (www.cdc.gov/nchs//icd/icd10.htm). It contains 69,101 diagnosis codes.

\section{ICD-10-PCS}

295. ICD-10-CM will not include a procedure classification based on the same principles of organization as the diagnosis classification. Instead, a separate procedure coding system - ICD-10-PCS has been developed to meet the rigorous and varied demands that are made of coded data in the healthcare industry. The following are the basic differences between ICD-9-CM Volume 3 and ICD-10-PCS. 


\begin{tabular}{|l|l|}
\hline \multicolumn{1}{|c|}{ ICD-9-CM Volume 3 } & \multicolumn{1}{|c|}{ ICD-10-PCS } \\
\hline $\begin{array}{l}\text { Follows ICD structure (designed for diagnosis } \\
\text { coding) }\end{array}$ & $\begin{array}{l}\text { Designed/developed to meet healthcare needs for a } \\
\text { procedure code system }\end{array}$ \\
\hline Codes available as a fixed/finite set in list form & $\begin{array}{l}\text { Codes constructed from flexible code components } \\
\text { (values) using tables }\end{array}$ \\
\hline Codes are numeric & Codes are alphanumeric \\
\hline Codes are 3-4 digits long & All codes are seven characters long \\
\hline
\end{tabular}

296. Undergirding ICD-10-PCS is a logical, consistent structure that informs the system as a whole, down to the level of a single code. This means that the process of constructing codes in ICD-10-PCS is also logical and consistent: individual letters and numbers, called "values," are selected in sequence to occupy the seven spaces of the code, called "characters". All codes in ICD-10-PCS are seven characters long. Each character in the seven-character code represents an aspect of the procedure, as shown in the following table of characters from the main section of ICD-10-PCS, called "Medical and surgical".

\begin{tabular}{|c|l|}
\hline $\begin{array}{c}\text { Code } \\
\text { character }\end{array}$ & \multicolumn{1}{c|}{ Description } \\
\hline 1 & Section \\
\hline 2 & Body system \\
\hline 3 & Root operation \\
\hline 4 & Body part \\
\hline 5 & Approach \\
\hline 6 & Device \\
\hline 7 & Qualifier \\
\hline
\end{tabular}

297. ICD-10-PCS is composed of 16 sections, represented by the numbers $0-9$ and the letters B-D and $\mathrm{F}-\mathrm{H}$. The broad procedure categories contained in these sections range from surgical procedures to substance abuse treatment.

298. The first section, Medical and surgical, contains the great majority of procedures typically reported in an inpatient setting. All procedure codes in this section begin with the section value 0 . Sections 1-9 of ICD-10-PCS comprise the Medical and Surgical-related sections. These sections include obstetrical procedures, administration of substances, measurement and monitoring of body functions, and extracorporeal therapies, as listed in the table below.

\begin{tabular}{|c|l|}
\hline Section & \multicolumn{1}{c|}{ Description } \\
\hline 1 & Obstretrics \\
\hline 2 & Placement \\
\hline 3 & Administration \\
\hline 4 & Measurement and monitoring \\
\hline 5 & Extracorporeal assistance and performance \\
\hline 6 & Extracorporeal therapies \\
\hline 7 & Osteopathic \\
\hline 8 & Other procedures \\
\hline 9 & Chiropractic \\
\hline
\end{tabular}


299. In sections 1 and 2, all seven characters define the same aspects of the procedure as in the Medical and Surgical section. Codes in sections 3-9 are structured for the most part like their counterparts in the Medical and Surgical section, with a few exceptions.

300. Additional differences include these uses of the sixth character:

- Section 3 defines the sixth character as substance

- Sections 4 and 5 define the sixth character as function

- $\quad$ Sections 7-9 define the sixth character as method

301. Sections B-D and F-H comprise the ancillary sections of ICD-10-PCS. These six sections include imaging procedures, nuclear medicine, and substance abuse treatment, as listed in the following table.

\begin{tabular}{|c|l|}
\hline Section & \multicolumn{1}{|c|}{ Description } \\
\hline B & Imaging \\
\hline C & Nuclear medicine \\
\hline D & Radiation oncology \\
\hline F & Physical rehabilitation and diagnostic audiology \\
\hline G & Mental health \\
\hline H & Substance abuse treatment \\
\hline
\end{tabular}

302. The definition of some characters in the ancillary sections differs from that seen in previous sections. In the Imaging section, the third character is defined as type, and the fifth and sixth characters define contrast and contrast/qualifier respectively.

303. Additional differences include:

- Section $\mathrm{C}$ defines the fifth character as radionuclide

- Section D defines the fifth character as modality qualifier and the sixth character as isotope

- Section F defines the fifth character as type qualifier and the sixth character as equipment

- Sections $\mathrm{G}$ and $\mathrm{H}$ define the third character as a type qualifier

304. The following table reports the number of codes for the 2011 revision of the ICD-10-PCS classification. 
DELSA/HEA/WD/HWP(2011)2

\begin{tabular}{|l|r|}
\hline \multicolumn{1}{|c|}{ Section } & $\begin{array}{c}\text { Number of } \\
\text { codes }\end{array}$ \\
\hline Medical and Surgical & 62,022 \\
\hline Obstetrics & 300 \\
\hline Placement & 864 \\
\hline Administration & 1,438 \\
\hline Measurement and Monitoring & 327 \\
\hline Extracorporeal Assistance and Performance & 41 \\
\hline Extracorporeal Therapies & 42 \\
\hline Osteopathic & 100 \\
\hline Other Procedures & 60 \\
\hline Chiropractic & 90 \\
\hline Imaging & 2,934 \\
\hline Nuclear Medicine & 463 \\
\hline Radiation Oncology & 1,929 \\
\hline Rehabilitation and Diagnostic Audiology & 1,382 \\
\hline Mental Health & 30 \\
\hline Substance Abuse Treatment & 59 \\
\hline Total & 72,081 \\
\hline
\end{tabular}

\section{Classification system}

305. Medicare beneficiaries enrolled in the traditional fee-for-service program receive care in about 3,500 facilities that contract with Medicare to provide acute inpatient care and agree to accept the program's predetermined payment rates as payment in full.

306. Medicare pays per-discharge rates that begin with two national base payment rates-covering operating and capital expenses - which are then adjusted to account for two broad factors that affect hospitals' costs of furnishing care: the patient's condition and related treatment strategy, and market conditions in the facility's location. As to the former, Medicare assigns discharges to Medicare severity diagnosis related groups (MS-DRGs), which group patients with similar clinical problems that are expected to require similar amounts of hospital resources.

307. MS-DRGs system (version 28, in use for Fiscal Year 2011) has a total of 747 groups. Discharge destination and use of a specific drug are occasionally used along with principal diagnosis and procedures in structuring base DRGs. The following table reports the number of groups and their relative frequency by MDC. 
DELSA/HEA/WD/HWP(2011)2

\begin{tabular}{|c|c|c|c|}
\hline$M D C$ & Description & $\begin{array}{l}\text { Number of } \\
\text { groups }\end{array}$ & $\begin{array}{c}\text { Relative } \\
\text { frequency } \\
(\%)\end{array}$ \\
\hline Pre & & 14 & 1.9 \\
\hline 01 & Diseases and disorders of the nervous system & 75 & 10 \\
\hline 02 & Diseases and disorders of the eye & 10 & 1.3 \\
\hline 03 & Diseases and disorders of the ear, nose, mouth and throat & 25 & 3.3 \\
\hline 04 & Diseases and disorders of the respiratory system & 40 & 5.4 \\
\hline 05 & Diseases and disorders of the circulatory system & 88 & 11.8 \\
\hline 06 & Diseases and disorders of the digestive system & 61 & 8.2 \\
\hline 07 & Diseases and disorders of the hepatobiliary system and pancreas & 36 & 4.8 \\
\hline 08 & $\begin{array}{l}\text { Diseases and disorders of the musculoskeletal system and } \\
\text { connective tissue }\end{array}$ & 99 & 13.3 \\
\hline 09 & $\begin{array}{l}\text { Diseases and disorders of the skin, subcutaneous tissue and } \\
\text { breast }\end{array}$ & 29 & 3.9 \\
\hline 10 & Endocrine, nutritional and metabolic diseases and disorders & 26 & 3.5 \\
\hline 11 & Diseases and disorders of the kidney and urinary tract & 43 & 5.8 \\
\hline 12 & Diseases and disorders of the male reproductive system & 21 & 2.8 \\
\hline 13 & Diseases and disorders of the female reproductive system & 25 & 3.3 \\
\hline 14 & Pregnancy, childbirth and puerperium & 15 & 2 \\
\hline 15 & $\begin{array}{l}\text { Newborns and other neonates with conditions originating in the } \\
\text { perinatal period }\end{array}$ & 7 & 0.9 \\
\hline 16 & $\begin{array}{l}\text { Diseases and disorders of the blood and blood forming organs } \\
\text { and immunological disorders }\end{array}$ & 15 & 2 \\
\hline 17 & $\begin{array}{l}\text { Myeloproliferative diseases and disorders, poorly differentiated } \\
\text { neoplasms }\end{array}$ & 27 & 3.6 \\
\hline 18 & Infectious and parasitic diseases & 17 & 2.3 \\
\hline 19 & Mental diseases and disorders & 9 & 1.2 \\
\hline 20 & $\begin{array}{l}\text { Alcohol/drug use and alcohol/drug induced organic mental } \\
\text { disorders }\end{array}$ & 4 & 0.5 \\
\hline 21 & Injuries, poisonings and toxic effects of drugs & 20 & 2.7 \\
\hline 22 & Burns & 6 & 0.8 \\
\hline 23 & $\begin{array}{l}\text { Factors influencing health status and other contacts with health } \\
\text { services }\end{array}$ & 10 & 1.3 \\
\hline 24 & Multiple significant trauma & 8 & 1.1 \\
\hline \multirow[t]{3}{*}{25} & Human Immunodeficiency Virus infections & 6 & 0.8 \\
\hline & Other & 11 & 1.5 \\
\hline & Total & 747 & 100 \\
\hline
\end{tabular}

308. The chosen numbering uses three digits. It is progressive within each MDC: first surgical DRGs, then medical DRGs.

309. The MS-DRG system has 335 base DRGs, most of which are split into 2 or 3 MS-DRGs based on the presence of either a comorbidity or complication (CC) or major CC (MCC). 
310. The following are three examples of the different splits of base DRGs.

\begin{tabular}{|c|l|}
\hline$D R G$ & \\
\hline 061 & Acute ischemic stroke with use of thrombolytic agent with MCC \\
\hline 062 & Acute ischemic stroke with use of thrombolytic agent with CC \\
\hline 063 & Acute ischemic stroke with use of thrombolytic agent without CC/MCC \\
\hline
\end{tabular}

\begin{tabular}{|l|l|}
\hline$D R G$ & \multicolumn{1}{c|}{ Description } \\
\hline 113 & Orbital procedures with CC/MCC \\
\hline 114 & Orbital procedures without CC/MCC \\
\hline
\end{tabular}

\begin{tabular}{|l|l|}
\hline$D R G$ & \multicolumn{1}{|c|}{ Description } \\
\hline 175 & Pulmonary embolism with MCC \\
\hline 176 & Pulmonary embolism without MCC \\
\hline
\end{tabular}

311. Each diagnosis was assigned a CC level:

- major CC, 1591 diagnoses (12.3\% of the total)

- $\quad \mathrm{CC}, 3427(26.6 \%)$

312. As an example, the following table reports the $\mathrm{CC}$ level assignment for Heart failure.

\begin{tabular}{|c|l|l|}
\hline $\begin{array}{c}\text { ICD-9-CM } \\
\text { code }\end{array}$ & \multicolumn{1}{|c|}{ Description } & \multicolumn{1}{|c|}{$\begin{array}{c}\text { Severity } \\
\text { level }\end{array}$} \\
\hline 428.0 & Congestive heart failure NOS & Non-CC \\
\hline 428.1 & Left heart failure & CC \\
\hline 428.20 & Unspecified systolic heart failure & CC \\
\hline 428.21 & Acute systolic heart failure & MCC \\
\hline 428.22 & Chronic systolic heart failure & CC \\
\hline 428.23 & Acute on chronic systolic heart failure & MCC \\
\hline 428.30 & Unspecified diastolic heart failure & CC \\
\hline 428.31 & Acute diastolic heart failure & MCC \\
\hline 428.32 & Chronic diastolic heart failure & CC \\
\hline 428.33 & Acute on chronic diastolic heart failure & MCC \\
\hline 428.40 & Unspecified combined systolic and diastolic heart failure & CC \\
\hline 428.41 & Acute combined systolic and diastolic heart failure & MCC \\
\hline 428.42 & Chronic combined systolic and diastolic heart failure & CC \\
\hline 428.43 & Acute on chronic combined systolic and diastolic heart failure & MCC \\
\hline 428.9 & Heart failure NOS & Non-CC \\
\hline & & \\
\hline
\end{tabular}

\section{Variables used in the assignment process}

313. MS-DRGs assignment is based on patients' clinical conditions and treatment strategies. Clinical conditions are defined by patients' discharge diagnoses, including the principal diagnosis - the main problem requiring inpatient care - and up to eight secondary diagnoses indicating other conditions that were present at admission (comorbidities) or developed during the hospital stay (complications). The treatment strategy - surgical or medical-is defined by the presence or absence of up to six procedures performed during the stay. 
314. The following graph describes the typical DRG structure for a Major Diagnostic Category.

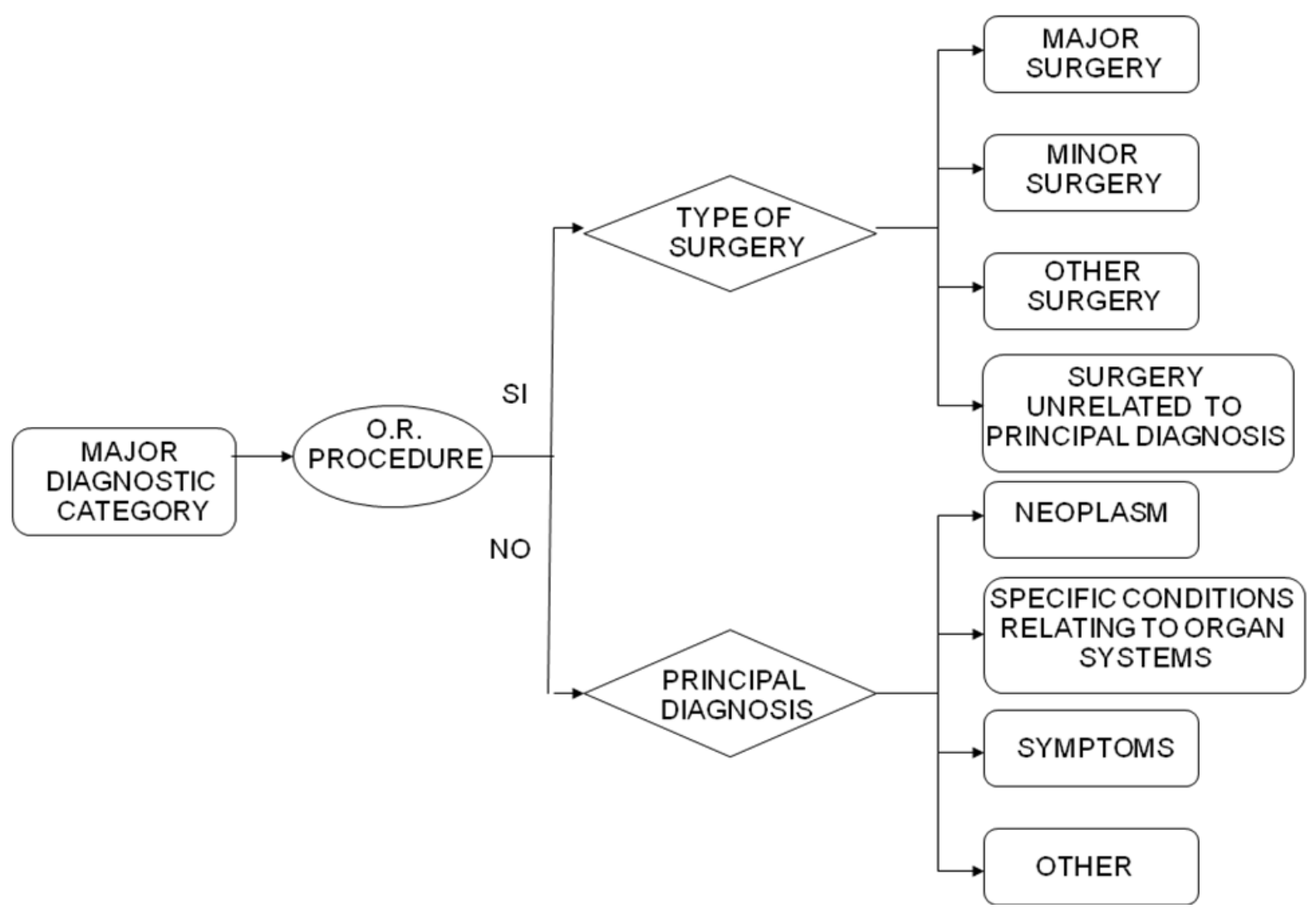


As an example of the assignment tree, the following figure reports the DRG structure for MDC 2, Disease and disorders of the eye.

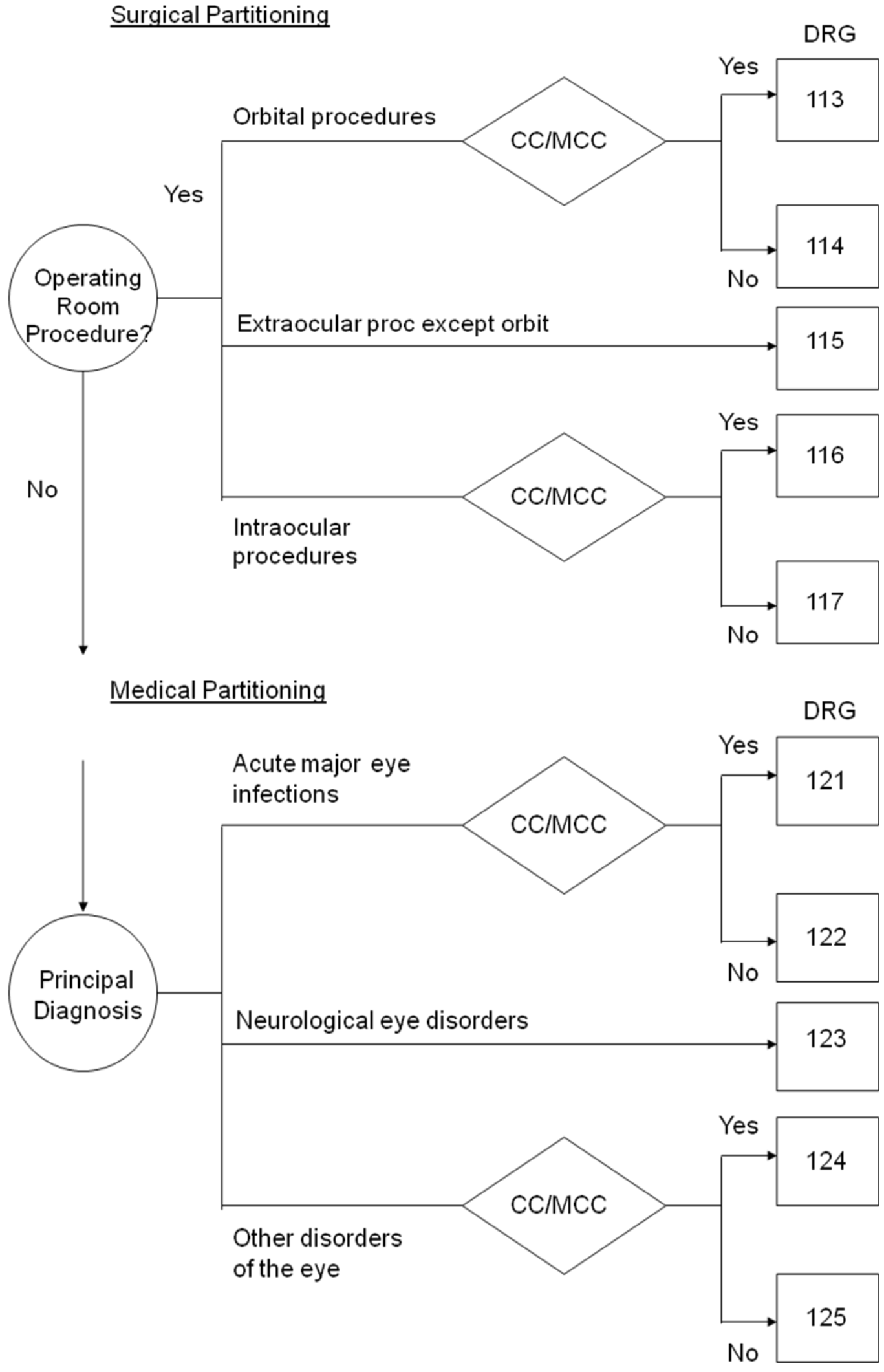




\section{Timing and process for the revision of the classification system}

315. The CMS annually reviews the MS-DRG definitions to ensure that each group continues to include cases with clinically similar conditions requiring comparable amounts of inpatient resources. When the review shows that subsets of clinically similar cases within an MS-DRG consume significantly different amounts of resources, CMS often reassigns them to a different MS-DRG with comparable resource use or creates a new MS-DRG.

\section{Cost-finding approach}

316. The Social Security Amendments of 1983 established a per-discharge prospective payment to encourage acute care hospitals to provide services to Medicare beneficiaries more efficiently. Previously, payment was based on the reasonable costs of providing inpatient services to Medicare patients. Under Inpatient Prospective Payment System (IPPS), each inpatient discharge is assigned to a DRG that includes patients expected to have similar resource use and clinical patterns of care. The Medicare payment is based on a standard payment rate adjusted for the relative weight of the DRG and facility-level characteristics. The relative weight represents the average cost of caring for cases in a specific DRG relative to the average cost for all Medicare cases. Facility-level geographic adjustments take into account hospital wage levels for the geographic area and, for hospitals in Alaska and Hawaii, the cost of living. Additional adjustments are made for indirect medical education (IME) costs and for serving a disproportionate share of lowincome patients (DSH). Separate payment rates apply to operating and capital costs, and hospital-specific rates affect payments for sole community and Medicare dependent hospitals. Special payment policies apply also to transfer cases and to extraordinarily high-cost cases.

317. The two main sources of cost data available in the Medicare programme are the Medicare cost report and the Medicare Provider Analysis and Review (MedPar).

318. The former relates to an annual cost report that Medicare-certified institutional providers are required to submit to a Fiscal Intermediary. The cost report contains provider information such as facility characteristics, utilization data, cost and charges by cost center (in total and for Medicare), cost-to-charge ratios by cost center, Medicare settlement data, and financial statement data. CMS maintains the cost report data in the Healthcare Provider Cost Reporting Information System (HCRIS). HCRIS includes subsystems for the Hospital Cost Report, Skilled Nursing Facility (SNF) Cost Report, Home Health Agency Cost Report, Renal Facility Cost Report and Hospice Cost Report.

319. The latter contains data from claims for services provided to beneficiaries admitted to Medicare certified inpatient hospitals and SNF. Beneficiary demographic characteristics, diagnosis and surgery information, and use of hospital or SNF resources are included on the MedPar records. In addition, the records contain detailed accommodation and departmental charge data, days of care, and entitlement data.

320. In the initial implementation of the IPPS, DRG weights were constructed from charges for services reported on Medicare claims that had been discounted using cost-to-charge ratios (CCRs ${ }^{43}$ ) for each standard hospital department appearing on the Medicare Cost Report (MCR). CCRs specific to each department were computed for each hospital provider. After standardizing charges for area wage variation and other factors, ancillary charges were converted to cost by applying hospital-specific CCRs to each ancillary charge appearing on the MedPAR claims file. Average cost per DRG was computed from the sum of the ancillary costs and per-diem based routine and critical care nursing costs. Relative weights were constructed by dividing average cost per DRG by the overall national average cost per case.

43 CCRs are derived from the Medicare hospital cost report data and are applied to individual claims charges to estimate cost. 
321. CMS adopted a new DRG weight computation method for FY 2007 IPPS payments. Under the new method, national aggregate CCRs were computed for each of 13 different service departments, based on total Medicare program costs and charges from MCRs ${ }^{44}$. New weights were constructed by:

- standardizing the MedPAR charges for systematic differences in costs attributable to facility characteristics, namely, adjustments for geographic differences in hospital wage levels and cost of living, IME costs, and serving a disproportionate share of low-income patients

- assigning each of the standardized charges from the claim to one of the thirteen service department groups

- computing the mean standardized charge by service department for each DRG

- discounting each of the DRG-level charge amounts to cost by applying the thirteen national CCRs

- computing relative weights from these DRG cost estimates

322. The table below reports each of the thirteen groups, the component cost centers from the cost reports that were used to compute the CCRs, and the associated types of charges on the MedPAR claims that are converted by these CCRs.

These 13 groups capture much of the variation in markup rates across major types of clinical services, thereby reducing much of the bias in weights created by cross-subsidizing pricing practices. The use of national CCRs rather than hospital-specific CCRs allows CMS to compute the cost conversion at the DRG level rather than the hospital and claim levels. This avoids the need for complex algorithms to match groups of services from each hospital's cost report cost centers to groups of services on MedPAR claims. 


\begin{tabular}{|c|c|c|c|c|c|c|}
\hline \multicolumn{2}{|c|}{$\begin{array}{c}\text { National CCR groups } \\
\text { (total }=13 \text { ) }\end{array}$} & \multicolumn{2}{|c|}{ MedPAR departments (total=28) } & \multicolumn{2}{|r|}{ Cost report lines } & \multirow{2}{*}{$\begin{array}{c}\text { CMS national } \\
\text { CCR from FY } \\
2007 \text { rules }\end{array}$} \\
\hline$\#$ & Description & Var. \# & Description & Line \# & Descriptions & \\
\hline 1 & Routine & $63,64,65$ & Routine & 25 & Routine & 0.56 \\
\hline $\begin{array}{l}2 \\
2\end{array}$ & $\begin{array}{l}\text { Intensive } \\
\text { Intensive }\end{array}$ & $\begin{array}{l}66 \\
67\end{array}$ & $\begin{array}{l}\mathrm{ICU} \\
\mathrm{CCU}\end{array}$ & $\begin{array}{l}26,28-30 \\
27\end{array}$ & $\begin{array}{l}\text { ICUs (all) } \\
\text { CCU }\end{array}$ & 0.50 \\
\hline 3 & Drugs & 69 & Pharmacy & 56,48 & Drugs Charged; Intravenous Therapy & 0.21 \\
\hline 4 & Supplies & 70 & Supplies & 55 & Supplies charged & \\
\hline 4 & Supplies & 71 & DME & 67 & DME sold & 0.34 \\
\hline 4 & Supplies & 72 & DME & 66 & DME rented & \\
\hline 5 & Therapy Services & 73 & Physical Therapy & 50 & Physical Therapy & \\
\hline 5 & Therapy Services & 74 & Occupation Therapy & 51 & Occupational Therapy & 0.44 \\
\hline 5 & Therapy Services & 75 & Speech Therapy & 52 & Speech Therapy & \\
\hline 6 & Inhalation Therapy & 76 & Respiratory Therapy & 49 & Respiratory Therapy & 0.20 \\
\hline 7 & Operating Room & 79 & Operating Room & 37,38 & Operating Room; Recovery Room & 0.32 \\
\hline $8^{1}$ & Labor \& Delivery & N/A & N/A & 39,63 & Labor \& Delivery: Other O/P & 0.46 \\
\hline 9 & Anesthesia & 82 & Anesthesia & 40 & Anesthesia & 0.16 \\
\hline 10 & Cardiology & 81 & Cardiology & $\begin{array}{l}53 \\
54\end{array}$ & $\begin{array}{l}\text { Electrocardiology, } \\
\text { Electroencephalography }\end{array}$ & 0.21 \\
\hline 11 & Laboratory & 83 & Lab & 44,45 & Laboratories & 0.19 \\
\hline 12 & Radiology & 84,85 & Radiology \& MRI & $\begin{array}{l}41 \\
42\end{array}$ & $\begin{array}{l}\text { Diagnostic Radiology } \\
\text { Therapeutic Radiology }\end{array}$ & 0.19 \\
\hline 13 & Other Services & N/A & $\begin{array}{l}\text { N/A (no separate } \\
\text { charge group) }\end{array}$ & $\begin{array}{c}43 \\
62,62.01 .\end{array}$ & $\begin{array}{l}\text { Radioisotopes } \\
\text { Observation, }\end{array}$ & \\
\hline 13 & Other Services & 68 & Other Services & 69 & Other Ancillary & \\
\hline 13 & Other Services & 77 & Blood & 46 & Blood & \\
\hline 13 & Other Services & 78 & Blood Admin & 47 & Blood Storage/Processing & \\
\hline 13 & Other Services & 80 & Lithotripsy & N/A & N/A (no cost center) & \\
\hline 13 & Other Services & 86 & Other O/P Services & 58,68 & ASC; Other OIP & 0.38 \\
\hline 13 & Other Services & 87 & Emergency & 61 & Emergency & \\
\hline 13 & Other Services & 88 & Ambulance & 65 & Ambulance & \\
\hline 13 & Other Services & 91 & ESRD & $\begin{array}{c}57,84 \\
60,63.50\end{array}$ & Renal Dialysis; Home Program Dialysis & \\
\hline 13 & Other Services & 92 & Clinics & 63.60 & Clinic; RHC; FQHC & \\
\hline
\end{tabular}

Source: RTI International, 2007. 


\section{WHO International Classification of Diseases}

323. The International Classification of Diseases (ICD) is the international standard diagnostic classification for all general epidemiological, many health management purposes and clinical use. These include the analysis of the general health situation of population groups and monitoring of the incidence and prevalence of diseases and other health problems in relation to other variables such as the characteristics and circumstances of the individuals affected, reimbursement, resource allocation, quality and guidelines.

324. It is used to classify diseases and other health problems recorded on many types of health and vital records including death certificates and health records. In addition to enabling the storage and retrieval of diagnostic information for clinical, epidemiological and quality purposes, these records also provide the basis for the compilation of national mortality and morbidity statistics by WHO Member States.

\section{ICD tenth revision}

325. The International Classification of Disease, tenth revision (ICD-10) was endorsed by the Fortythird World Health Assembly in May 1990 and came into use in WHO Member States as from 1994. The classification is the latest in a series which has its origins in the 1850s. The ICD-10 classification axis is the following:

- $\quad$ epidemic diseases

- constitutional or general diseases

- local diseases - by site

- developmental diseases

- $\quad$ injuries

326. The classification is structures in 3 volumes, 22 chapters (identified by roman numerals I-XXII) and uses alphanumerical codes. The following table reports the description and code range by chapter. 
DELSA/HEA/WD/HWP(2011)2

\begin{tabular}{|c|l|c|}
\hline Chapter & \multicolumn{1}{|c|}{ Description } & Code range \\
\hline I & Certain infectious and parasitic diseases & A00-B99 \\
\hline II & Neoplasms & C00-D48 \\
\hline III & $\begin{array}{l}\text { Diseases of the blood and blood-forming organs and } \\
\text { certain disorders involving the immune mechanism }\end{array}$ & D50-D89 \\
\hline IV & Endocrine, nutritional and metabolic diseases & E00-E90 \\
\hline V & Mental and behavioural disorders & F00-F99 \\
\hline VI & Diseases of the nervous system & G00-G99 \\
\hline VII & Diseases of the eye and adnexa & H00-H59 \\
\hline VIII & Diseases of the ear and mastoid process & H60-H95 \\
\hline IX & Diseases of the circulatory system & J00-I99 \\
\hline X & Diseases of the respiratory system & K00-K93 \\
\hline XI & Diseases of the digestive system & L00-L99 \\
\hline XII & Diseases of the skin and subcutaneous tissue & M00-M99 \\
\hline XIII & $\begin{array}{l}\text { Diseases of the musculoskeletal system and connective } \\
\text { tissue }\end{array}$ & N00-N99 \\
\hline XIV & Diseases of the genitourinary system & O00-O99 \\
\hline XV & Pregnancy, childbirth and the puerperium & P00-P96 \\
\hline XVI & Certain conditions originating in the perinatal period & Q00-Q99 \\
\hline XVII & $\begin{array}{l}\text { Congenital malformations, deformations, and } \\
\text { chromosomal abnormalities }\end{array}$ & R00-R99 \\
\hline XVIII & $\begin{array}{l}\text { Symptoms, signs and abnormal clinical and laboratory } \\
\text { findings not elsewhere classified }\end{array}$ & S00-T98 \\
\hline XIX & $\begin{array}{l}\text { Injury, poisoning and certain other consequences of } \\
\text { external causes }\end{array}$ & V00-Y98 \\
\hline XX & External causes of morbidity and mortality & Z00-Z99 \\
\hline XXI & $\begin{array}{l}\text { Factors influencing health status and contact with health } \\
\text { services }\end{array}$ & \\
\hline XXII & Morphology of Neoplasms & \\
\hline
\end{tabular}

327. Volume 1 contains the Tabular list, the alphanumeric listing of diseases and disease groups. Volume 2 reports Instructions and guidelines. Volume 3 contains the Alphabetical index, the comprehensive listing of all conditions in the Tabular list.

328. Chapters are further divided into blocks, three characters categories, four characters subcategories, and some optional five characters codes.

329. The following is an example of the classification of senile cataract.

Chapter: Disease of the eye and adnexa (VII)

Block: Disorders of lens (H25-H28) 


\begin{tabular}{|l|l|}
\hline H25 & $\begin{array}{l}\text { Senile cataract } \\
\text { Excludes: capsular glaucoma with pseudoexfoliation of lens }(\mathrm{H} 40.1)\end{array}$ \\
\hline H25.0 & $\begin{array}{l}\text { Senile incipient cataract } \\
\text { Senile cataract: } \\
\cdot \text { coronary } \\
\cdot \text { cortical } \\
\text { punctate } \\
\text { Subcapsular polar senile cataract (anterior) (posterior) } \\
\text { Water clefts }\end{array}$ \\
\hline H25.1 & $\begin{array}{l}\text { Senile nuclear cataract } \\
\text { Cataracta brunescens } \\
\text { Nuclear sclerosis cataract }\end{array}$ \\
\hline H25.2 & $\begin{array}{l}\text { Senile cataract, morgagnian type } \\
\text { Senile hypermature cataract }\end{array}$ \\
\hline H25.8 & $\begin{array}{l}\text { Other senile cataract } \\
\text { Combined forms of senile cataract }\end{array}$ \\
\hline H25.9 & Senile cataract, unspecified \\
\hline
\end{tabular}

330. As an example of the five digit codes, the following subclassification is provided for optional use with appropriate categories to indicate the site of involvement in Chapter XIII:

0 , Multiple sites

1, Shoulder region (clavicle; scapula)

2, Upper arm (humerus; elbow joint)

3, Forearm (radius; ulna; wrist joint)

4, Hand (carpus; fingers; metacarpus; joints between these bones)

5, Pelvic region and thigh (buttock; femur; pelvis; hip (joint); sacroiliac joint)

6, Lower leg (fibula; knee joint; tibia)

7, Ankle and foot (metatarsus; tarsus; toes; ankle joint; other joints in foot)

8, Other (head; neck; ribs; skull; trunk; vertebral column)

9 , Site unspecified

\section{ICD update process}

331. Over the period since 1970, WHO has designated a number of collaborating centres to work with it in the development, maintenance and use of health classifications. The collaborating centres have met annually. Increasingly the centres and the WHO are progressing their work through committees, which conduct their business outside the annual meetings of collaborating centres. These committees report to the annual meeting. WHO and the collaborating centres now recognise that the interactions are best characterised as a collaborative network (WHO-FIC Network).

332. The Mission Statement of the WHO-FIC Network is to develop, disseminate, implement and update the WHO-FIC to support national and international health information systems, statistics and evidence. In fulfilling this mission, the Network has these broad purposes:

- to promote the development of WHO-FIC, so that high quality classifications are available for all relevant sectors of the health system, and that gaps are filled according to priorities agreed within the Network. 
- to assist the timely and appropriate use of WHO-FIC classifications across member states by ensuring, in conjunction with the relevant Regional Office, that classifications are actively disseminated, implementation tools are available and that necessary education arrangements are developed and delivered.

- to ensure that WHO-FIC member classifications are updated as required and that the need for a major revision of WHO-FIC members is identified and appropriately addressed.

333. The Network is governed through the annual meeting of collaborating centres with WHO headquarters and regional offices. The WHO-FIC Network has established six committees: Planning Committee; Implementation Committee; Updating \& Revision Committee; Electronic Tools Committee; Education Committee; Family development committee. The annual meeting may establish time limited working groups to carry out a specific task, and these will generally be placed within one of the established committees.

334. The Update and Revision Committee (URC) assesses the need for updating the ICD and develops detailed proposals for annual meetings. It fosters reference groups for specific areas of interest and addresses issues brought forward by reference groups, The Committee may identify where major revision is required and how such a revision could be undertaken. Once a revision is approved by the Network, the Committee may undertake or direct the revision work.

335. The Official Updates to the published volumes of ICD-10 are available as annual lists of changes as of October 1996. The lists indicate the source of recommendation and implementation date. Date of approval has been indicated for all changes except the corrigenda. These updates are approved annually at the October meeting of Heads of WHO-FIC Collaborating Centres.

\section{ICD eleventh revision}

336. The creation of a new edition of ICD was announced by WHO in April 2007. It should be available for use in 2015.

337. A coordinated series of methods will be utilized to revise the current ICD-10 to arrive at a new generation of classification. The revision process will aim to create a platform for the ICD that allows continuous improvement in terms of following three streams of work:

- $\quad$ scientific evidence: ICD should reflect the advances in medicine and all health sciences. The scientific understanding of the underlying process should guide the classification and representation of knowledge in the classification.

- clinical utility and health system utility: ICD should be easy to use, support clinical decisions and health system management and should be readily integrated into routine practice in different settings including primary care, more specialized clinical care and research. Accordingly it may have different but compatible versions that can be used interchangeably in different levels of health care.

- $\quad$ public health usefulness: ICD should assist in public health policy, resource allocation and monitoring outcomes by recording mortality, morbidity and other population health parameters. It should also be compatible with other classification schemes and health information system elements. 
338. The ICD-11 revision proceeds in three stages: systematic review of scientific, clinical and public health evidence relevant to classification; creation of a draft ICD-11 and field-testing it; development of meaningful linkages to standardized health care terminologies to facilitate communication, standardized data processing and research.

339. The traditional form and uses of the ICD for mortality and morbidity reporting will be maintained. Material from other WHO classifications, notably the International Classification Functioning Disability and Health (ICF) and national modifications of ICD will be included to improve the ICD content and to improve alignment between the classifications. The revision process will make use of distributed web-based tools such as a structured open database platform to collate suggestions, discussions and evidence. This internet based knowledge management and sharing process will allow broader participation of multiple stakeholders in the creation and review of the new classification.

340. A review and coordination mechanism will be built in order to evaluate the progress of the revision process to ensure that it is proceeding in desired directions. Currently a Revision Steering Group has been established as oversight mechanism. Each main area of revision will be worked through a topic advisory group and multiple workgroups. Following this roadmap WHO expects to arrive at a desired product that not only serves as a classification system but also as a building block for health information systems. 


\section{BIBLIOGRAPHY}

Agence Technique de l'Information sur l'Hospitalisation (2008). Classification commune des actes médicaux (CCAM). (www.atih.sante.fr)

Agence Technique de l'Information sur l'Hospitalisation (2007). Guide de l'Etude Nationale de Coûts à méthodologie Commune.

Australian Government. Department of Health and Ageing (2010). National Hospital Cost Data Collection. Cost Report Round 13 (2008-09) (www.health.gov.au).

Australian Government. Department of Health and Ageing (2007). National Hospital Cost Data Collection. Hospital Reference Manual Round 11 (2006-07).

Bellanger MM, and Tardif L (2006). Accounting and reimbursement schemes for inpatient care in France. Health Care Management Science vol 9 (3): 295-305.

Busse, R., Schreyogg, J. and Smith, P.C. (2008). Variability in Healthcare Treatment Costs amongst Nine EU Countries - Results from the Health Basket Project. Health Economics 17 (suppl. 1): S1-S8.

Canadian Institute for Health Information (2009). International Statistical Classification of Diseases and Related Health Problems - Tenth Revision, Canada (ICD-10-CA).

Canadian Institute for Health Information (2008). The Cost of Hospital Stays: Why Costs Vary. Ottawa (www.cihi.ca).

Canadian Institute for Health Information (2007b). Introducing the new CMG+. Information sheet.

Canadian Institute for Health Information (2007a). Canadian Coding Standards for ICD-10-CA and CCI for 2008.

Canadian Institute for Health Information (2006). Canadian Classification of Health Interventions (CCI).

Chapko MK, Liu CF, Perkins M, Li YF, Fortney JC, and Maciejewski ML (2008). Equivalence of two healthcare costing methods: bottom-up and top-down. Health Economics (published online).

Department of Health, United Kingdom (2010). Reference costs 2008/2009 collection and guidance.

Department of Health, United Kingdom (2008). NHS Costing Manual 2007/2008.

Department of Health, United Kingdom (2007). OPCS Classification of Interventions and Procedures Version 4.4. Volume I, Tabular List.

Department of Health and Human Services, United States (2009). Modification to Medical Data Code Set Standard to Adopt ICD-10-CM and ICD-10-PCS. Federal Register 74 (11) Friday, January 16, 2009. 
Eurostat-OECD (2006). Methodological Manual on Purchasing Power Parities, OECD, Paris.

German Institute for the Hospital Remuneration System (2008). German DRGs System 2009. (www.gdrg.de).

German Institute for Medical Documentation and Information (DIMDI) (2008). Operationen- und Prozedurenschlüssel, OPS. (www.dimdi.de).

Hakkinen U, and Joumard I (2007). Cross-Country Analysis of Efficiency in OECD Health Care Sectors: Options for Research. OECD Economic Department Working Paper n. 554, Paris.

Koechlin F, Lorenzoni L, and Schreyer P (2010). Comparing Price Levels of Hospital Services Across Countries: Results of a Pilot Study. OECD Health Working Paper n. 53, Paris. (www.oecd.org/els/health/workingpapers)

Ministère de la Santé et des Sports (2009). Manuel des Groupes Homogènes de Malades. 11e version de la classification. Volume 3: Arbre de decision.

Nordic Casemix Centre (2011). NordDRG Manual System. (www.nordcase.org).

Ontario Ministry of Health and Long-Term Care (2006). Ontario Guide to Case Costing (www.occp.com).

Or Z, Renaud T (2009). Principes et enjeux de la tarification à l'activité à l'hôpital. Enseignements de la théorie économique et des expériences étrangères. IRDES, DT 23.

Paris V, Devaux M, and Wei L (2009). Health Ssytems Institutional Characteristics: A Survey of 29 OECD Countries. OECD Health Working Paper No. 50, Paris (www.oecd.org/els/health/workingpapers)

RTI International (2007). A study of charge compression in calculating DRG relative weights (www.cms.gov/reports/downloads).

Schreyer, P. (2010). Towards Measuring the Volume Output of Education and Health Services: A Handbook; OECD Statistics Working Paper No 31, Paris (www.oecd.org/findDocument/0,3354,en_2649_33715_1_119684_1_1_1,00.html).

Tan SS, Rutten FFH, van Ineveld BM, Redekop WK, and Hakkaart-van Roijen L (2009). Comparing methodologies for the cost estimation of hospital services. European Journal of Health Economics 10: 39-45.

The Audit Commission for Local Authorities and the National Health Service in England (2008). The right results? Payment by results 2003-2007. (www.audit-commission.gov.uk)

The Information Centre, UK. The Casemix Service (2008). HRG4 Design Concepts. (www.ic.nhs.uk/services/casemix). 


\section{OECD HEALTH WORKING PAPERS}

A full list of the papers in this series can be found on the OECD website: www.oecd.org/els/health/workingpapers

No. 55 MORTALITY AMENABLE TO HEALTH CARE IN 31 OECD COUNTRIES:ESTIMATES AND METHODOLOGICAL ISSUES (2011) Juan G. Gay, Valerie Paris, Marion Devaux, Michael de Looper

No. 54 NURSES IN ADVANCED ROLES: A DESCRIPTION AND EVALUATION OF EXPERIENCES IN 12 DEVELOPED COUNTRIES (2010) Marie-Laure Delamaire and Gaetan Lafortune

No. 53 COMPARING PRICE LEVELS OF HOSPITAL SERVICE ACROSS COUNTRIES: RESULTS OF A PILOT STUDY (2010) Francette Koechlin, Luca Lorenzoni, and Paul Schreyer

No. 52 GUIDELINES FOR IMPROVING THE COMPARABILITY AND AVAILABILITY OF PRIVATE HEALTH EXPENDITURES UNDER THE SYSTEM OF HEALTH ACCOUNTS FRAMEWORK (2010) Ravi P. Rannan-Eliya and Luca Lorenzoni

No. 51 EFFECTIVE WAYS TO REALISE POLICY REFORMS IN HEALTH SYSTEMS (2010) Jeremy Hurst

No. 50 HEALTH SYSTEMS INSTITUTIONAL CHARACTERISTICS A SURVEY OF 29 OECD COUNTRIESValerie Paris, Marion Devaux and Lihan Wei

No. 49 THE CHALLENGE OF FINANCING HEALTH CARE IN THE CURRENT CRISIS (forthcoming) Peter Scherer, Marion Devaux

No. 48 IMPROVING LIFESTYLES, TACKLING OBESITY: THE HEALTH AND ECONOMIC IMPACT OF PREVENTION STRATEGIES (2009) Franco Sassi, Michele Cecchini, Jeremy Lauer and Dan Chisholm

No. 47 HEALTH CARE QUALITY INDICATORS PROJECT: PATIENT SAFETY INDICATORS REPORT 2009 (2009) Saskia Drösler, Patrick Romano, Lihan Wei; and ANNEX Saskia Drösler

No. 46 EDUCATION AND OBESITY IN FOUR OECD COUNTRIES (2009) Franco Sassi, Marion Devaux, Jody Church, Michele Cecchini and Francesca Borgonovi

No. 45 THE OBESITY EPIDEMIC: ANALYSIS OF PAST AND PROJECTED FUTURE TRENDS IN SELECTED OECD COUNTRIES (2009) Franco Sassi, Marion Devaux, Michele Cecchini and Elena Rusticelli

No. 44 THE LONG-TERM CARE WORKFORCE: OVERVIEW AND STRATEGIES TO ADAPT SUPPLY TO A GROWING DEMAND (2009) Rie Fujisawa and Francesca Colombo

No. 43 MEASURING DISPARITIES IN HEALTH STATUS AND IN ACCESS AND USE OF HEALTH CARE IN OECD COUNTRIES (2009) Michael de Looper and Gaetan Lafortune

No. 42 POLICIES FOR HEALTHY AGEING: AN OVERVIEW (2009) Howard Oxley 
No. 41 THE REMUNERATION OF GENERAL PRACTITIONERS AND SPECIALISTS IN 14 OECD COUNTRIES: WHAT ARE THE FACTORS EXPLAINING VARIATIONS ACROSS COUNTRIES? (2008) Rie Fujisawa and Gaetan Lafortune

No. 40 INTERNATIONAL MOBILITY OF HEALTH PROFESSIONALS AND HEALTH WORKFORCE MANAGEMENT IN CANADA: MYTHS AND REALITIES (2008) Jean-Christophe Dumont, Pascal Zurn, Jody Church and Christine Le Thi

No. 39 PHARMACEUTICAL PRICING \& REIMBURSEMENT POLICIES IN GERMANY (2008) Valérie Paris and Elizabeth Docteur

No. 38 MIGRATION OF HEALTH WORKERS: THE UK PERSPECTIVE TO 2006 (2008) James Buchan, Susanna Baldwin and Miranda Munro

No. 37 THE US PHYSICIAN WORKFORCE: WHERE DO WE STAND? (2008) Richard A. Cooper

No. 36 MIGRATION POLICIES OF HEALTH PROFESSIONALS IN FRANCE (2008) Roland Cash and Philippe Ulmann

No. 35 NURSE WORKFORCE CHALLENGES IN THE UNITED STATES: IMPLICATIONS FOR POLICY (2008) Linda H. Aiken and Robyn Cheung

No. 34 MISMATCHES IN THE FORMAL SECTOR, EXPANSION OF THE INFORMAL SECTOR: IMMIGRATION OF HEALTH PROFESSIONALS TO ITALY (2008) Jonathan Chaloff

No. 33 HEALTH WORKFORCE AND INTERNATIONAL MIGRATION: CAN NEW ZEALAND COMPETE? (2008) Pascal Zurn and Jean-Christophe Dumont

No. 32 THE PREVENTION OF LIFESTYLE-RELATED CHRONIC DISEASES: AN ECONOMIC FRAMEWORK (2008) Franco Sassi and Jeremy Hurst

No. 31 PHARMACEUTICAL PRICING AND REIMBURSEMENT POLICIES IN SLOVAKIA (2008) Zoltán Kaló, Elizabeth Docteur and Pierre Moïse

No. 30 IMPROVED HEALTH SYSTEM PERFORMANCE THROUGH BETTER CARE COORDINATION (2007) Maria M. Hofmarcher, Howard Oxley, and Elena Rusticelli

No. 29 HEALTH CARE QUALITY INDICATORS PROJECT 2006 DATA COLLECTION UPDATE REPORT (2007) Sandra Garcia-Armesto, Maria Luisa Gil Lapetra, Lihan Wei, Edward Kelley and the Members of the HCQI Expert Group

No. 28 PHARMACEUTICAL PRICING AND REIMBURSEMENT POLICIES IN SWEDEN (2007) Pierre Moïse and Elizabeth Docteur

No. 27 PHARMACEUTICAL PRICING AND REIMBURSEMENT POLICIES IN SWITZERLAND (2007) Valérie Paris and Elizabeth Docteur

No. 26 TRENDS IN SEVERE DISABILITY AMONG ELDERLY PEOPLE: ASSESSING THE EVIDENCE IN 12 OECD COUNTRIES AND THE FUTURE IMPLICATIONS (2007) Gaetan Lafortune, Gaëlle Balestat, and the Disability Study Expert Group Members 


\section{RECENT RELATED OECD PUBLICATIONS}

IMPROVING VALUE IN HEALTH CARE: MEASURING QUALITY (2010)

IMPROVING HEALTH SECTOR EFFICIENCY - THE ROLE OF INFORMATION AND COMMUNICATION TECHNOLOGIES (2010)

MAKING REFORM HAPPEN - LESSONS FROM OECD COUNTRIES (2010)

HEALTH AT A GLANCE: ASIA/PACIFIC (2010)

HEALTH AT A GLANCE: EUROPE (2010)

VALUE FOR MONEY IN HEALTH SPENDING (2010)

OBESITY AND THE ECONOMICS OF PREVENTION: FIT NOT FAT (2010)

HEALTH AT A GLANCE 2009: OECD INDICATORS (2009).

See http://www.oecd.org/health/healthataglance for more information

ACHIEVING BETTER VALUE FOR MONEY IN HEALTH CARE (2009), OECD HEALTH POLICY STUDIES

OECD HEALTH DATA 2010 (2010), available online and on CD-ROM. The database can be queried in English, French, German, and Spanish. Italian, Japanese and Russian are available exclusively in the online version. www. oecd.org/health/healthdata.

OECD REVIEWS OF HEALTH SYSTEMS - TURKEY (2009)

THE LOOMING CRISIS IN THE HEALTH WORKFORCE: CAN OECD COUNTRIES RESPOND? (2008)

PHARMACEUTICAL PRICING POLICIES IN A GLOBAL MARKET (2008)

OECD REVIEWS OF HEALTH SYSTEMS - SWITZERLAND (2006)

LONG-TERM CARE FOR OLDER PEOPLE (2005), OECD HEALTH PROJECT SERIES

HEALTH TECHNOLOGIES AND DECISION MAKING (2005), OECD HEALTH PROJECT SERIES

OECD REVIEWS OF HEALTH CARE SYSTEMS - FINLAND (2005)

OECD REVIEWS OF HEALTH CARE SYSTEMS - MEXICO (2005)

PRIVATE HEALTH INSURANCE IN OECD COUNTRIES (2004), OECD HEALTH PROJECT SERIES

TOWARDS HIGH-PERFORMING HEALTH SYSTEMS (2004), OECD HEALTH PROJECT SERIES

For a full list, consult the OECD On-Line Bookstore at www.oecd.org,

or write for a free written catalogue to the following address:

OECD Publications Service

2, rue André-Pascal, 75775 PARIS CEDEX 16

or to the OECD Distributor in your country 
DELSA/HEA/WD/HWP(2011)2 